\title{
The ant genus Strumigenys Smith, 1860 (Hymenoptera: Formicidae) in western North America North of Mexico
}

\section{DOUGLAS B. BOOHER}

Yale Center for Biodiversity and Global Change, 165 Prospect Street, New Haven, CT 06520-8106, USA

Georgia Museum of Natural History, 101 Cedar Street, Athens, GA 30602, USA

झ"dbooher@antmuseum.com; — https://orcid.org/0000-0002-4257-7401

\section{Table of contents}

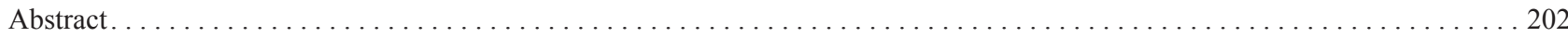

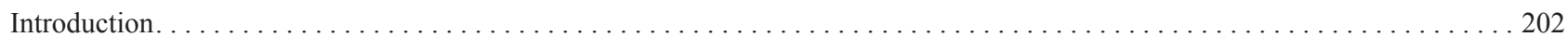

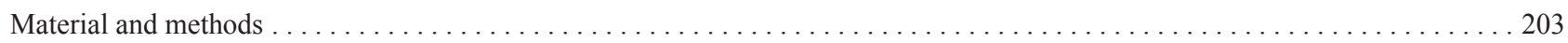

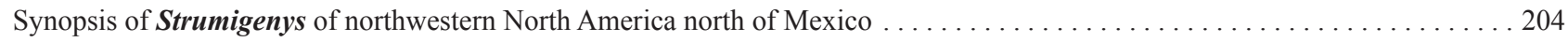

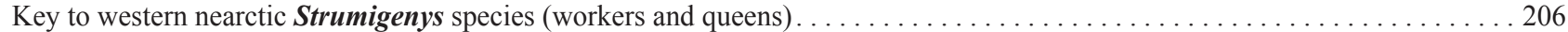

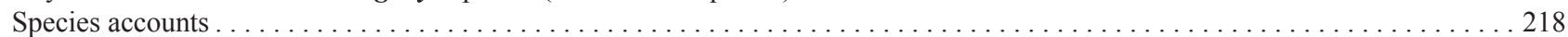

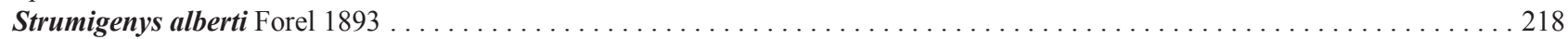

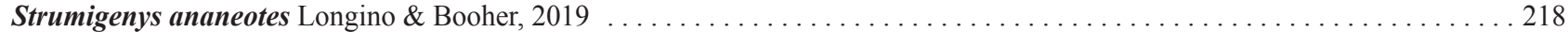

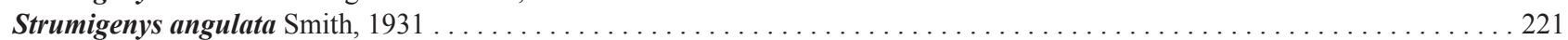

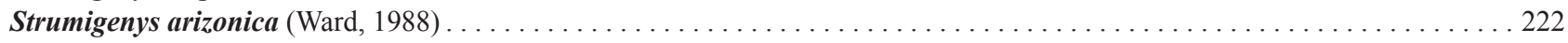

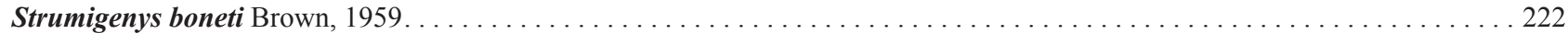

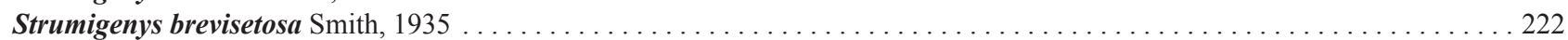

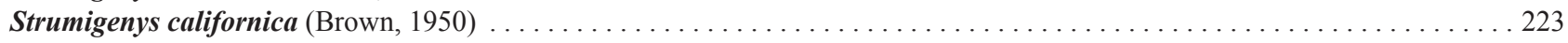

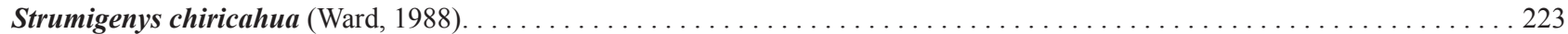

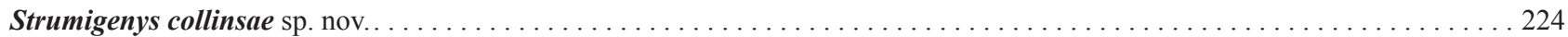

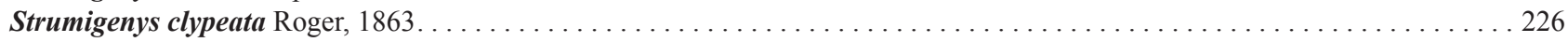

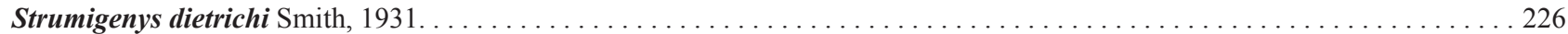

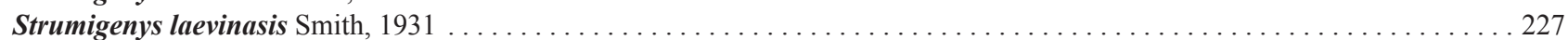

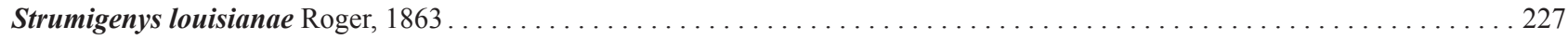

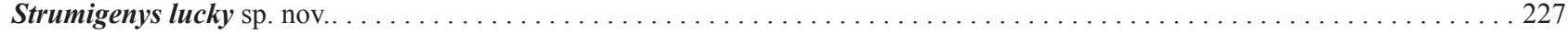

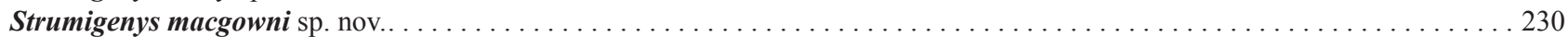

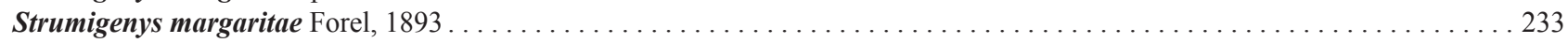

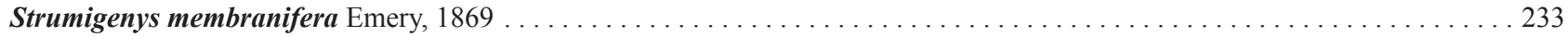

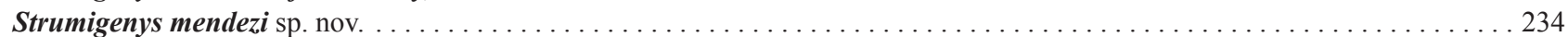

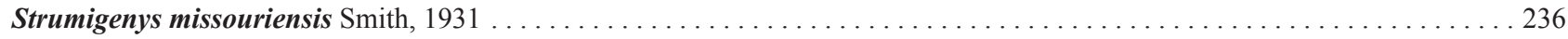

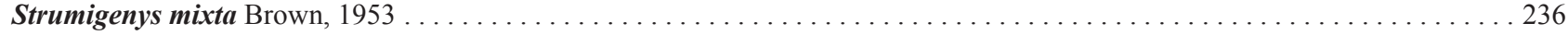

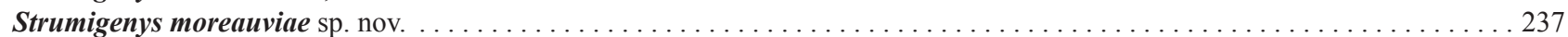

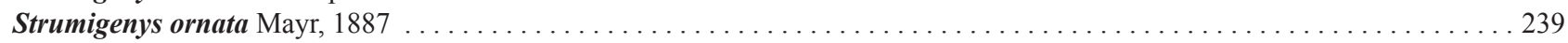

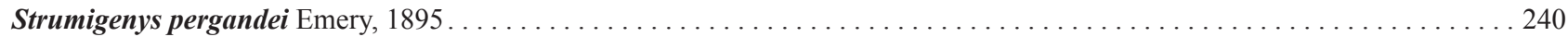

Strumigenys pilinasis Forel, 1901 (Note: senior synonym of ohioensis) . . . . . . . . . . . . . . . . . . . . . . . . 240

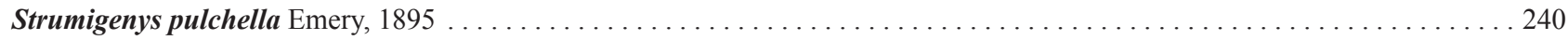

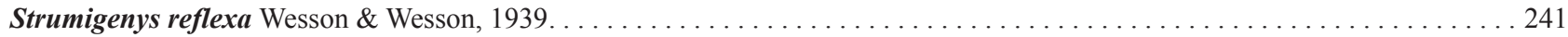

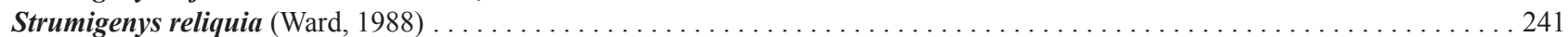

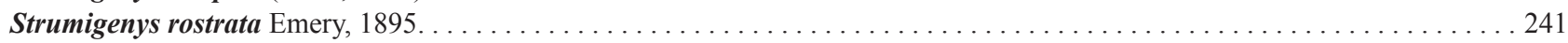

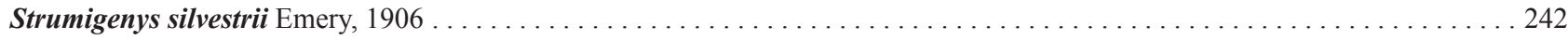

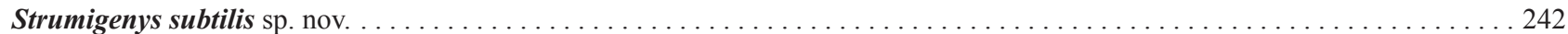

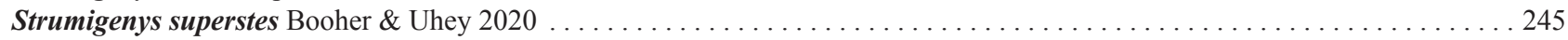

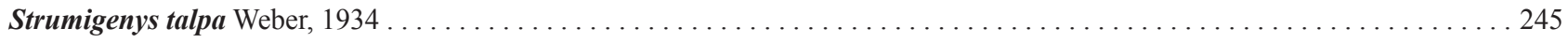

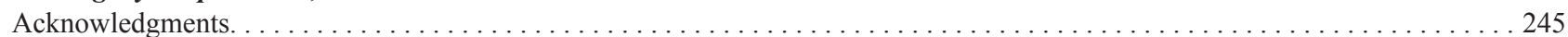

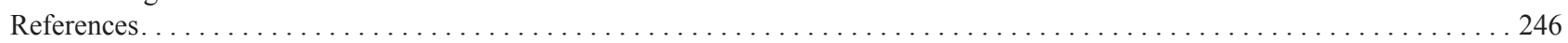




\begin{abstract}
Strumigenys is a globally distributed genus of mostly cryptic leaf-litter ants. In North America they are common throughout eastern deciduous forests but become increasingly rare to the west. Here I review the Strumigenys fauna of western North America north of the Mexico border including all states west of the eastern border of Texas. Six new native species with ranges entirely within this region are described: $S$. collinsae sp. nov., $S$. macgowni sp. nov., $S$. mendezi sp. nov., $S$. moreauviae sp. nov., S. lucky sp. nov., and S. subtilis sp. nov. Strumigenys ananeotes Longino \& Booher 2019 is given a more thorough description, and $S$. alberti Forel 1893, a Neotropical species, is reported from the region for the first time. All new species bear clear morphological relationships with a native North American clade of "smithistrumiform" species. I include species accounts and provide an illustrated key for all species of this region.
\end{abstract}

Key words: new species, United States, biodiversity, trap jaw, endemic, Pyramica, Smithistruma, native, non-native, tramp, alien

\title{
Introduction
}

Strumigenys is a hyper-diverse, globally-distributed genus with more than 850 described extant species (Bolton 2020). They are most diverse in moist tropical and subtropical rainforests, absent from arctic zones, and typically with low diversity in temperate zones and arid regions. However, the Nearctic region of the United States houses an unusually large temperate Strumigenys fauna with more than 55 species, a sharp contrast to the depauperate native fauna of other temperate regions such as Europe and the Middle East where there are only four species (Janicki et al. 2016; Guénard et al. 2017). The only other species-rich temperate fauna of Strumigenys is in Japan (22 species occur north of subtropical Okinawa).

Nearctic Strumigenys can be divided into two main categories, 1) native species belonging to a large temperate clade and 2) species of various lineages that originated outside the Nearctic region. The majority of Nearctic species belong to the clade of morphologically similar Nearctic and northeastern Asian species that are associated with temperate mesic forests, here named the 'smithistrumiform' clade after the obsolete genus Smithistruma to which many of these species previously belonged (Brown 1949; Bolton 2000; Deyrup \& Cover 2009; Janicki et al. 2016; Guénard et al. 2017; Booher et al. 2021). The smithistrumiform clade is made up of two geographically distinct subclades, one Asian and one Nearctic. The North American subclade split from Asian ancestors between 4-10 Mya, after which it underwent an explosive radiation which now includes 34 currently described extant species within the USA (Booher et al. 2021). Species of the second category include native and introduced species from lineages originating in other biogeographic regions (Booher et al. 2021). All but one of the Nearctic natives are Neotropical species whose ranges extend into the USA. One is endemic (S. superstes Booher \& Uhey, 2020) but has close relatives south of the USA. The other species are non-native introduced species that are mostly weedy global tramps from various biogeographic regions.

Although most of the North American species inhabit eastern mesic forested habitats, a few are known from western North America, which is more arid (Ward 1988). Species occupying the most arid western states often have close associations with moist micro-environments or are thought to have more subterranean habits. For example, Strumigenys arizonica (Ward, 1988) has a mutualistic relationship with Trachymyrmex arizonensis (Wheeler, 1907), where it feeds on Collembola in moist underground refuse chambers of T. arizonensis (Gray et al. 2018), and Strumigenys ananeotes Longino \& Booher, 2019 was recently discovered in a moist garden bed in a backyard, foraging at night (Longino \& Booher 2019). Strumigenys ananeotes, S. chiricahua (Ward, 1988), and S. reliquia (Ward, 1988) have all been collected in moist microsites underneath litter, log or rock debris, in small moist patches of soil, or from flight traps in mesic ravines. However, one western species, S. californica (Brown, 1950) was found foraging on vegetation above ground and has seemingly adapted to survive more arid conditions of this region.

New collections and new species discoveries that more than double the known western fauna motivated the current study on the Strumigenys fauna of the western Nearctic. The geographic scope of the study is North America north of Mexico and west of the eastern TX border. One species outside this region, Strumigenys lucky sp. nov., is included as it has an unusual northern-midwestern distribution and has little range overlap with most eastern species. Thirty-one species are included in this regional study. Nineteen are eastern species whose ranges extend westward. The remaining 12 species have ranges almost entirely within the study area. Here I describe new species, give brief 
species accounts with state distribution records, and provide the first key including all observed species known to occur in the region. The scarcity of mesic environments, as well as the cryptic subterranean or nocturnal habits observed in some western Strumigenys, make them difficult to observe or collect. Undoubtedly additional undescribed western species await discovery and description.

\section{Material and methods}

Imaged specimens have specimen-level codes affixed to each pin. Sometimes these codes are associated with multiple specimens on the same pin; if so, then specimens are identified by their mounted position. Digital color images were used with permission of AntWeb.org (AntWeb 2021). All images presented are available online and can be viewed on AntWeb. The measurements and indices used in this study are based on those used by Bolton (2000) or described here. The measurements were taken using the measurement application of the LAS-X Leica software using a Leica IC90 E digital camera and Leica M165 C microscope with either a 1.0x or 1.6x PLANAPO objective. Measurements and indices are presented as minimum and maximum values with arithmetic means in parentheses; measurements are expressed in millimeters to three decimal places. Tooth count, when not explicitly stated, is from the base to the apex of mandible. The dichotomous key is primarily based on a new suite of characters but also has portions adapted from Bolton (2000).

Specimen repositories. The collection abbreviations below follow Evenhuis (2020). The material upon which this study is based is located and/or was examined at the following institutions:

$\begin{array}{ll}\text { ABS } & \text { Archbold Biological Station, FL, USA } \\ \text { BYU } & \text { Brigham Young University, Monte L. Bean Life Science Museum, Provo, Utah, USA } \\ \text { CASC } & \text { California Academy of Sciences, San Francisco, California, USA } \\ \text { CUIC } & \text { Cornell University Insect Collection, Ithaca, New York, USA } \\ \text { CWEM } & \text { Collection of William and Emma Mackay, University of Texas, El Paso, Texas, USA } \\ \text { DBBC } & \text { Collection of Dr. Douglas Brent Booher, Athens, Georgia, USA } \\ \text { FMNH } & \text { Field Museum of Natural History, Chicago, Illinois, USA } \\ \text { JTLC } & \text { Collection of Dr. John T. Longino, Salt Lake City, Utah, USA } \\ \text { LACM } & \text { Los Angeles County Museum of Natural History, Los Angeles, California, USA } \\ \text { MCZC } & \text { Museum of Comparative Zoology, Harvard University, Cambridge, Massachusetts, USA } \\ \text { MEM } & \text { Mississippi Entomological Museum, Mississippi State University, Mississippi, USA } \\ \text { MNA } & \text { Museum of Northern Arizona, Flagstaff, Arizona, USA } \\ \text { PSWC } & \text { Collection of Dr. Philip S. Ward, Davis, California, USA } \\ \text { RAJC } & \text { Collection of Dr. Robert A. Johnson, Tempe, Arizona, USA } \\ \text { SEMC } & \text { Snow Entomological Museum, University of Kansas, Lawrence, Kansas, USA } \\ \text { SHSU } & \text { Sam Houston State University Museum of Natural History, Huntsville, Texas, USA } \\ \text { TAMU } & \text { Texas A \& M University Insect Collection, College Station, Texas, USA } \\ \text { UCDC } & \text { University of California Davis R. M. Bohart Museum of Entomology, Davis, California, USA } \\ \text { UGCA } & \text { University of Georgia, Athens, Georgia, USA } \\ \text { UMNH } & \text { Utah Museum of Natural History, University of Utah, Salt Lake City, Utah, USA } \\ \text { USNM } & \text { National Museum of Natural History, Washington D.C., USA }\end{array}$

\section{Measurements and indices.}

HL Cephalic length: the length of the head capsule excluding the mandibles, measured in full-face view in a straight line from the mid-point of the anterior clypeal margin to the mid-point of the cephalic margin. In species where one or both of these margins is concave, the measurement is taken from the mid-point of a transverse line that spans the apices of the projecting portions.

HW Cephalic width: the maximum width of the head in full-face view, excluding the eyes.

ML Mandible length: the straight-line length of the mandible at full closure, measured in the same plane for which the HL measurement is taken (i.e., full face view), from the mandibular apex to the anterior clypeal 
margin, or to the transverse line connecting the anteriormost points of the clypeus in taxa where the anterior clypeal margin is concave medially.

PW Pronotal width: the maximum width of the pronotum in dorsal view. Projecting spines, tubercles or other cuticular prominences at the pronotal humeral angles are excluded.

SL Scape length: the maximum straight-line length of the scape, excluding the basal constriction or neck that occurs just distal of the condylar bulb. In taxa with a hypertrophied subbasal lobe on the scape SL is measured from the tip of the subbasal lobe to the scape apex.

FL Femoral length: the length of femur from junction with trochanter to apex.

HT Head thickness: the maximum thickness or depth of head in profile, from the lowest ventral border to the highest dorsal border in profile.

EL Eye Length: in profile, the maximum diameter of the compound eye.

WL Weber's length: diagonal length of mesosoma in profile, from anterior declivity of pronotum (exclusive of pronotal "neck") to apex of metapleural lobe.

CI Cephalic index: HW/HL * 100.

MI Mandibular index: ML/HL * 100

SI Scape index: SL/HW * 100

Morphology. Diagnostic characters used to key out species and important for species description are illustrated in Figure 1. Most of the characters are typical of previous taxonomic work. New to this work is the division of the clypeal margin into anterior and lateral portions, delimited by the outer mandibular insertions, and the referencing of seta positions with respect to these portions.
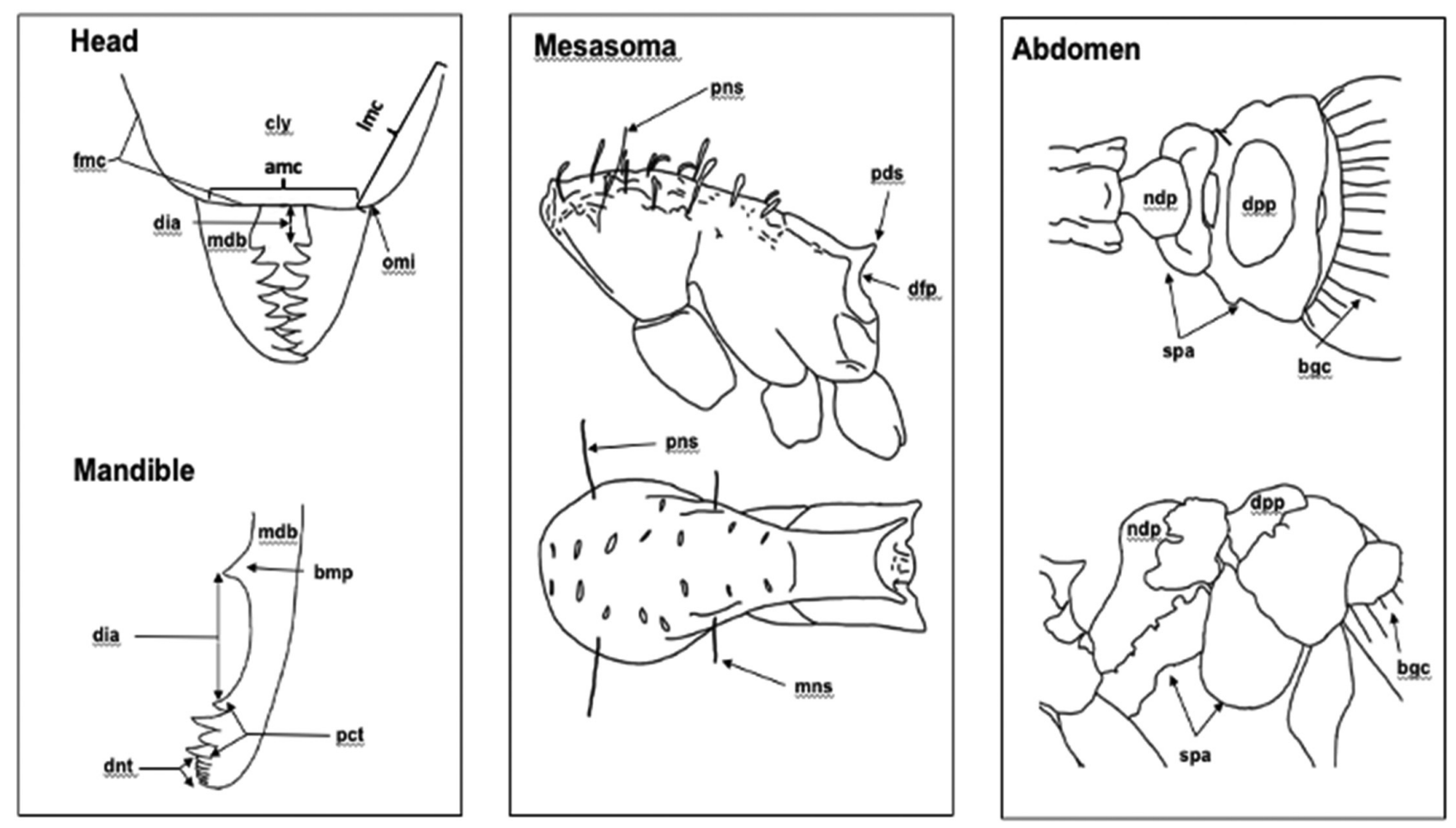

FIGURE 1. Head and Mandible: (amc) anterior margin of clypeus; basal mandibular process/lamina (bmp); clypeus (cly); denticles (dnt); diastema (dia); free margin of clypeus (fmc); (lmc) lateral margin of clypeus; mandible (mdb); outer insertion of mandible (omi); principle teeth (pct). Mesosoma: carina of the declivitous face of the propodeum (dfp); differentiated mesonotal setae (mns); differentiated pronotal setae (pns); propodeal spines (pds). Abdomen: basigastral costulae (bgc); exposed disc of postpetiole (dpp); node of petiole (ndp); spongiform appendages (spa). 
"Smithistrumiform" native Nearctic clade

New species unassigned to species-groups

ananeotes Longino \& Booher, 2019

collinsae sp. nov.

lucky sp. nov.

macgowni sp. nov.

mendezi sp. nov.

moreauviae sp. nov.

subtilis sp. nov.

clypeata-group

brevisetosa Smith, 1935

clypeata Roger, 1863

laevinasis Smith, 1931

ohioensis-group

pilinasis Forel, 1901 (Note: senior synonym of ohioensis)

reliquia (Ward, 1988)

ornata-group

dietrichi Smith, 1931

ornata Mayr, 1887

pergandei-group

angulata Smith, 1931

pergandei Emery, 1895

pulchella-group

pulchella Emery, 1895

reflexa Wesson \& Wesson, 1939

rostrata-group

arizonica (Ward, 1988)

californica (Brown, 1950)

chiricahua (Ward, 1988)

rostrata Emery, 1895

talpa-group

talpa Weber, 1934

Species groups from Neotropical lineages

alberti-group

alberti Forel 1893

excisa-group

superstes Booher \& Uhey 2020

louisianae-group

louisianae Roger, 1863

mixta Brown, 1953

ludia-group

boneti Brown, 1959

schulzi-group

margaritae Forel, 1893

silvestrii-group

silvestrii Emery, 1906

Species groups from Indomalayan lineages

membranifera-group

membranifera Emery, 1869 


\title{
Key to western nearctic Strumigenys species (workers and queens)
}

\author{
Illustrations by C. Dandridge
}

Mandibles with at least some teeth interlocking or overlapping in the first half of mandible when fully closed (Fig. 2A); MI <

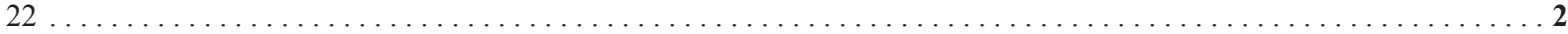
Mandibles with interlocking teeth limited to the apical half of mandible (Fig. 2AA); MI $\geq 25$ (see also third choice below). 30 Mandibles with an elongate flat-topped basal lamella of the mandible followed by a second flat topped elongate lamella that extends to the middle of masticatory margin (Fig. 2AAA); MI $\geq 27-33$. .
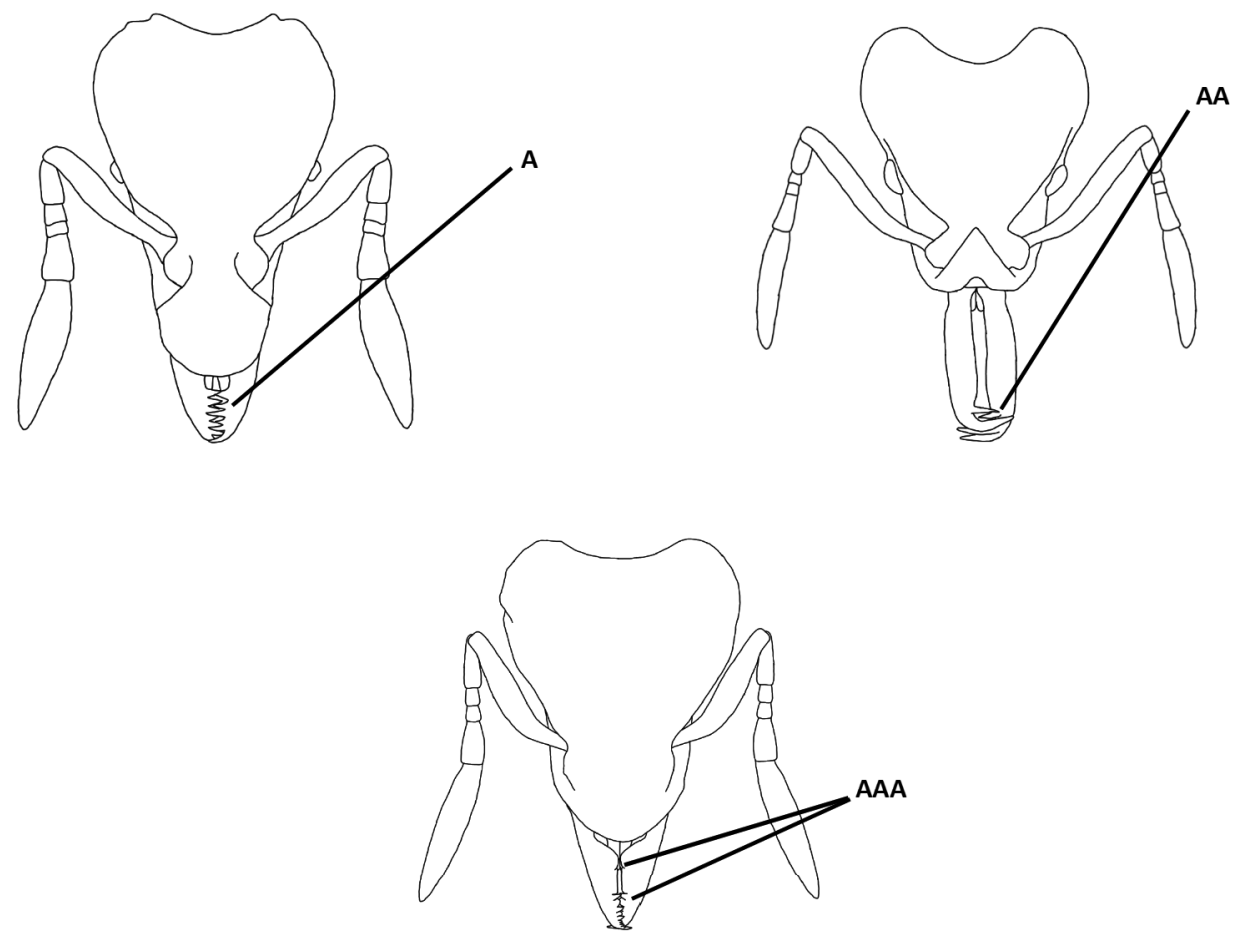

FIGURE 2. Face views of representative Strumigenys species.

Four to six erect setae radiate from the medial anterior dorsum of clypeus and spread out like ribs of a fan, most easily observed

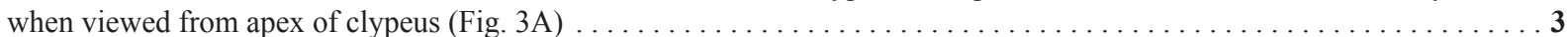
Erect setae are not present on anterior dorsum of clypeus, or if present, these setae are not organized like ribs of a fan (Fig. 3AA).

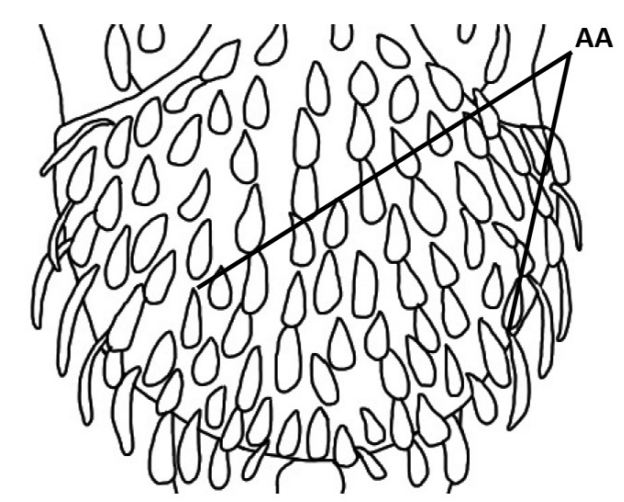

FIGURE 3. Clypeus in face view of representative Strumigenys species.

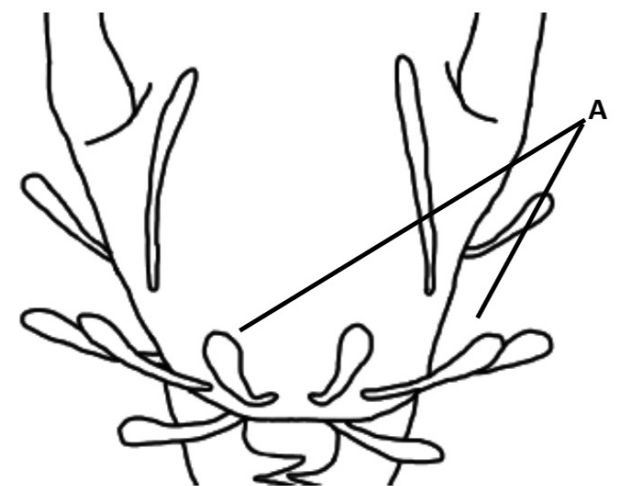

Fan shaped clypeal setae expanded and bulbous at tips (Fig. 4A), curving posteriorly in lateral view.

.ornata Mayr, 1887 (OK, TX, and many eastern states) Fan shaped clypeal setae are apically acute to slightly expanded (Fig. 4AA) and do not curve posteriorly in lateral view ..... dietrichi Smith, 1931 (KS, OK, TX, and many eastern states) 

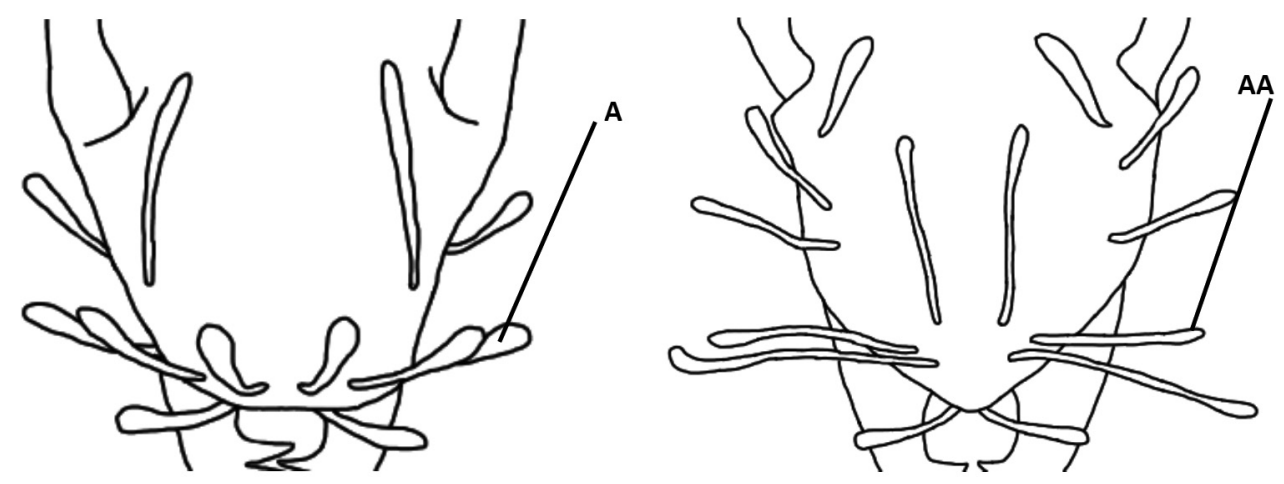

FIGURE 4. Clypeus in face view of representative Strumigenys species.

Fringe of setae on margins of clypeus either absent or minute and appressed but never projecting outward away from margin

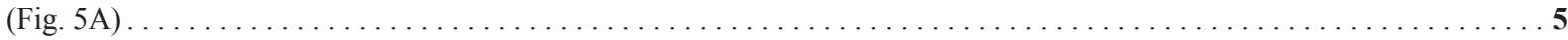
Fringe of setae on margins of clypeus present and project outward from margin, these setae may be of various shapes from long fine and apically acute to spoon shaped (Fig. 5AA, AAA)
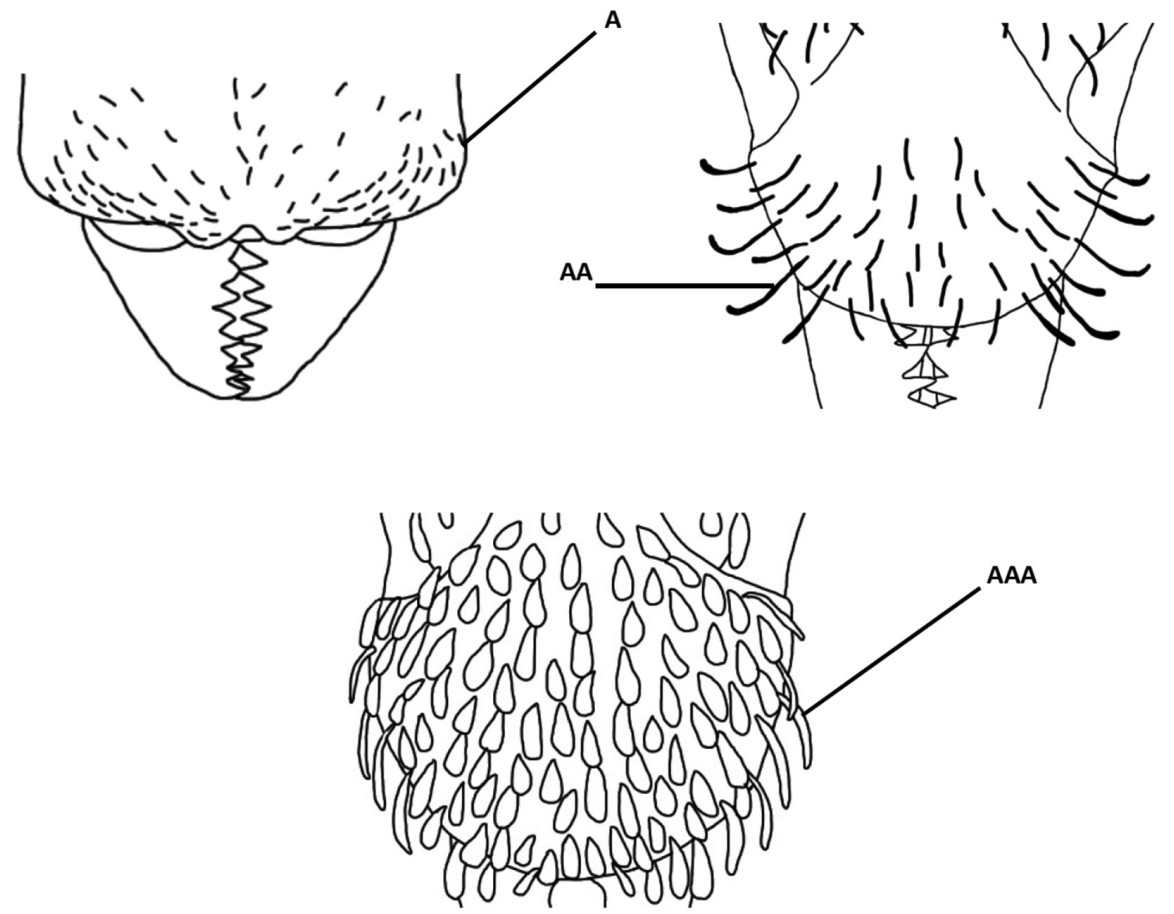

FIGURE 5. Clypeus in face view of representative Strumigenys species.

5 Mandible with transverse carinae on dorsal surface of mandible just anterior of clypeal margin (Fig. 6A) (Cosmopolitan tramp species).... membranifera Emery, 1869 (AZ, CA, TX, and several southeastern states) Mandible without transverse carinae on dorsal surface of mandible just anterior of clypeal margin (Fig. 6AA) . . . . . . . . .
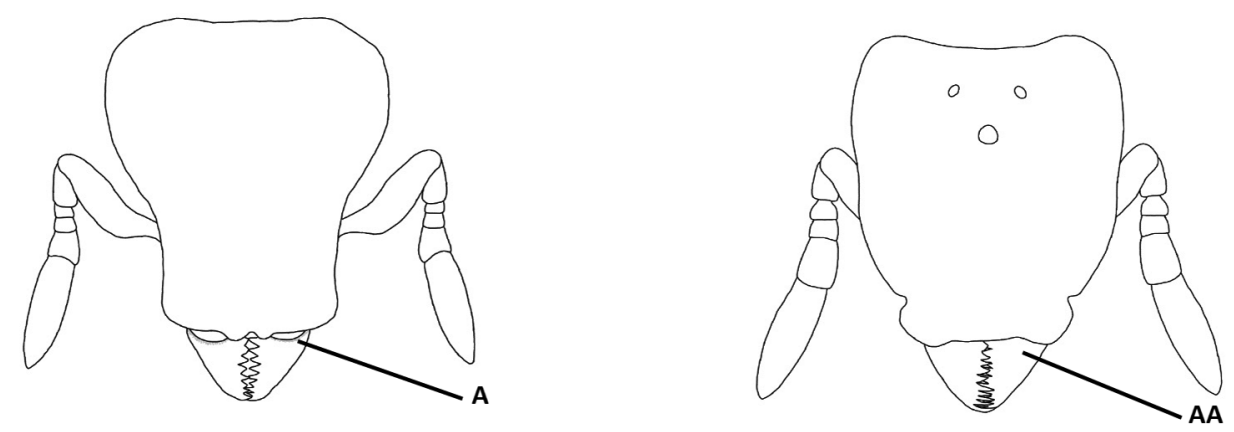

FIGURE 6. Face views of representative Strumigenys species. 
Setae on margins and dorsum of clypeus consist of only apically acute, elongate, simple fine setae that may be coarse, straight,

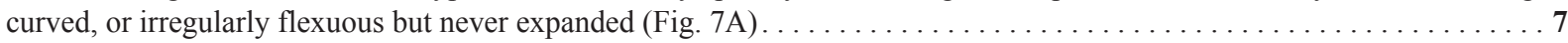
Setae on either clypeal margins or dorsum are expanded or flattened (Fig. 7AA) $\ldots \ldots \ldots \ldots \ldots \ldots \ldots \ldots \ldots \ldots \ldots$
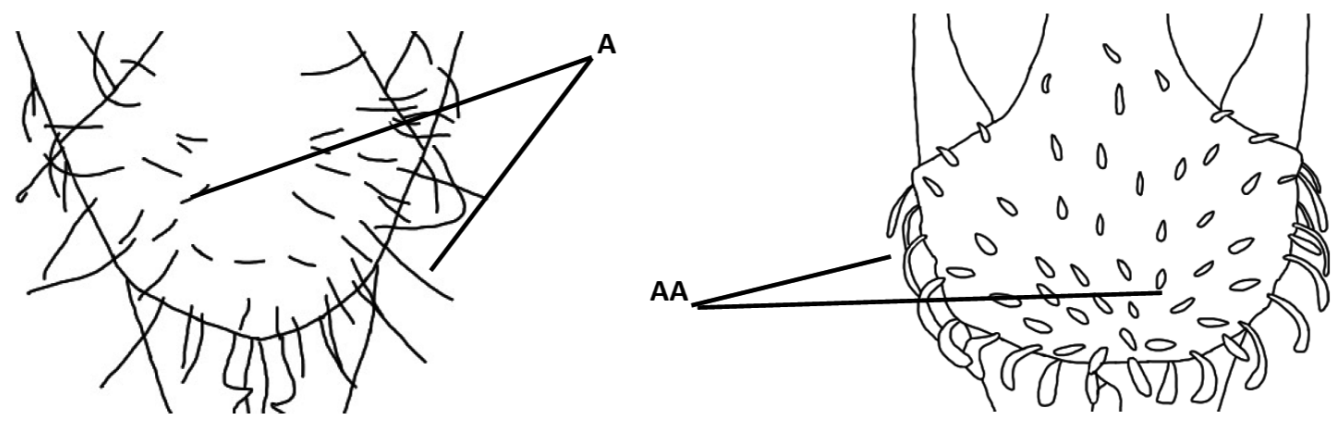

FIGURE 7. Clypeus in face view of representative Strumigenys species.

In dorsal view, spongiform appendages absent on petiolar and postpetiolar nodes, and are replaced by smooth cuticular lamellae

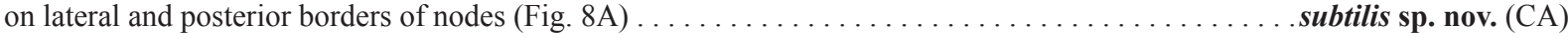
In dorsal view, spongiform appendages large and apparent as white processes on lateral and posterior borders of petiolar node and encircling exposed disc of postpetiole (Fig. 8AA) .
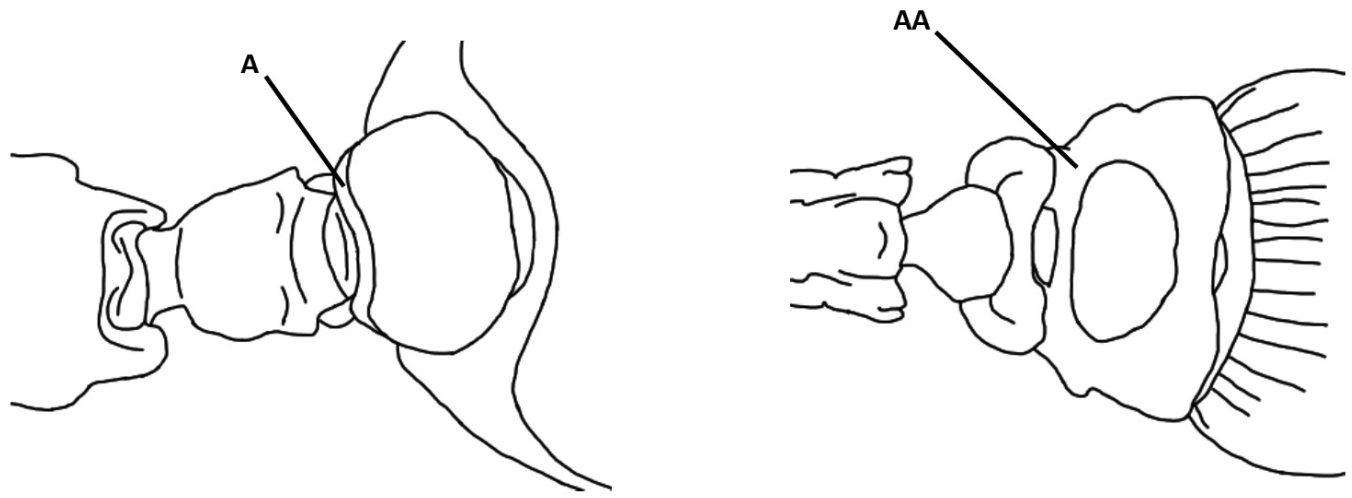

FIGURE 8. Dorsal views of petiolar area of representative Strumigenys species.

Clypeus in lateral view with a broad conspicuous peripheral groove along free margins (Fig. 9A) $\ldots \ldots \ldots \ldots \ldots \ldots 9$

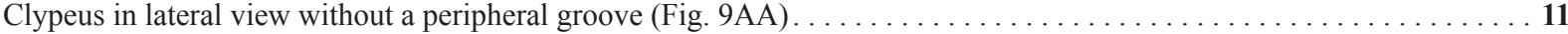
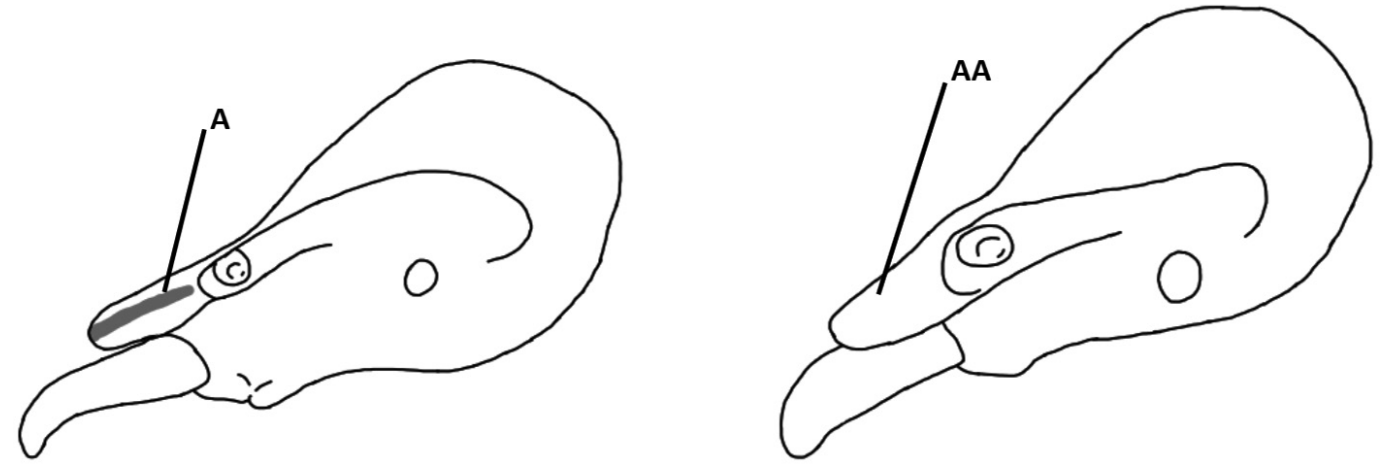

FIGURE 9. Lateral head views of representative Strumigenys species.

9 Basalmost tooth not following a large diastemmic gap, overlapping when mandible closed and less than half the length of the following tooth (Fig. 10A). Setae on margins and dorsum of clypeus are coarse, straight or evenly and shallowly curved along

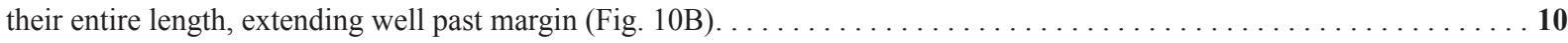
Basalmost tooth following a large diastemmic gap, not overlapping when mandible closed and less than half the length of the following tooth (Fig. 10AA). Setae on margins and dorsum of clypeus are fine, often curving strongly along apical portion and barely extending past margin (Fig. 10BB)

collinsae sp. nov. (CO) 


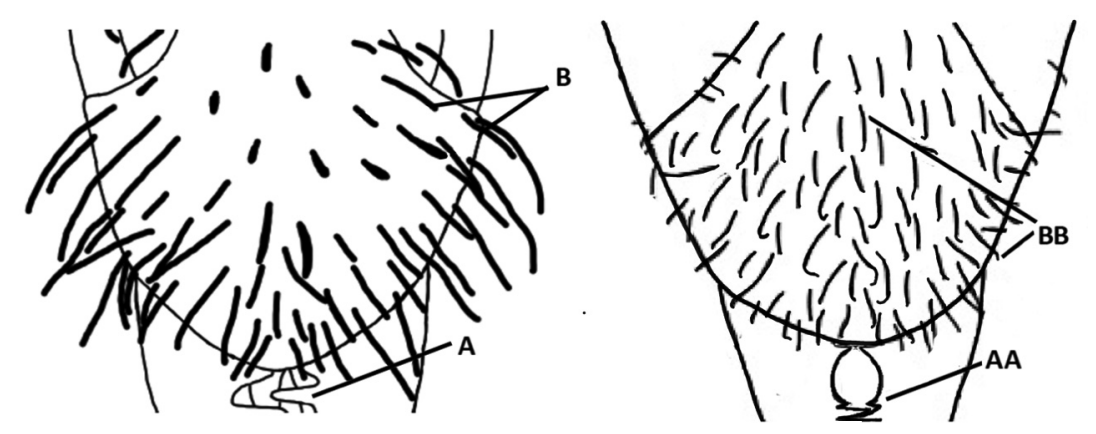

FIGURE 10. Clypeus in face view of representative Strumigenys species.

10 Setae on dorsum of clypeus inclined anterior at base and evenly curve so that their apices point upwards or posteriorly (Fig. $11 \mathrm{~A}) \ldots \ldots \ldots \ldots \ldots \ldots \ldots \ldots \ldots$ laevinasis Smith, 1931 (KS, OK, TX, and many eastern states) Setae on dorsum of clypeus inclined anterior at base and evenly curve so that their apices point upwards or posteriorly (Fig.

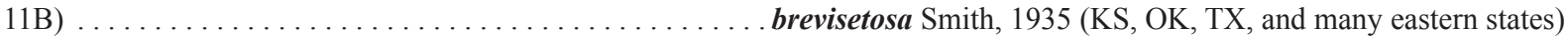
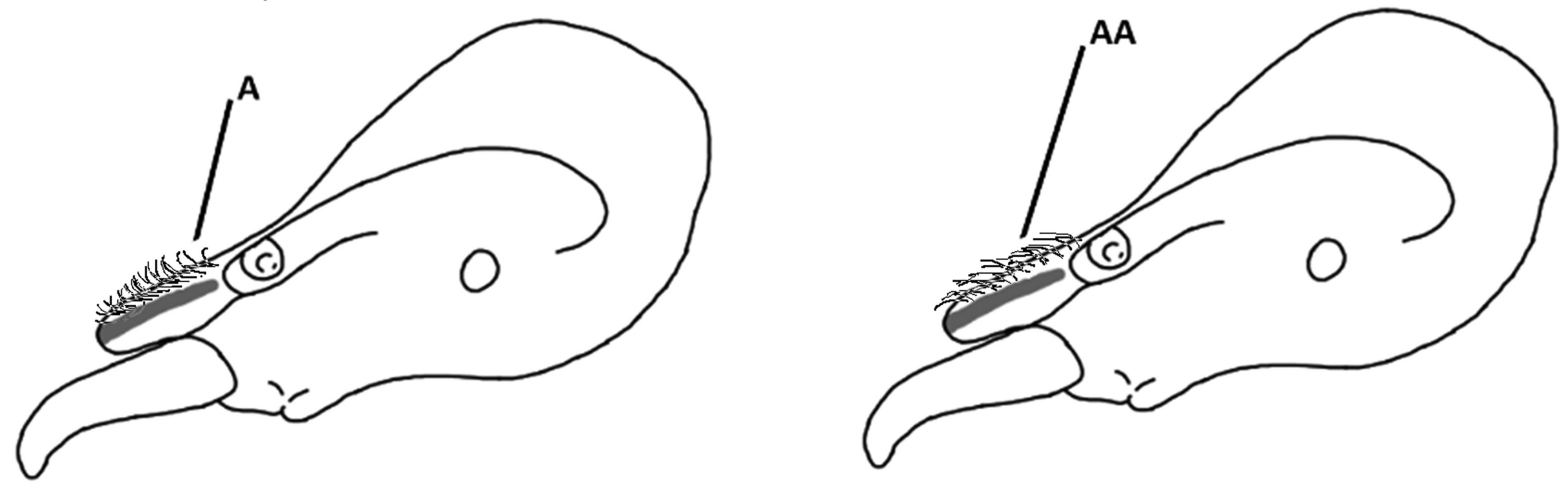

FIGURE 11. Lateral head views of representative Strumigenys species.

11 With head in full-face view setae that project from the lateral clypeal margin fine, conspicuously J-shaped and curve posteriorly (Fig. 12A) . . . . . . . . pilinasis Forel, 1901 (Note: senior synonym of ohioensis) (KS, OK, TX, and many eastern states) With head in full-face view setae that project from the lateral clypeal margin variable in form but not J-shaped and curve or are inclined anteriorly (Fig. 12AA) reliquia (Ward, 1988) (CA)
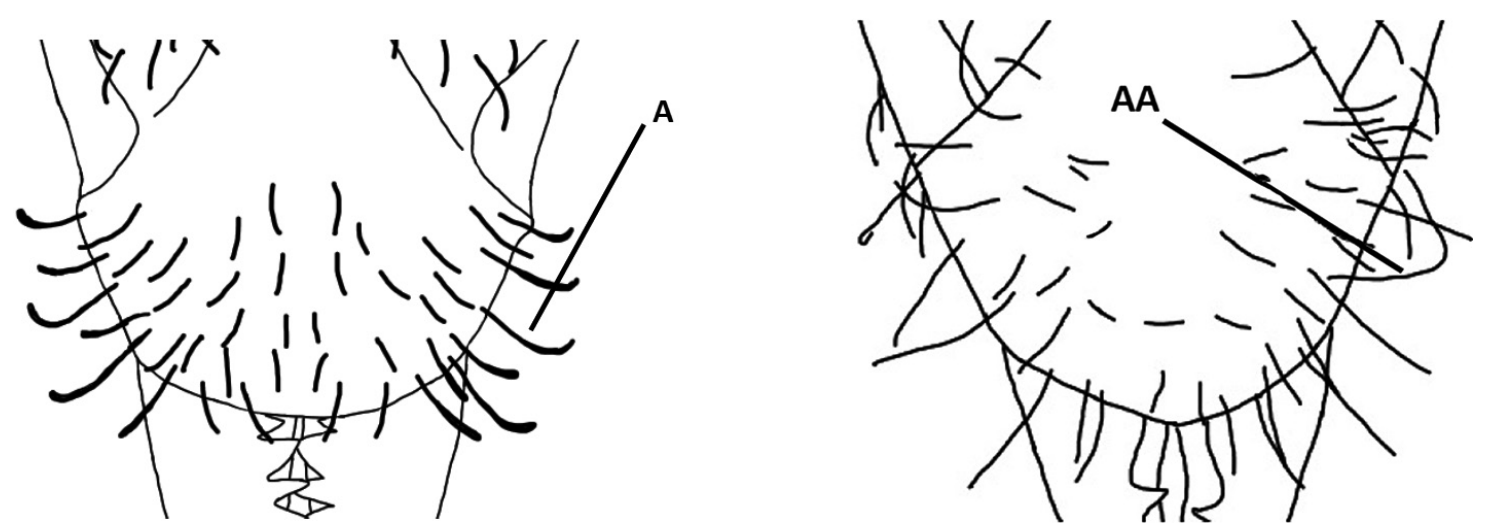

FIGURE 12. Clypeus in face view of representative Strumigenys species.

12 The pair of setae positioned nearest the outer mandible insertions (Fig. 13A; sometimes on the anterior margin of clypeus) and often those occurring on the lateral margin of clypeus (Figs. 14A, 13B) curve posteriorly, with apices directed towards the back

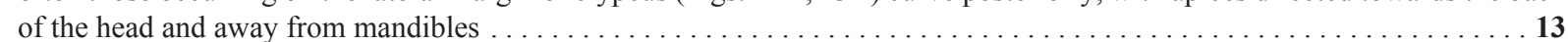
The pair of setae positioned nearest the outer mandible insertions (Fig. 13AA) and those on the lateral margin of clypeus (Fig. $13 \mathrm{BB}$ ) all curve ventrally or towards mandibles, without apices directed posteriorly $\ldots \ldots \ldots \ldots \ldots \ldots \ldots \ldots \ldots$ 

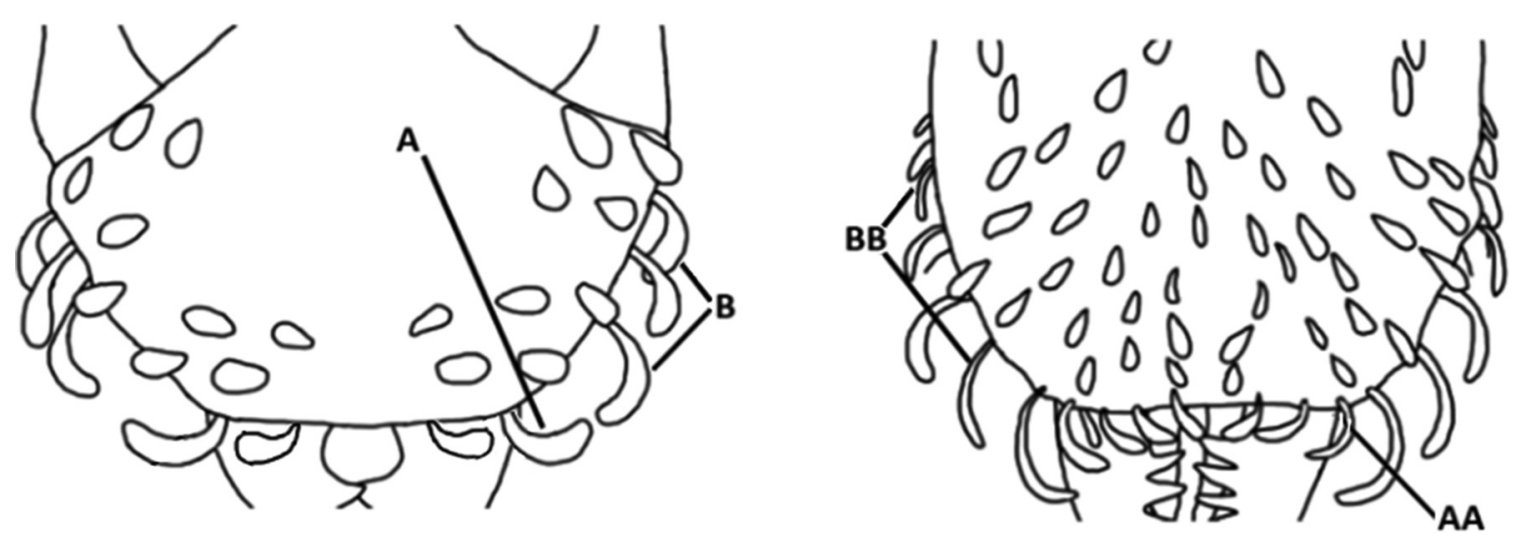

FIGURE 13. Clypeus in face view of representative Strumigenys species.

13 Two or more pairs of setae positioned nearest the outer mandible insertions Fig. 14A) or on the lateral margin of clypeus curve away from mandibles . . . . . . . . . . . . reflexa Wesson \& Wesson, 1939 (KS, TX, and many other eastern states). One pair of setae positioned nearest the outer mandible insertions (Fig. 14B) curve away from mandibles. Those on the lateral margin curve towards the mandibles . . . . . . . . missouriensis Smith, 1931 (possible, many eastern states; may be a complex of species; should also compare with eastern species)
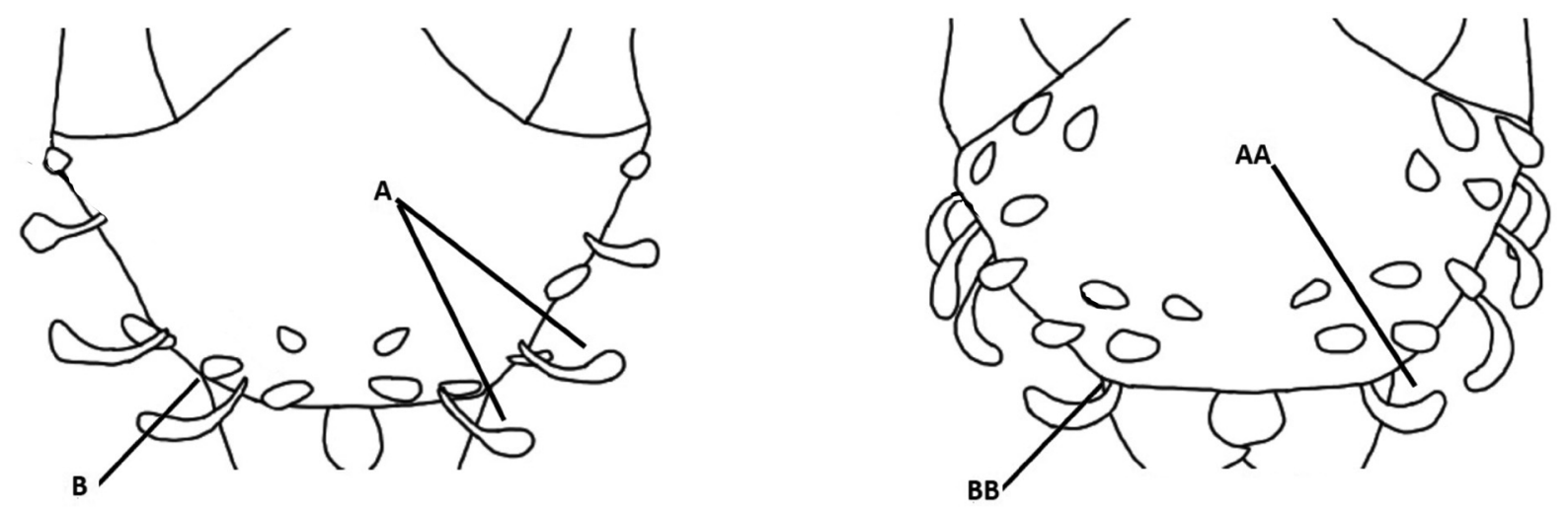

FIGURE 14. Clypeus in face view of representative Strumigenys species.

14 Ventral surface of petiolar peduncle with no trace of spongiform tissue (Fig. 15A) $\ldots \ldots \ldots \ldots \ldots \ldots \ldots$ $\ldots \ldots \ldots \ldots \ldots \ldots \ldots \ldots \ldots \ldots \ldots \ldots \ldots \ldots \ldots \ldots \ldots \ldots \ldots \ldots$ margatae Forel, 1893 (TX and many other southeastern states) Ventral surface of petiolar peduncle with obvious lamella of spongiform tissue (Fig. 15AA) $\ldots \ldots \ldots \ldots \ldots \ldots \ldots$
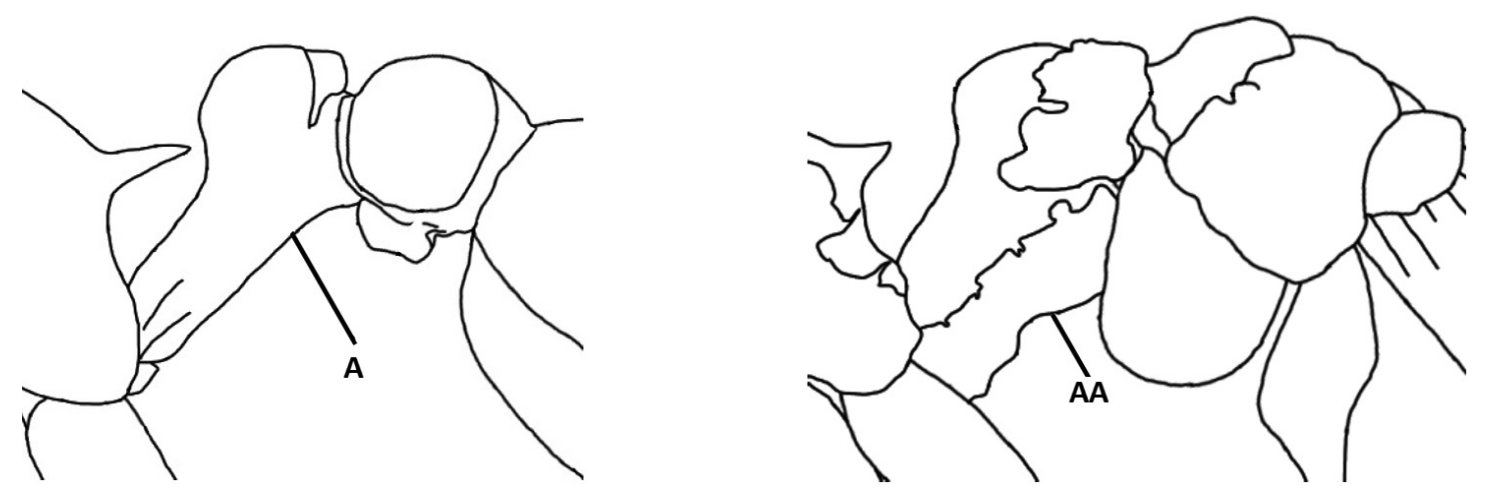

FIGURE 15. Lateral petiolar views of representative Strumigenys species.

15 Setae on the posterior half of clypeal dorsum (Fig. 16A) with several to many setae that curve and are directed posteriorly or

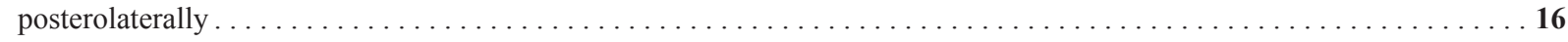
Setae on posterior half of clypeal dorsum (Fig. 16AA) consisting of anteriorly or anterolaterally directed setae; without posteriorly directed setae 

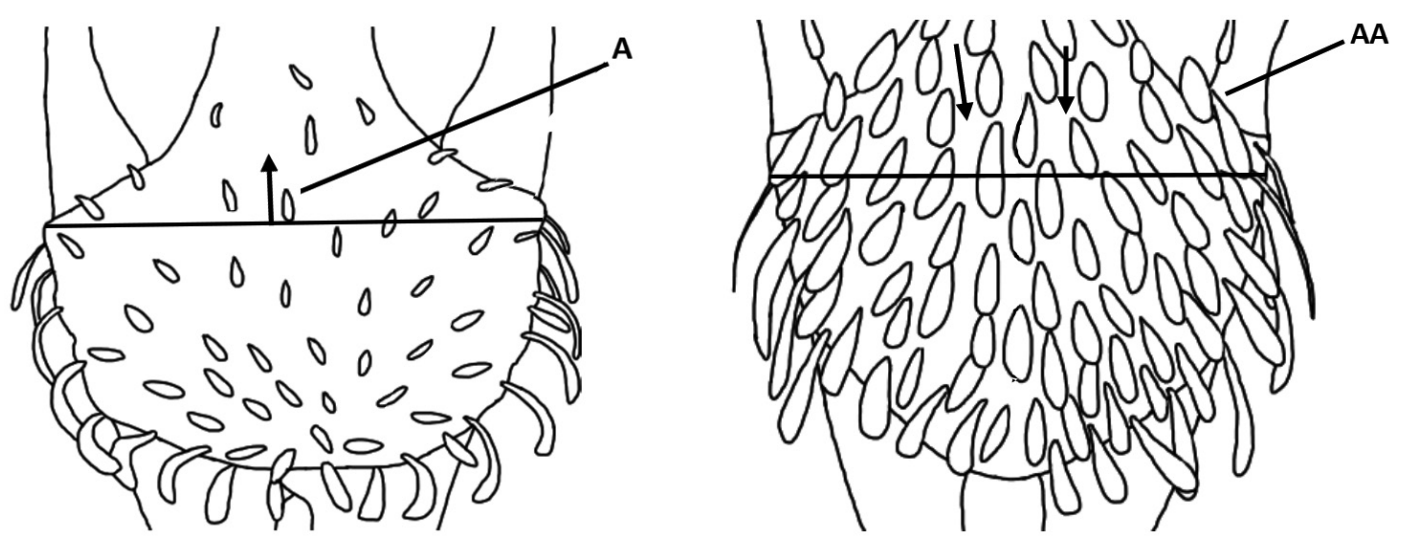

FIGURE 16. Clypeus in face view of representative Strumigenys species.

16 Setae on the anterior margin of clypeus (Fig. 17A) curve away from midline . . . . . . lucky sp. nov. (IA, IL, MN, WI)

- Setae on the anterior margin of clypeus (Fig. 17AA) curve ventrally or towards midline
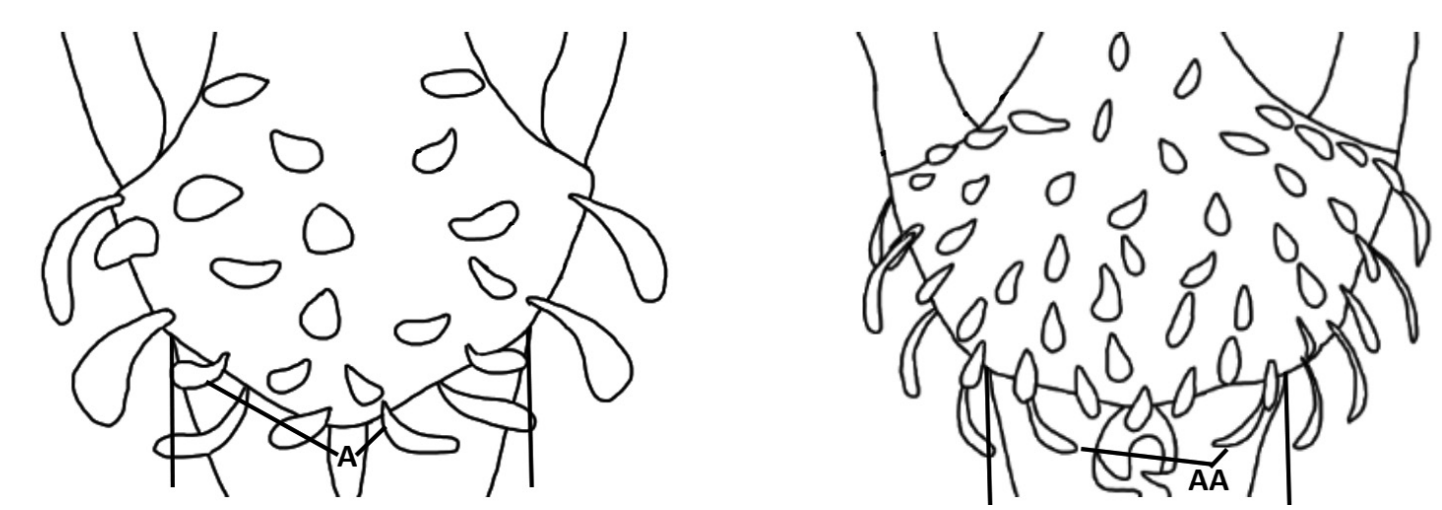

FIGURE 17. Clypeus in face view of representative Strumigenys species.

17 Setae covering dorsum of clypeus short, simple to narrowly expanded, and all curving posteriorly (Fig. 18A) .

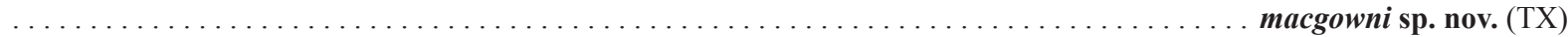

- Setae on clypeal dorsum expanded, spoon-shaped to scale-like and translucent; those on the anterior portion of clypeus curve anteriorly and posteriormost setae curve posteriorly (Fig. 18AA) . . . chiricahua (Ward, 1988) (AZ)
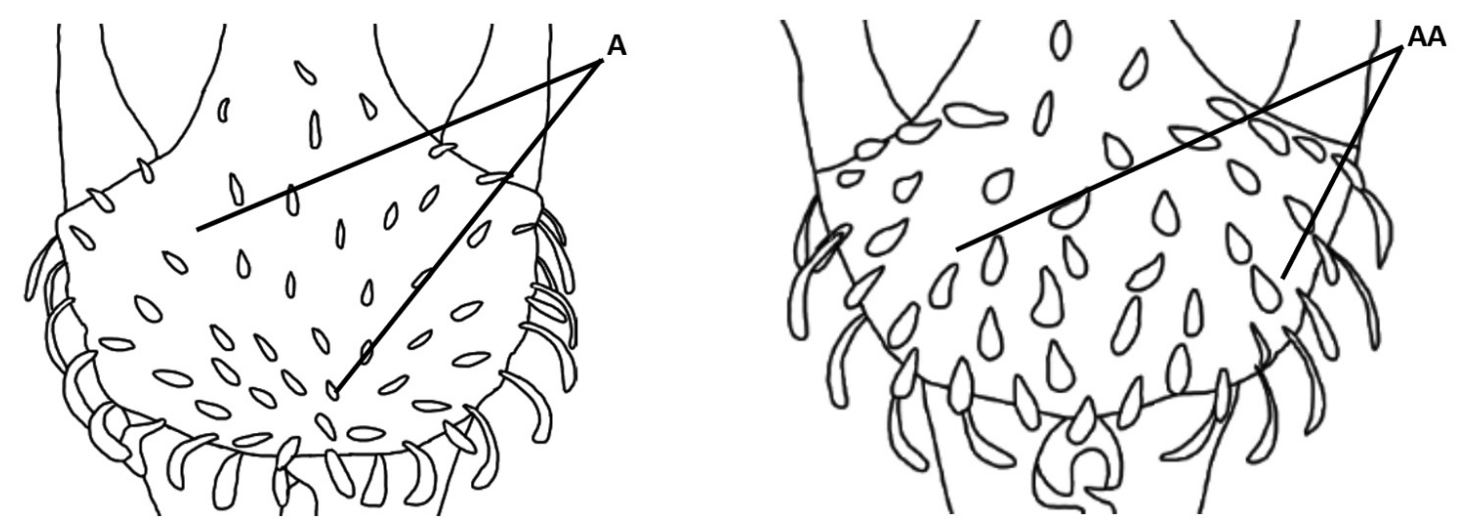

FIGURE 18. Clypeus in face view of representative Strumigenys species.

18 Clypeus with a wide peripheral groove along entire free margin (Fig. 19A); maximum width of groove more than 1/3 the maximum length of eye (usually 0.5 times or wider and most easily seen when clypeus is viewed in profile or from anterior apex of

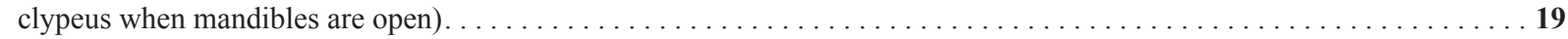
Clypeus without a peripheral groove (Fig. 19AA) along margin or, if present, the maximum width of groove is less than $1 / 3$ the

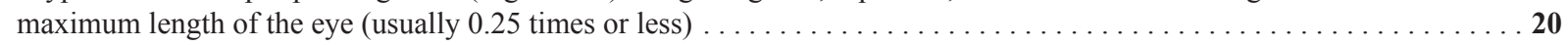



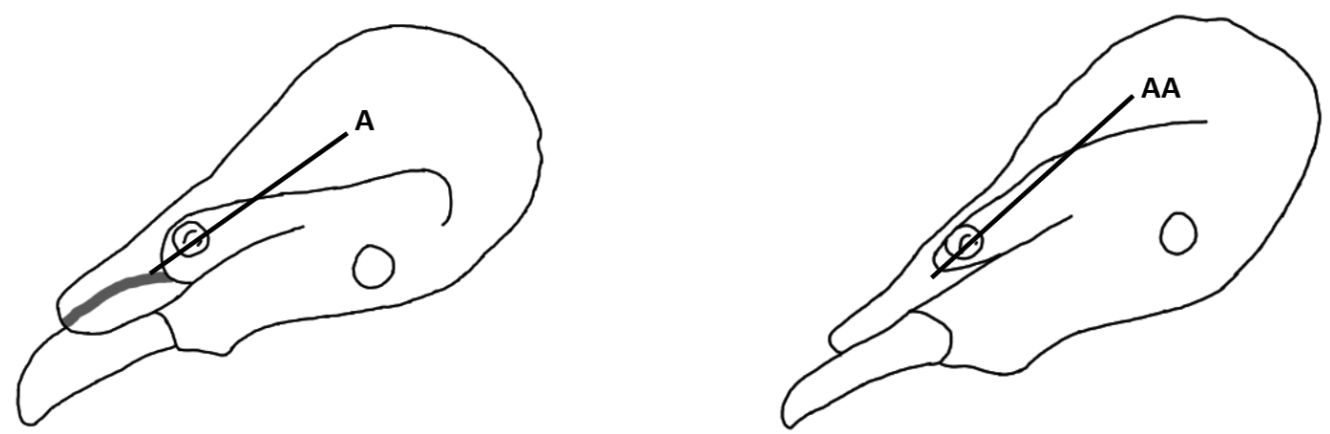

FIGURE 19. Lateral head views of representative Strumigenys species.

19 Setae on lateral margins of clypeus simple-linear to slightly and evenly expanded along apical portion (Fig. 20A), directed anteriorly, and not strongly curving towards the midline; setae on dorsum of clypeus (Fig. 20B) similarly shaped but shorter and inclined anteriorly...................... brevisetosa Smith, 1935 (KS, OK, TX, and many eastern states) Setae on lateral margins of clypeus spatulate (Fig. 20AA), directed antero-medially and strongly curving towards the midline; setae on dorsum of clypeus (Fig. 20BB) consisting of shorter spatulate setae

clypeata Roger, 1863 (KS, OK, TX, and many eastern states)
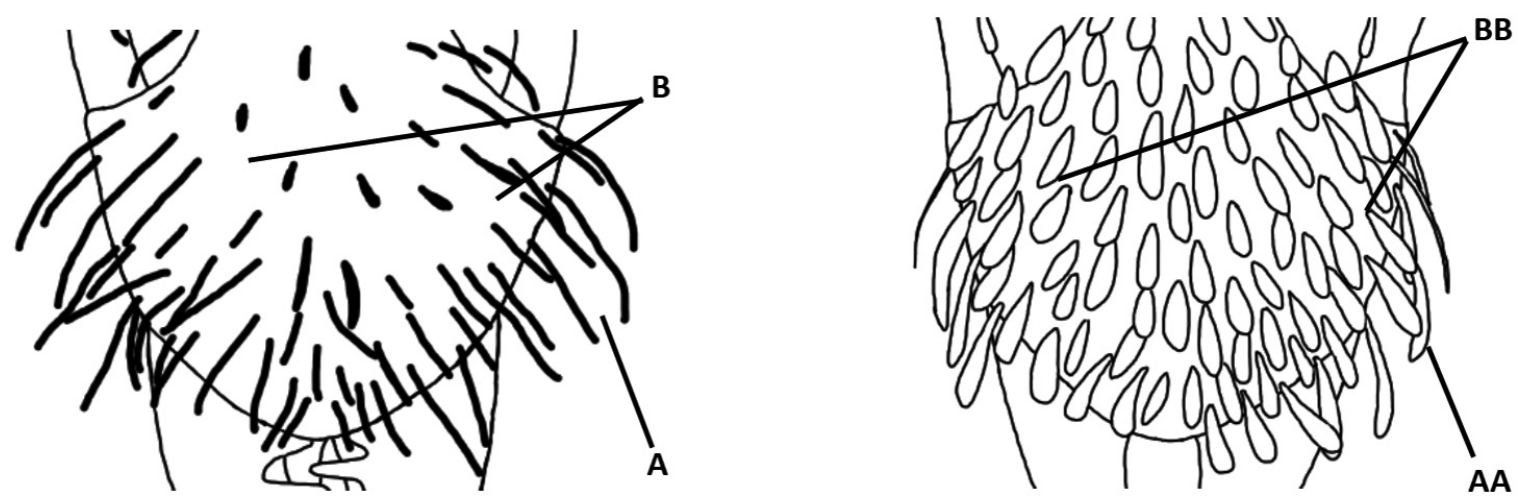

FIGURE 20. Clypeus in face view of representative Strumigenys species.

Diastemmic gap absent (Fig. 21A) or if present it is shorter than the length of the first principle tooth (measured between anterior edge of clypeus to first tooth if apex of basal lamella is hidden by clypeus in full frontal view) $\ldots \ldots \ldots \ldots \ldots 21$ Diastemmic gap present (Fig. 21AA) and is equal to or longer than the length of the first principle tooth (measured between anterior edge of clypeus to first tooth if apex of basal lamella is hidden by clypeus in full frontal view) $\ldots \ldots \ldots \ldots \ldots 24$
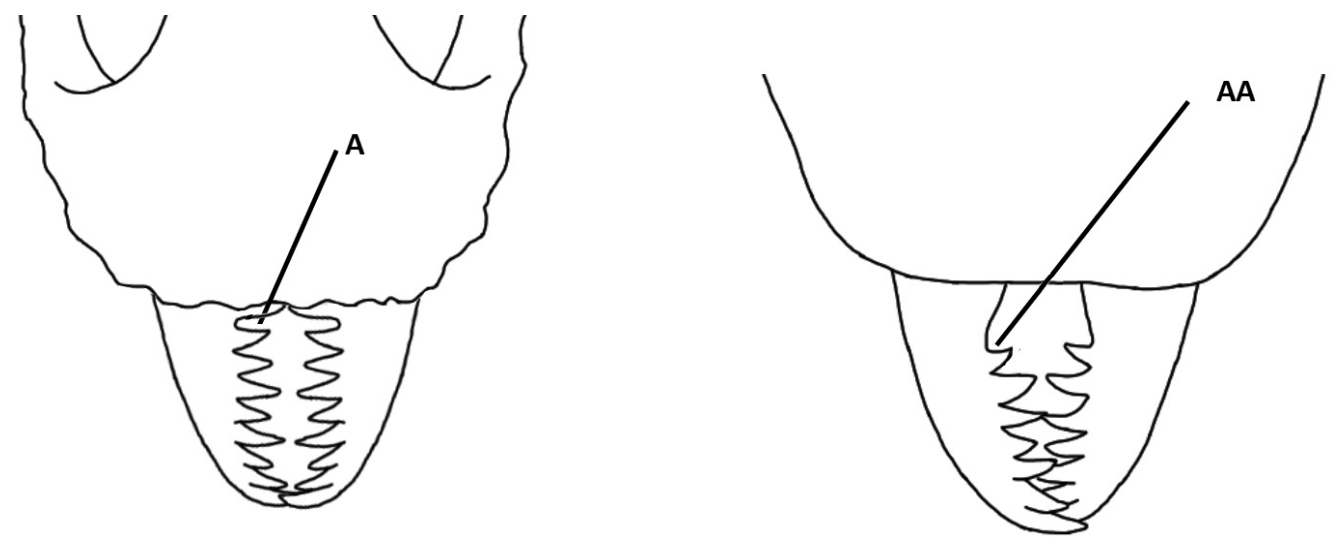

FIGURE 21. Face views of representative Strumigenys species.

21 Differentiated pronotal humeral setae absent (Fig. 22A), diastema apparent and nearly equal to length of first tooth (Fig. 22B)

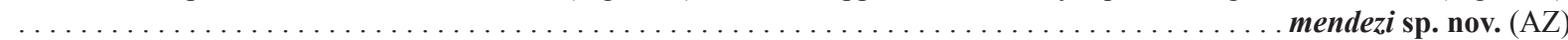
Pronotal humeral setae present (Fig. 22AA) although may be short, extremely fine and difficult to see; diastema obviously shorter than length of first tooth (Fig. 22BB). 

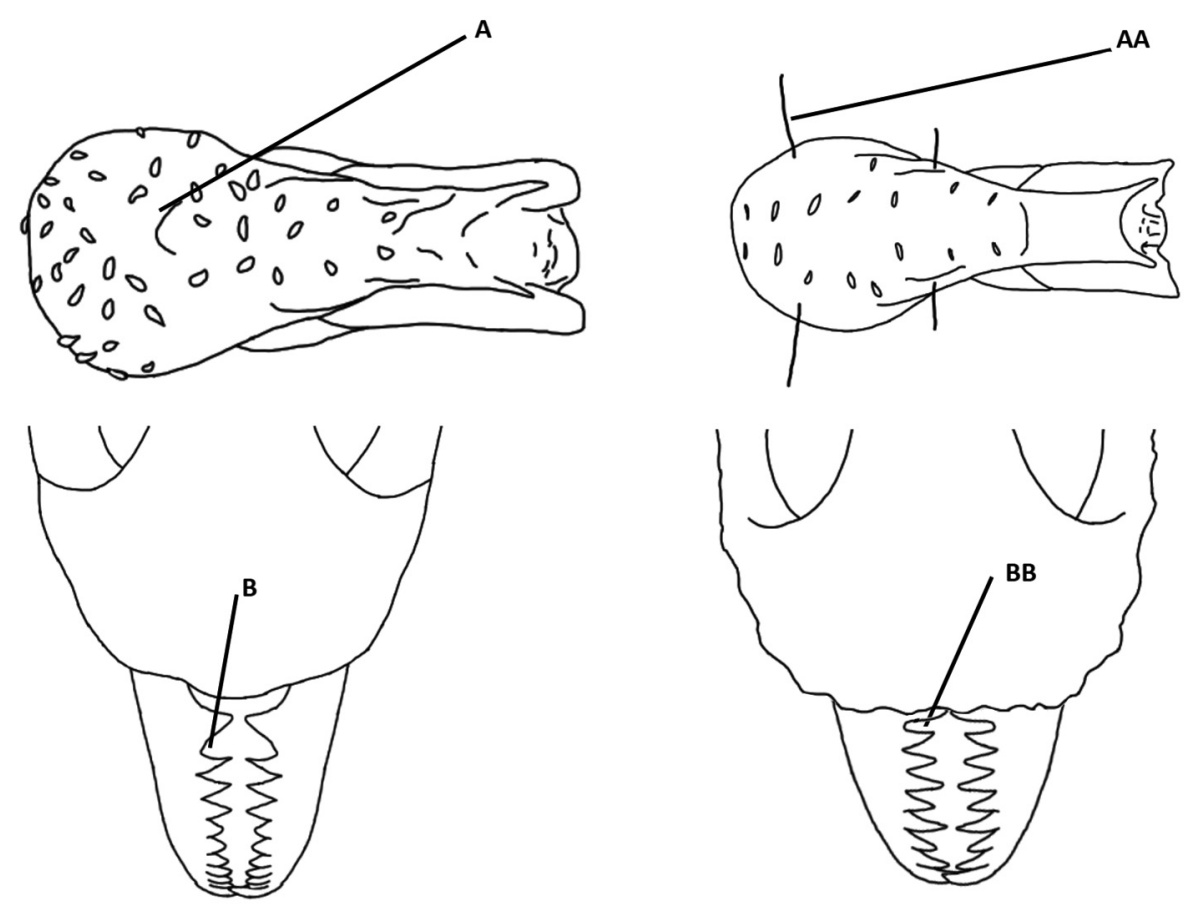

FIGURE 22. Top, dorsal pronotal views and bottom, face views of representative Strumigenys species.

Pronotal humeral (Fig. 23A) setae erect, simple, straight, and stiff (always apparent)
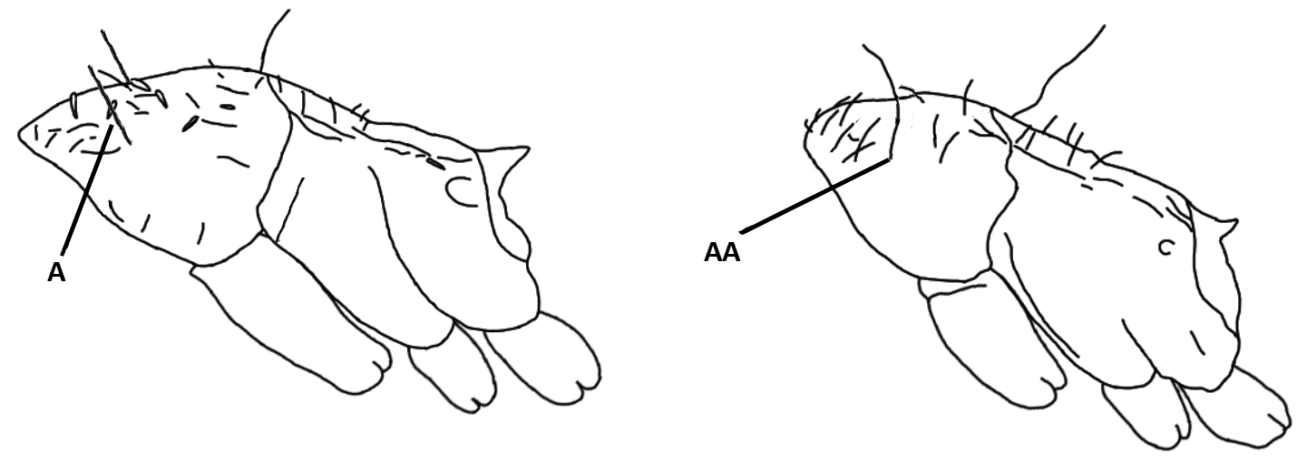

FIGURE 23. Lateral mesosomal views of representative Strumigenys species.

With head in profile clypeus abruptly raised, interrupting the outline of head, with the frontal area impressed and concave (Fig.

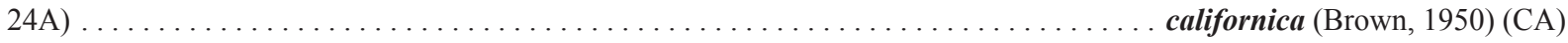
With head in profile clypeus not abruptly raised and not interrupting the outline of head, the frontal area continuous with clypeus, straight and not concave (Fig. 24AA) . . . . . . arizonica (Ward, 1988) (USA - TX, AZ, NM; MEX - Sonora, Chihuahua)
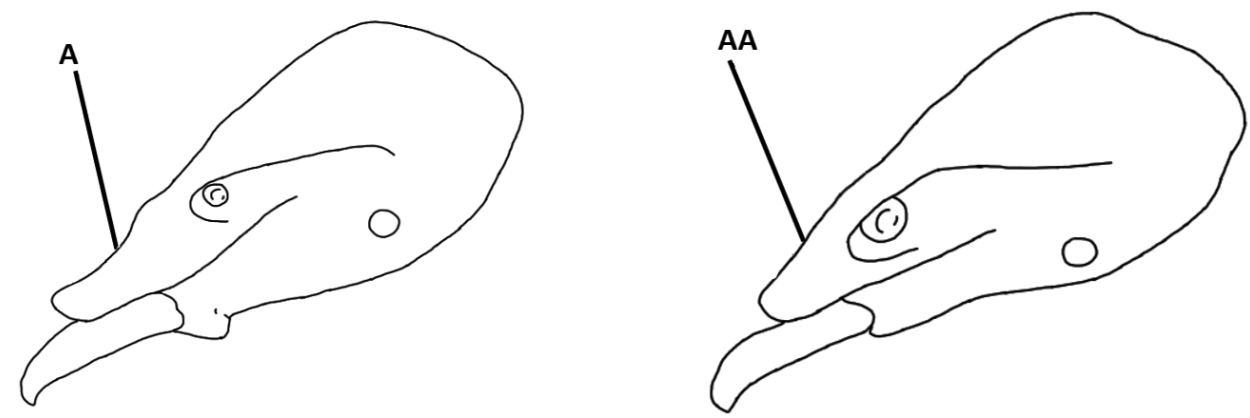

FIGURE 24. Lateral mesosoma views of representative Strumigenys species. 
Standing flagellate setae present at apicoscrobal position and usually another pair just posterior to the apicoscrobal position along the vertex margin, straddling the midline of head (Fig. 25AA).
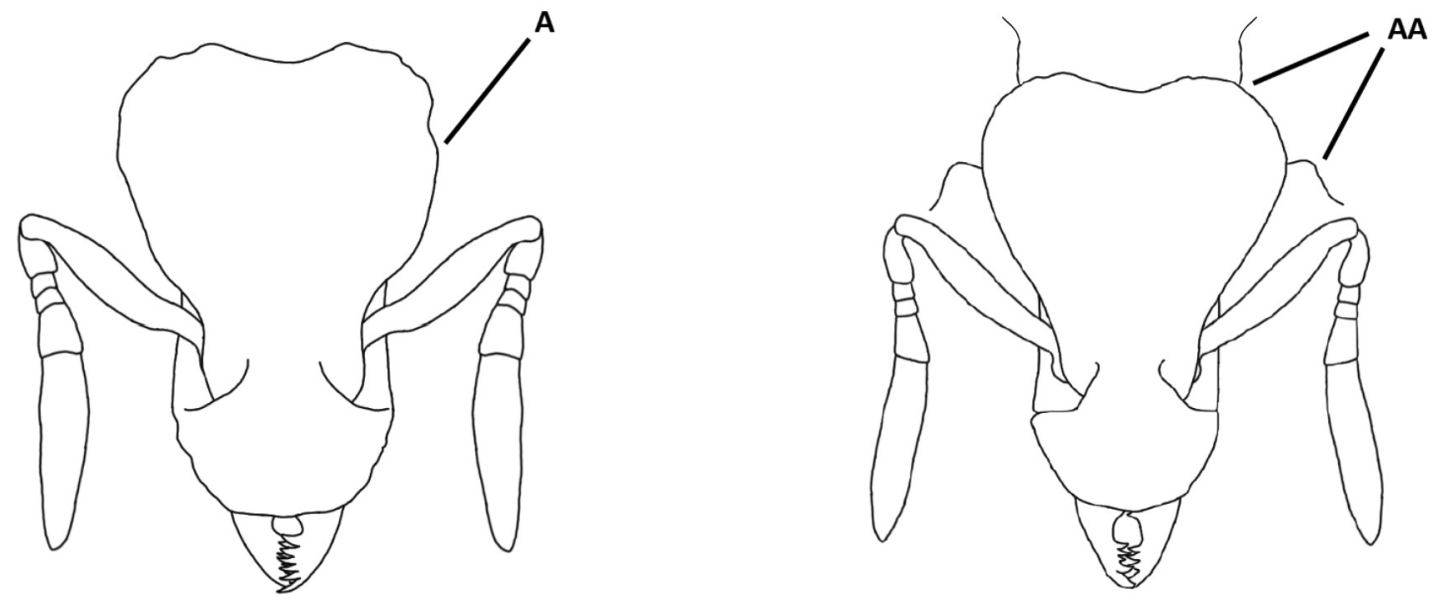

FIGURE 25. Face views of representative Strumigenys species.

First (basal) tooth about half the length of second tooth and not overlapping opposing tooth in closed position (Fig. 26A). .. . $\ldots \ldots \ldots \ldots \ldots \ldots \ldots \ldots \ldots \ldots \ldots \ldots \ldots \ldots \ldots \ldots \ldots \ldots \ldots \ldots \ldots \ldots \ldots \ldots \ldots \ldots \ldots \ldots \ldots$ moreauviae sp. nov. (NM) First (basal) two teeth approximately equal in length and overlapping opposed teeth in closed position (Fig. 26AA) . . . . 26
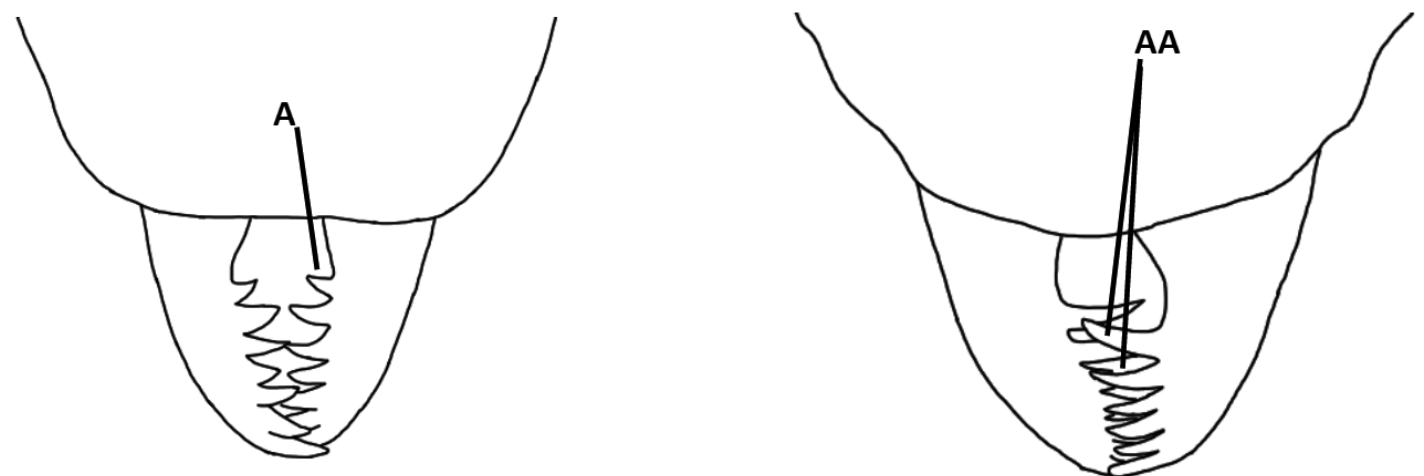

FIGURE 26. Face views of mandibles of representative Strumigenys species.

At least one pair of setae on the anterior clypeal margin curve strongly away from the midline (sometimes two pairs) (Fig. 27A); posterior half of clypeal dorsum with few or no setae . . . missouriensis Smith, 1931 (possible, many eastern states; may be a complex of species; should also compare with eastern species)

All setae on the anterior margin of clypeus curve towards the midline (Fig. 27AA); posterior half of clypeal dorsum with many setae talpa Weber, 1934 (part, specimens from OK)
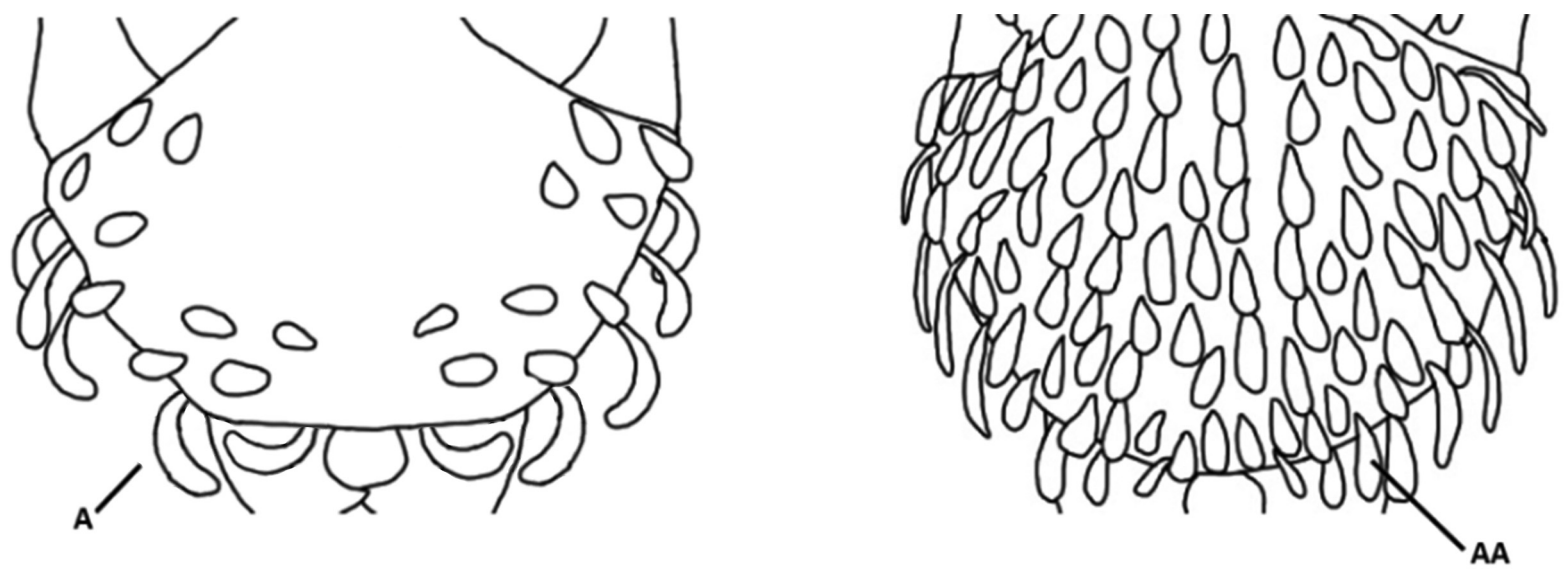

FIGURE 27. Clypeus in face view of representative Strumigenys species. 
First five teeth alternate in size between similarly large and small teeth, in some individuals basalmost tooth is a small adventitious tooth and in others the first tooth is a large well-developed tooth (Fig. $28 \mathrm{~A}) \ldots \ldots \ldots \ldots \ldots \ldots \ldots \ldots \ldots \ldots$ First and second tooth are nearly equal in size and much larger than third tooth, never alternating in size among the first five basal teeth (Fig. 28AA)
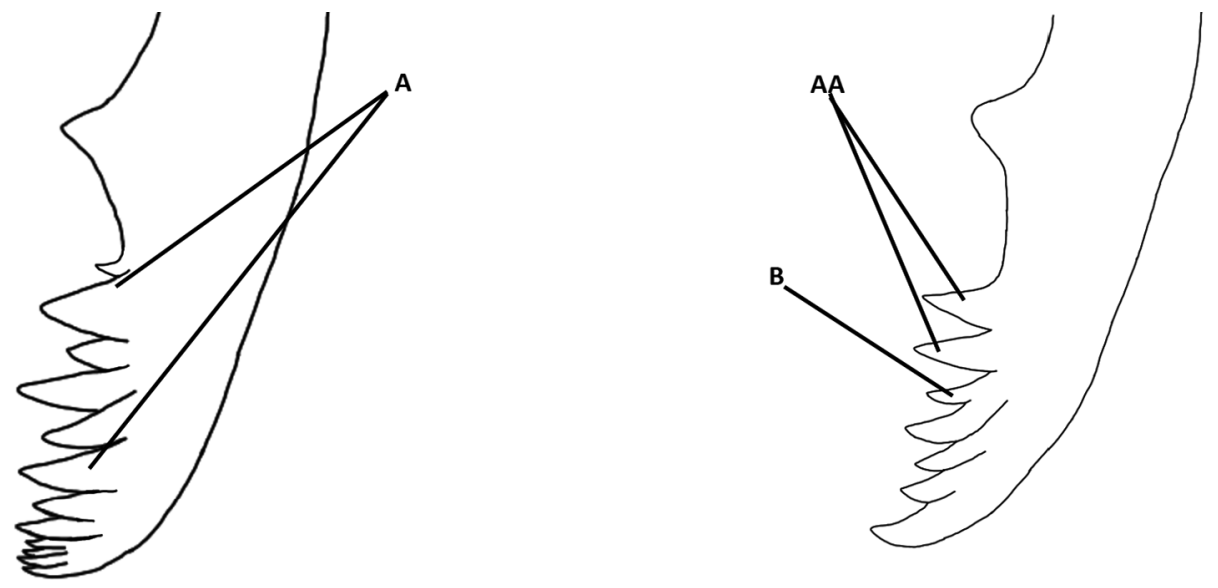

FIGURE 28. Mandibles of representative Strumigenys species.

Setae on anterior margin of clypeus (Fig. 29A) curve away from midline; setae on anterior dorsum of clypeus curve laterally or posterolaterally (Fig 29B); setae are club shaped and opaque . . . . . . . . . . lucky sp. nov. (IA, IL, MN, WI) Setae on anterior margin of clypeus (Fig. 29AA) curve ventrally or towards midline; setae on anterior dorsum of clypeus curve anteriorly or anterolaterally (Fig 29BB); setae spoon-shaped and translucent. . . . . ananeotes Longino \& Booher, 2019 (UT)
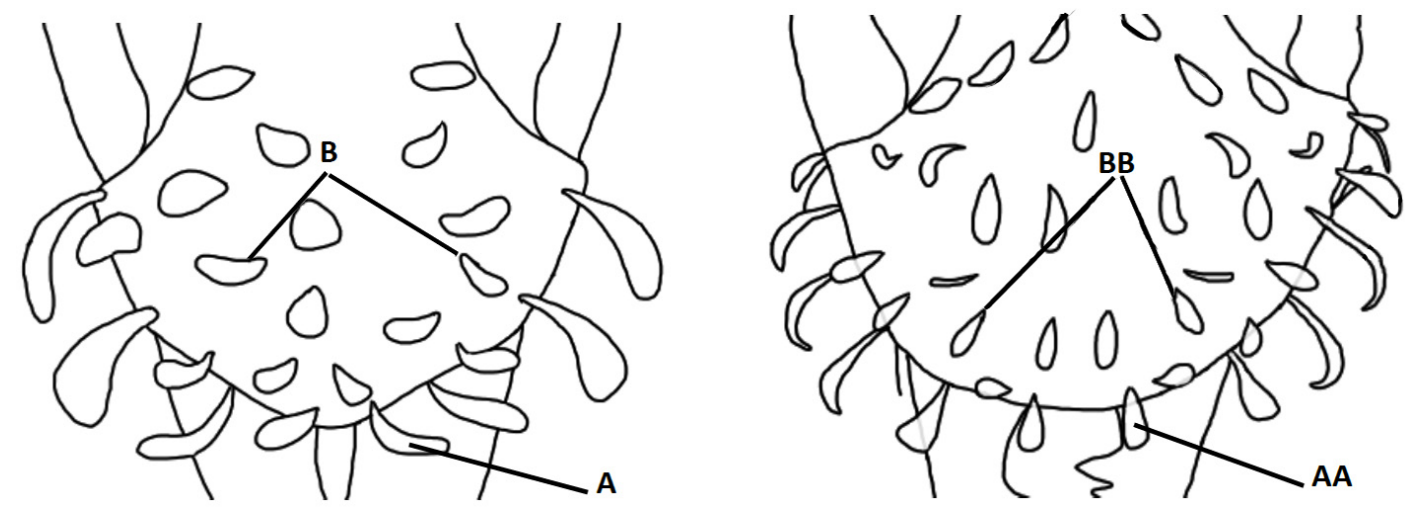

FIGURE 29. Clypeus in face view of representative Strumigenys species.

One to two pairs of setae on anterior clypeal margin curve away from midline of mandibles (Fig. 30A); fewer than five setae are present on lateral margin of clypeus (Fig. 30B) ......... pulchella Emery, 1895 (KS, TX, and many eastern states) All setae on anterior clypeal margin curve towards the midline (Fig. 30AA); more than five setae present on lateral margin of clypeus (Fig. 30BB) . talpa Weber, 1934 (OK, TX, and many eastern states)
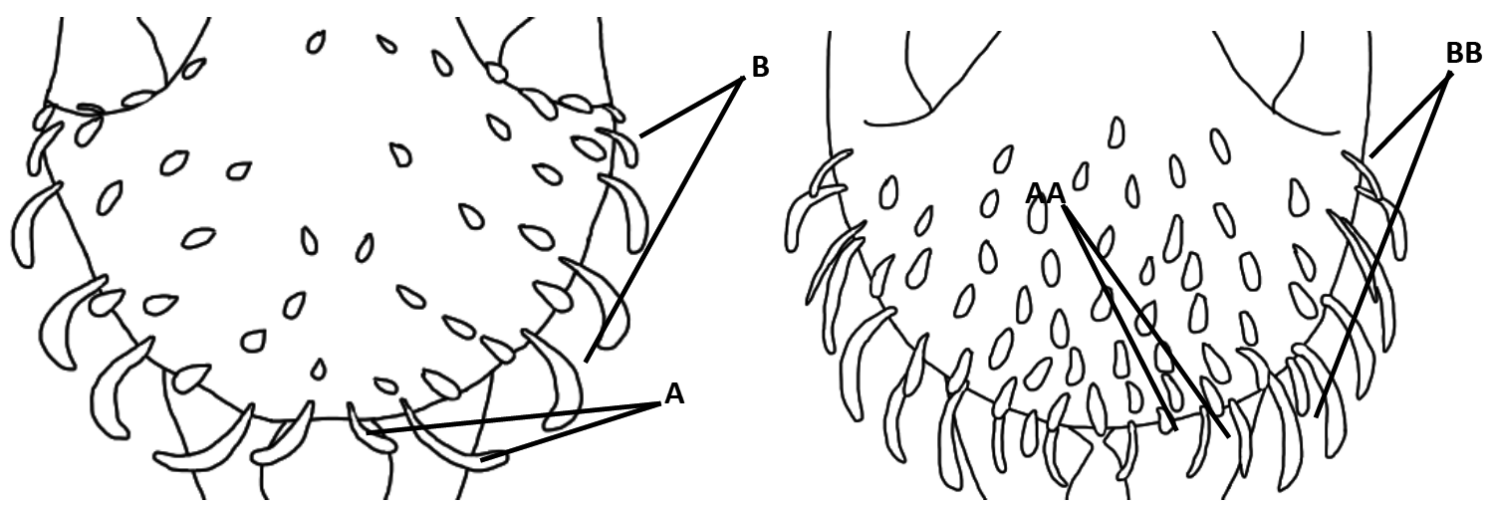

FIGURE 30. Clypeus in face view of representative Strumigenys species. 

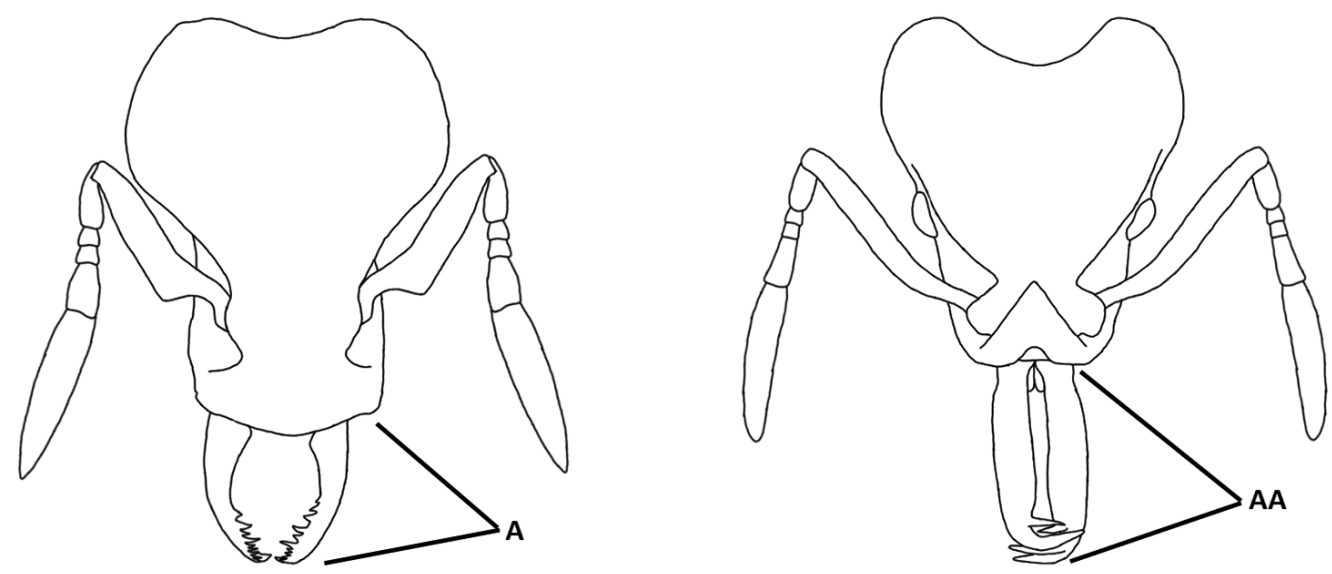

FIGURE 31. Face views of representative Strumigenys species.

31 Along apical half of mandible basal three teeth triangular (Fig. 32A); anterior and lateral margins of the clypeus angulate (Fig. 32B); scapes shorter, SI 65-69 (Fig. 32C) . . . . . . . . . . . . . angulata Smith, 1931 (OK and many eastern states) Along apical half of mandible second tooth following basal tooth bluntly rounded (Fig. 32AA); anterior and lateral margins of the clypeus rounded (Fig. 32BB); scapes longer, SI 65-69 (Fig. 32CC). pergandei Emery, 1895 (KS and many eastern states)
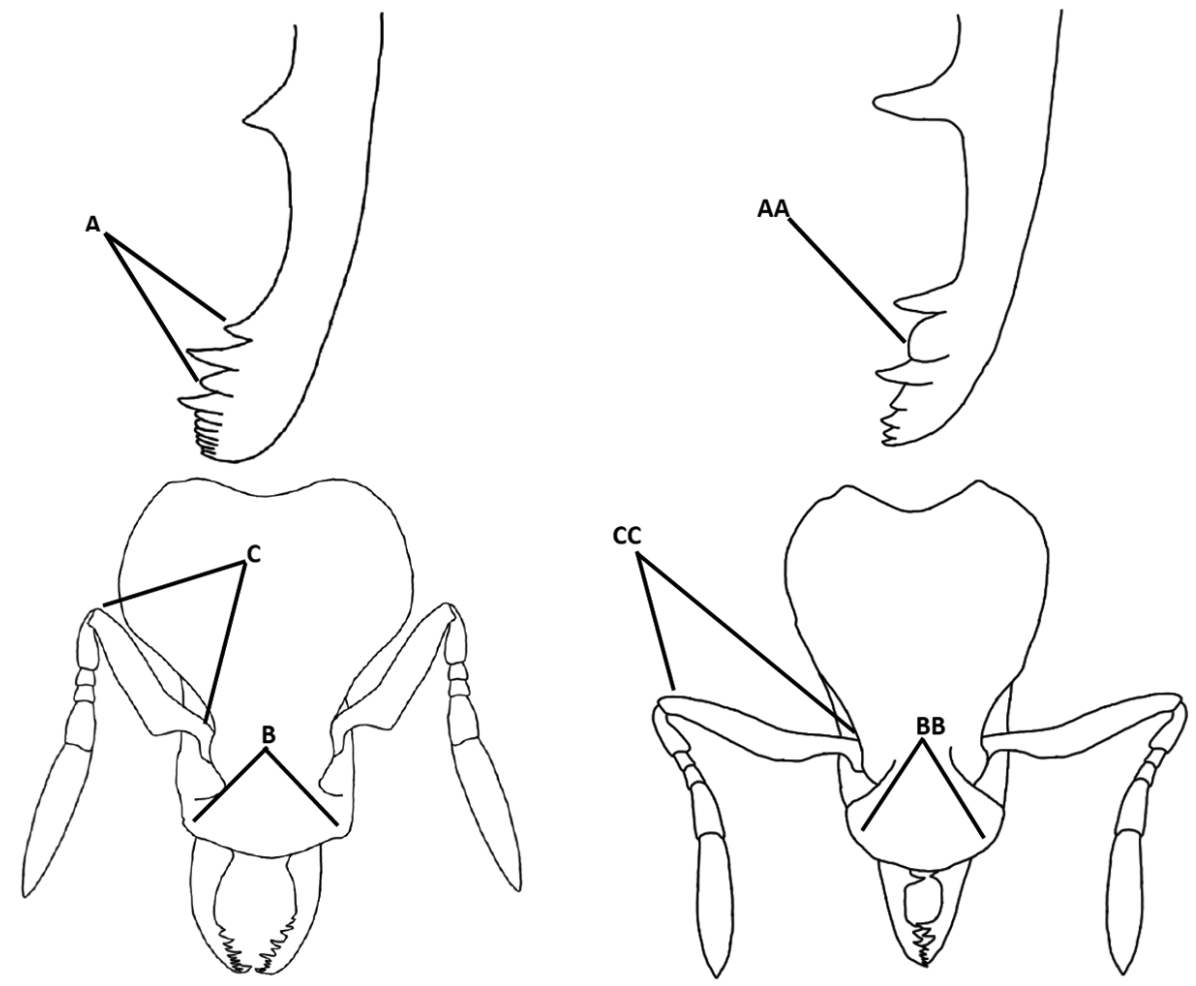

FIGURE 32. Top, mandibles and bottom, face views of representative Strumigenys species.

NOTE - species keying out in the rest of the key should also be checked with Bolton (2000) key to Neotropical Strumigenys.

32 Mandible without enlarged preapical tooth just basal of apicodorsal tooth (Fig. 33A) (however a minute denticle is present at midlength of mandible); all setae on anterior margin of scape directed towards apex (Fig. 33B); pronotal humeral seta short, stiff and stout (Fig. 33C) . . . . . . . . . . . . . . . . . . . . . . . . . . . . . . . . . boneti Brown, 1959 (TX) Mandible with enlarged preapical tooth just basal of apicodorsal tooth (Fig. 33AA) (with or without a minute denticle at midlength of mandible); one or more pairs of setae on anterior margin of scape directed towards base (Fig. 33BB); pronotal humeral

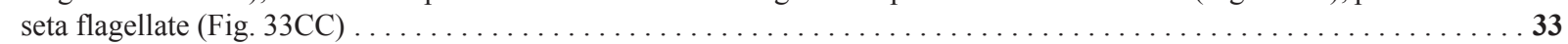



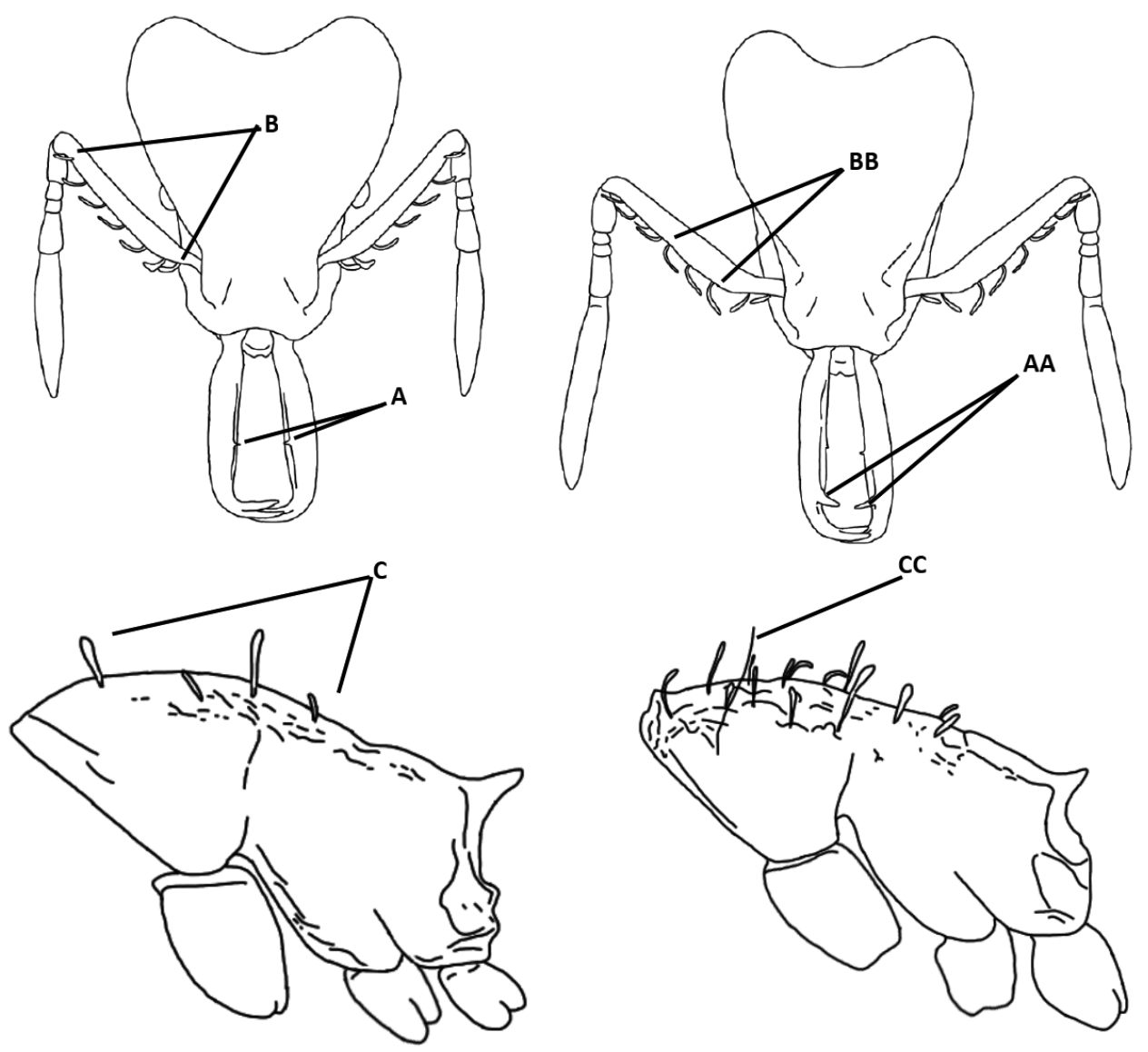

FIGURE 33. Top, face view and bottom, lateral mesasoma views of representative Strumigenys species.

33 Smaller species (HW 0.33-0.37) with a minute preapical denticle located at about midlength of mandible (Fig. 34A) (global tramp species $) \ldots \ldots \ldots \ldots \ldots \ldots \ldots \ldots \ldots \ldots \ldots \ldots \ldots$ silvestrii Emery, 1906 (CA, TX, and many southeastern states) Larger species (HW 0.38-0.54) without a minute preapical denticle (Fig. 34AA), or if preapical denticle present it is located near the apical portion of the second third of mandible. .34
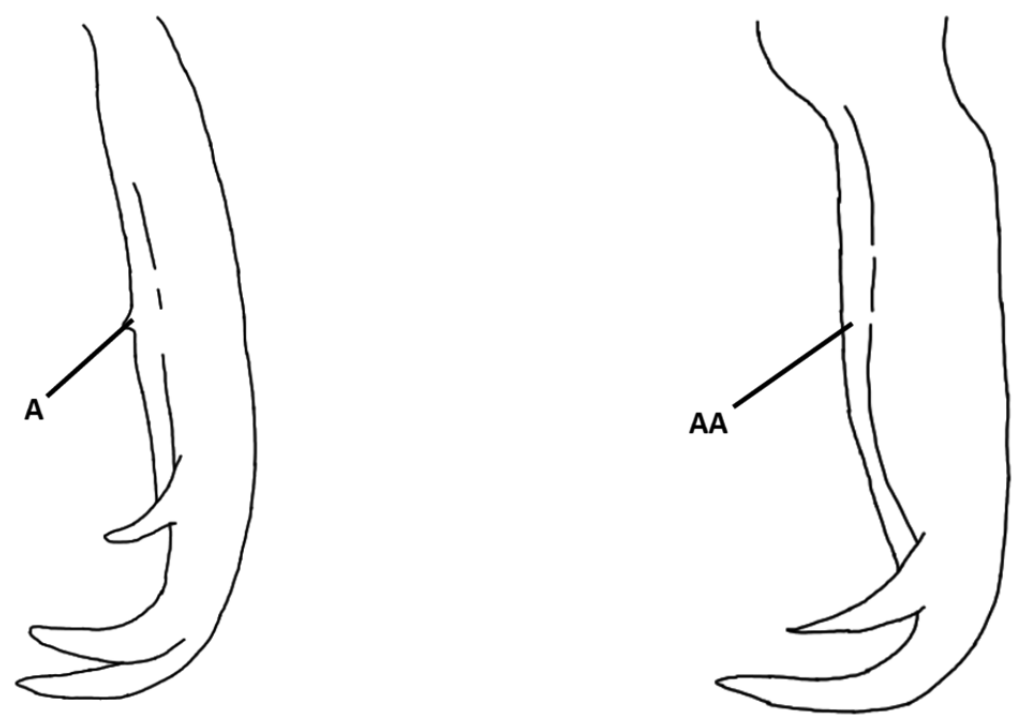

FIGURE 34. Mandibles of representative Strumigenys species.

34 Mandible with preapical denticle located near the apical portion of the second third of mandible (Fig. 35A). ... mixta Brown, 1953 (AZ)

Mandible without preapical denticle (Fig. 35AA) . .

louisianae Roger, 1863 (OK, TX, and many eastern states) 

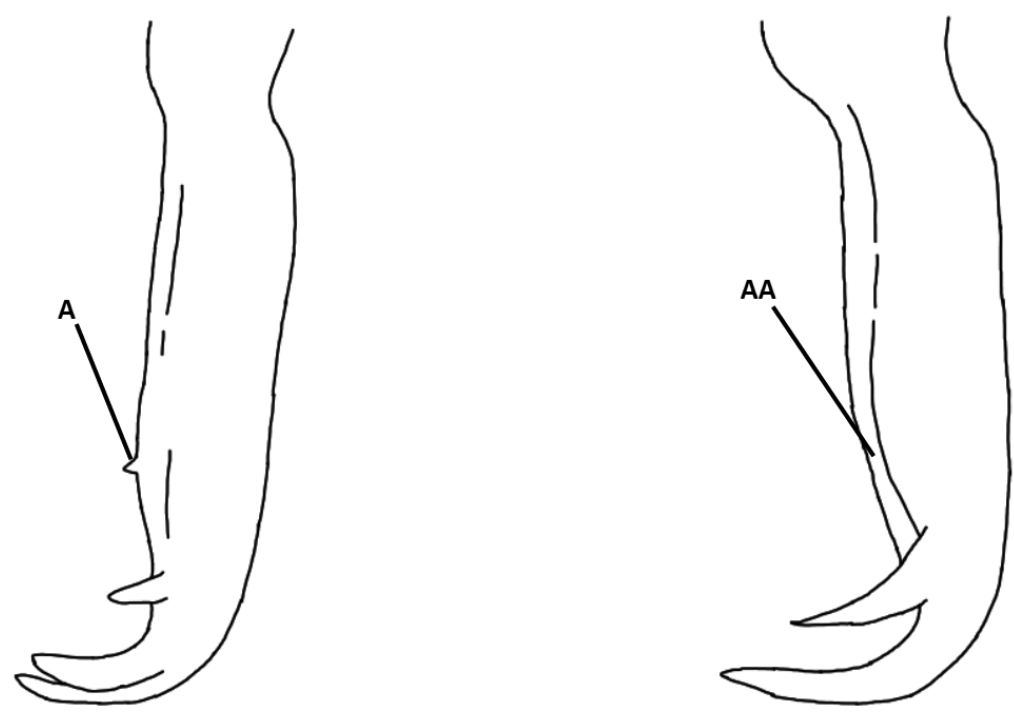

FIGURE 35. Mandibles of representative Strumigenys species.

\section{Species accounts}

Although this study focuses on the examination of species occurring in the western half of the USA, many species have larger geographic ranges outside of this area. Summarized global ranges are given at the country level for species occurring outside the USA and summarized at the state level for their eastern USA range. All states are provided for species occurring in western USA.

\section{Strumigenys alberti Forel 1893}

Distribution. Mexico to Brazil and most Caribbean islands; one USA record from Nevada.

Comments. This is a common species with a large range in the Neotropics. A single specimen is known from the USA, collected by Emma Mackay. This specimen was collected in a natural area, underneath a small rock in a dry and rocky juniper shrubland in Spring Valley State Park in Lincoln Co., Nevada. This new record is well north of the previous range limit of the species ( $38^{\circ} \mathrm{N}$ vs. $23^{\circ} \mathrm{N}$; Guénard et al. 2017; Janicki et al. 2016). The occurrence may be an introduction or a rarely collected native with a much larger range than previously known. According to $\mathrm{W}$. Mackay, he immediately recognized it as a Strumigenys $s p$. and knowing no other collections of Strumigenys in Nevada, he and Emma Mackay spent quite a bit of time searching for additional specimens without luck. Other ants W. Mackay collected as part of the same collecting event were Tapinoma sessile (Say, 1836), Formica moki Wheeler, 1906, Camponotus sansabeanus (Buckley, 1866), Camponotus vicinus Mayr, 1870, Dorymyrmex sp., Temnothorax sp., Solenopsis sp., and Forelius sp. (unpublished data).

Material examined: USA, Nevada, Lincoln Co., 0.70 km NE Panaca, 38.053031, -114.17002 \pm 1000 m, 1783 $\mathrm{m} \pm 15,24-$ May-13, found in a shrubland under small stone, dry rocky sandy loam, 1w, coll. W\&E Mackay, MacKay\#25374, (casent0799751)[CWEM]

\section{Strumigenys ananeotes Longino \& Booher, 2019}

\section{Figure 36}

Distribution. USA; Utah.

Type material: Holotype worker: USA, Utah, Salt Lake Co.: Salt Lake City, $40.77100-111.85419 \pm 20$ m, 1410 m, 13-14 Aug 2018, urban garden, nest in soil (J. Longino\#10240), unique specimen identifier (casent0645955)[CAS]. 
Paratypes: Paratype workers, alate queens: same data as holotype, unique specimen identifiers for workers; (casent0645954) [UMNH], (casent0645956) [MCZC], (casent0645957) [USNM], (casent0645965) [JTLC], (casent0648042) [BYU], (casent0799940) [UGCA], (casent0799942) [UGCA], and for queens (casent0799941) [UGCA], (casent0799943) [JTLC].

Worker measurements (holotype and paratypes $\mathbf{n}=\mathbf{6})$ : $\mathrm{HL}=0.524-0.554(0.544) ; \mathrm{HW}=0.388-0.398(0.393)$; $\mathrm{ML}=0.09-0.102$ (0.097); $\mathrm{PW}=0.254-0.271(0.265) ; \mathrm{SL}=0.275-0.306(0.288) ; \mathrm{FL}=0.342-0.356(0.352) ; \mathrm{HT}$ $=0.279-0.303(0.289) ; \mathrm{EL}=0.039-0.047(0.043) ; \mathrm{WL}=0.544-0.572(0.554) ; \mathrm{CI}=71-75$ (72); $\mathrm{MI}=16.3-18.4$ (17.5); SI =70-76 (73).

Queen measurements (n=1): $\mathrm{HL}=0.587 ; \mathrm{HW}=0.423 ; \mathrm{ML}=0.103 ; \mathrm{PW}=0.344 ; \mathrm{SL}=0.304 ; \mathrm{FL}=0.396 ; \mathrm{HT}$ $=0.316 ; \mathrm{EL}=0.113 ; \mathrm{WL}=0.665 ; \mathrm{CI}=72 ; \mathrm{MI}=17.6 ; \mathrm{SI}=72$.

Diagnosis (adapted from Longino \& Booher 2019). Strumigenys ananeotes can be distinguished from all other North American species by tooth morphology and clypeal pilosity. In some specimens of $S$. ananeotes, the basalmost tooth is small or missing, which gives a count of eight or seven teeth of alternating sizes. The setae on the anterior margin of clypeus between the mandibles are dorsoventrally directed translucent spoon-shaped setae with irregularly scalloped apical borders. Strumigenys ananeotes shares similar dentition with three other Nearctic species that have principal teeth alternating between large and small pointed teeth: midwestern species $S$. lucky, and eastern species S. metazytes (Bolton, 2000) and S. hyalina (Bolton, 2000). Strumigenys metazytes has only three larger principle teeth flanked by smaller teeth. Strumigenys lucky and S. hyalina have four larger teeth flanked by smaller teeth as does $S$. ananeotes but the larger teeth decrease in size such that tooth seven (the fourth of the large teeth) is only about half the length of first large tooth; in S. ananeotes tooth seven is only slightly smaller than tooth one. Strumigenys lucky and S. hyalina also differ in the shape and orientation of setae on the anterior margin of the clypeus between mandible insertions. In S. hyalina, these setae are translucent and spoon-shaped but have evenly flat apical margins; in $S$. lucky they are opaque, more narrowly expanded, and evenly rounded or pointed apically. Of western species, $S$. ananeotes is most similar to $S$. chiricahua, but in S. chiricahua, the first three teeth increase in size and do not completely overlap when the mandibles are closed, whereas in S. ananeotes the large teeth overlap the opposing smaller teeth when the mandibles are closed. The only other USA species with similar mandibular teeth is the introduced species $S$. margaritae Forel, 1893, which also has teeth that alternate in size, but the smaller teeth are blunt and not pointed as in S. ananeotes. However, in other characters $S$. margaritae bears little resemblance to $S$. ananeotes.

Description of worker. Mandibles with a short diastemmic gap, when measured from margin of clypeus to the first tooth, the gap is longer than the length of the first tooth. Basal lamella broadly and evenly triangulate with slightly concave free sides. Mandibles with seven or eight main teeth alternating between similarly sized long and short teeth (if eight then basalmost tooth is an additional small tooth). These teeth followed by five minute denticles and ending apically with a small tooth. In closed position long teeth overlap short teeth of opposite mandible. Eyes well developed with $7-10$ ommatidia.

Maximal width of clypeus 1.1-1.3 times length. Free margins of clypeus smooth, broadly and evenly rounded, with outline only obscured slightly by heavily punctate sculpture.

Pronotum and mesonotum are broadly rounded in profile. In profile view, metanotal groove is apparent and broadly impressed. The mesonotum is raised above groove and forms a step down to the propodeum. Some paratypes have a sharply raised transverse ridge at the anterior dorsal border of the mesonotal groove that interrupts outline. Propodeal teeth triangular, directed posteriorly and only slightly longer than lamellae that subtends teeth, which evenly follows declivitous face of the propodeum and is nearly equal in width along its length. Bulla of propodeal spiracle large (0.031-0.042 in widest length) and directed posteriorly. Bullae of femoral glands apparent on all femora and oval in shape, positioned at a distance to apex that is equal to or less than length of the bulla.

Sculpture. Head and clypeus densely punctate to reticulopunctate except for a small area of the frontal triangle. Similar sculpture on the dorsum of mesosoma, dorsal half of the declivitous face of the propodeum, and dorsal node of petiole. Side of mesosoma with punctate sculpture peripherally, but otherwise smooth and shining. Disc of postpetiole free of sculpture and shining. Bulla of metapleural gland heavily reticulopunctate with a band connecting sculpture to propodeal spiracle. The rest of the side of propodeum smooth and shining. Gaster with basigastral costulae prominent and extending approximately one quarter of the length of the first gastral tergite, otherwise smooth and shining. 


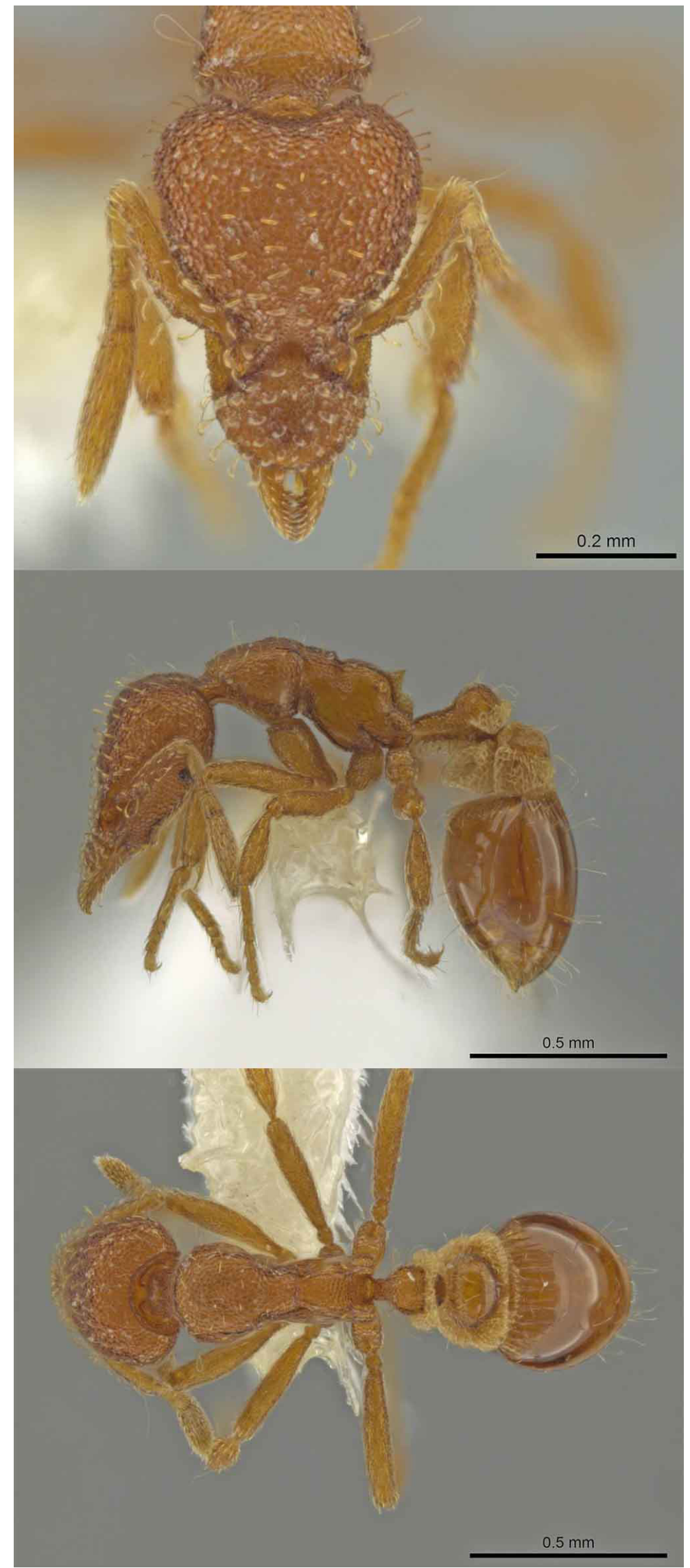

FIGURE 36. Holotype worker of Strumigenys ananeotes [CAS: casent0645955]. Photographed by Michele Esposito (AntWeb 2021). 
Pilosity. Ground pilosity of head consisting of simple to clavate erect setae that curve towards the midline of head, these setae on head being more expanded towards the clypeus. Dorsum of clypeus with similar setae but smaller than those along anterior margin. Anterior fringe of setae of clypeus with most setae curving ventrally and/or towards the midline of clypeus. A pair of much smaller setae between the mandibles curve ventrally and somewhat away from the midline. In some individuals a single seta or pair of outer neighboring setae also curve ventrolaterally away from midline. Setae along anterior margin of scape clavate with at least one pair curving towards the base; additional numerous simple setae of similar or shorter length also present on scape. Two pairs of elongate differentiated flagellate setae present on head, one pair at apicoscrobal region and one pair straddling the midline near posterior margin of head.

Ground pilosity of mesosoma sparse, consisting of simple short curved reclinate setae. Differentiated elongate flagellate setae present singly on each humeral angle, as a pair on dorsum of pronotum between humeral setae, and as a pair on the dorsal surface of mesonotum. Two pairs of similar elongate flagellate setae present on petiole and postpetiole and are numerous on gastral tergites. First gastral tergite with short appressed to subappressed setae lateral to the medial pairs of flagellate setae. Legs with numerous short reclinate simple setae. A single differentiated elongate flagellate seta present on meso- and meta-tibia, meso-basitarsi, and two setae on meta-basitarsi.

Spongiform appendages. Spongiform appendages present on lateral and posterior surfaces of petiolar node, as an irregular flange along the ventral surface of petiole, as a ventral lobe on postpetiole and as a narrow flange on dorsal anterior surface of postpetiole that connects to a broad flange on lateral and posterior surfaces of postpetiole.

Description of queen. Other than typical queen morphology e.g., wings and enlarged mesonotum, queens are similar to workers. The most apparent morphological differences are larger size (see queen measurements above); larger eyes (eyes with 45-50 pigmented ommatidia); wider petiolar node (1.5-1.8 times wider than long in workers and $>2$ times wider in queen); and a spiracle present on anterior of metapleural gland bulla (absent or inconspicuous in workers).

Comments. Longino \& Booher (2018) provided a diagnosis but no measurements or description, anticipating doing this in a more thorough treatment. Measurements and a full description are provided here. There are now two collections of this species, the type series and a second collection $<1 \mathrm{~km}$ from the first. The type series was collected by myrmecologist J.T. Longino in his back yard garden in an urban area of Salt Lake City, Utah. On the evening of August 13, 2018, Longino found four workers foraging on the soil surface at night in his raised garden bed. The following night he sifted through several layers of soil to a depth of about $10 \mathrm{~cm}$ collecting a total of 66 workers (some carrying larvae), and six alate queens. The presence of alates in this August collection predicts mating flight phenology similar to observed native eastern species that produce sexuals in late summer that disperse from late summer through fall (Duffield \& Alpert 2012). Also collected in the vicinity were other ant species Tetramorium immigrans Santschi, 1927, Brachymyrmex depilis Emery, 1893, Solenopsis molesta (Say, 1836), and Formica neoclara Emery, 1893 (Longino \& Booher 2019). The name S. ananeotes, meaning newly emerged, reflects the unintended stewardship of this species provided by urban irrigation of green spaces, which may increase preferred moist environments for Strumigenys and their springtail prey (Blackith \& Blackith 1975). A second collection was made by Tobias Hays, a University of Utah student, under some paving stones in a nearby neighborhood (J. Longino, pers. com.).

\section{Strumigenys angulata Smith, 1931}

Distribution. USA; widespread in eastern USA from Florida to Illinois, west to Missouri; in western USA occurs in Oklahoma.

Comments. This species is morphologically most similar to $S$. pergandei, the only other non-trap jaw species with elongate mandibles in North America. Strumigenys angulata is uncommonly encountered over most of its range but is fairly common in upland hardwood and mixed pine and hardwood forests in areas of northern Mississippi (MacGown et al. 2012). Although it has been collected numerous times across the Ozarks in Arkansas, I know of only a single specimen from the western region collected near Le Flore, Oklahoma by W.G. Carter (examined by Bolton [2000]). There is a mistakenly reported Texas record (Forster 2003:144). Forster incorrectly summarized distribution records from Bolton (2000); Bolton did not report any Texas specimens of S. angulata. 
Distribution. USA to Mexico; in USA occurs in Texas, Arizona, and New Mexico.

Comments. Strumigenys arizonica forms mutualistic compound nests with Trachymyrmex arizonensis, where it feeds on Collembola in moist underground refuse chambers (Gray et al. 2018). Although other Strumigenys species have been collected in associations with other ant refuse piles, they are not exclusively associated. For example, S. pergandei is found nesting with Aphaenogaster rudis Wesson \& Wesson, 1940, Aphaenogaster fulva Roger, 1863, and others, but it also nests freely and unassociated with other ant species (Brown 1964; Wesson 1935). In contrast, $S$. arizonica has never been found nesting separately from $T$. arizonensis. The new species $S$. mendezi is morphologically similar to $S$. arizonica, and sympatric with it, but nests freely, without associations with $T$. arizonensis or other ants.

Strumigenys arizonica is most often collected above $1000 \mathrm{~m}$ in the Madrean Sky Islands of Arizona and Northern Mexico, in woodlands (oak, pine, juniper, mesquite) and riparian chaparral where its host $T$. arizonensis occurs. Colonies typically consist of 1-2 dealate queens and 30-40 workers. Colonies produce males and alate queens from July through September, but interestingly they never produce both sexes in the same nest at the same time. Gray et al. (2018) provide a thorough account of distributions, the mutualism, and a link to a video showing this species capturing Collembola.

Material examined: USA, Arizona, Santa Cruz Co., 31.448179, -111.18912, 1400 m , 12 Aug 1998, woodland, 1 male and 1 worker, coll. S.P. Cover, 5093, [ABS]; USA, Arizona, Santa Cruz Co., 31.43333, -111.18333, 1100 m, 17 Aug 2002, 1 queen, coll. M. Deyrup, [ABS]; USA, Arizona, Cochise Co., 31.883333, -109.233333, 1750 m , 7-17 Aug 2005, 1 worker, coll. B.L. Fisher, BLF08662, (casent0747689)[CASC]; USA, Arizona, Cochise Co., 31.883333, 109.2063333, 1646 m , 5-15 Aug 2001, desert scrub, 1 worker, coll. D. Booher, DBB-az0120, (casent0747782)[DBBC]; USA, Arizona, Cochise Co., 31.842222, -109.14472, 1575 m, 14 Jul 2002, oak woodland with pines, 1 alate queen, W.\&E. Mackay, Mackay\#19960, (casent0875736)[DBBC]; USA, Arizona, Cochise Co., 31.842222, -109.14472, 1575 m, 14 Jul 2002, oak woodland with pines, 1 worker, W.\&E. Mackay, Mackay\#19960, (casent0875737)[DBBC].

\section{Strumigenys boneti Brown, 1959}

Distribution. USA to Honduras; in USA occurs in Texas.

Comments. Strumigenys boneti has a mainly Central American distribution with a range barely entering the USA, in two Texas counties (Hidalgo and Cameron) bordering the Rio Grande. Stray workers of this species have been collected mostly by litter sifting in woodland habitats in at least seven localities in the most southern subtropical refugia of Texas. The collections of this species south of Texas tend to follow the Gulf and Atlantic states of Mexico into the Yucatán Peninsula, Guatemala, Belize, and Honduras.

Material examined: USA, Texas, Cameron Co., Sabal Palm Grove Sanctuary, 25.84975, $-97.41892 \pm 5$ m, 10 m, 3 Nov 2013, sabal palm leaf litter, 1worker, coll. R. \& C. Anderson, RSA2013TX04, (jt1713343)[JTLC]; USA, Texas, Cameron Co., dense coastal brush Laguna Atascosa NWR, 26.265451, -97.390284, 3 m, 8 Oct 2003, ex. pitfall, 1 worker, coll. J. King \& E. Riley [SHSU]; USA, Texas, Cameron Co., 15 miles E of Rio Hondo, 26.224013, -97.351508, 3 m, 22 Oct 1995, pitfall, swine feces, 1 worker, coll. C.S. Wolfe, [SHSU]; USA, Texas, Hidalgo Co., 26.08023, - $98.13996 \pm 50 \mathrm{~m}, 25 \mathrm{~m} \pm 20,5$ Nov 2013, ex. Winkler of cedar elm sifted leaf litter, 1 worker, coll. R. Anderson, RSA2013TX01, (casent0635914)[JTLC]; USA, Texas, Hidalgo Co., Anzalduas County Park, 26.140785, $-98.328243 \pm 100 \mathrm{~m}, 35 \mathrm{~m} \pm 2,15$ Oct 1988, berlese, mixed hardwood forest leaf litter, 1 worker, R. Anderson, (casent0875747)[DBBC]; USA, Texas, Hidalgo Co., Santa Ana National Wildlife Refuge, 26.06667, -98.13333 tone minute, 30 m, 14 Dec 1984, Strays from leaf litter, dense woodland in leaf litter, Night collecting, 1 worker, J. Longino, JTL0085-s, (lacment002372)[LACM].

\section{Strumigenys brevisetosa Smith, 1935}

Distribution. USA; widespread in eastern USA from Florida to Pennsylvania and west to Missouri; in western USA occurs in Kansas, Oklahoma, and Texas. 
Comments. There has been much confusion about this species and until recently it has been misidentified as S. pilinasis. At the time of this work, there are no other published keys that reflect this recent taxonomic change (Booher 2019) (see S. pilinasis, senior synonym of S. ohioensis). This species has variable clypeal setae across its range varying from fine-filiform to slightly expanded. The most consistent character in separating $S$. brevisetosa from $S$. laevinasis is that the setae on the dorsum of the clypeus are always inclined and pointing anteriorly (Fig. 11). These setae are inclined anteriorly at the base, but curve evenly along their length such that their apices are pointing up or posteriorly.

Strumigenys brevisetosa is one of the more common and wide-ranging eastern USA species with a range extending into several western states. Habitats recorded by collectors for collections in Kansas, Oklahoma, and Texas were deciduous forests and bogs with workers extracted from litter and log debris (DuBois 1985). A single malaise collection from Texas suggests Fall mating flights in the western portion of its range.

Material examined: USA, Oklahoma, Payne Co., 36.144999, -97.006839, 284 m, 1 Jul 1963, 2 dealate queens \& 5 workers, W.G. Carter, [MCZC]; USA, Oklahoma, Latimer Co., 34.835035, -95.31025, 227 m, 15 May 1983, 1worker, K. Stephan, [ABS]; USA, Texas, Lamar Co., Camp Maxey, Osmuda bog, 33.848745, -95.538077, 165 m, 25 Sep 2003, malaise, 1 alate queen, S.F. Godwin, [DBBC]; USA, Texas, Nacogdoches Co., 12 miles south southwest of Nacogdoches, 31.470424, -94.715606, 60 m, 1 Feb 1984, Hardwood, 4 workers, Jenks Byers, [ABS]; USA, Texas, San Jacinto Co., Big Creek Scenic Area, 30.513102, -95.090501, 83 m, 16 Jul 1998, J.L. Cook \& J.B. Martin, [SHSU]; USA, Texas, Wood Co., 3.5 miles SW of Hainesville, 32.663324, -95.360107, 101 m, 30 Apr 2000, ex. berlese, Forest, 1 worker, E.G. Riley, (casent0799679)[DBBC].

\section{Strumigenys californica (Brown, 1950)}

\section{Distribution. USA; California}

Comments. This species was initially known from three alate queens that lacked any collection information other than locality and collector. C.F. Baker collected these specimens in Claremont, a small city located on the eastern edge of Los Angeles Co., California sometime before 1950 (Brown 1964). Brown (1950) noted the similarity of this species with the Japanese species $S$. rostrataeformis (Brown, 1949), and posited that it might be a non-native introduction. Since the first collection, several other smithistrumiform natives have been discovered as well as additional S. californica collections from Monterey, San Luis Obispo, and Los Angeles counties, supporting it being native (Ward 1988).

Strumigenys californica appears to be associated with more arid environments than many of the other more western native species, with two workers collected foraging on Eriogonum buckwheat (Ward 1988), and a mostly intact dead worker found among the middens of a Solenopsis xyloni McCook, 1880 colony. A dealate queen was collected in mid-October, suggesting a flight/dispersal period that is about a month later than eastern counterpart species and coinciding with the onset of winter precipitation. This dealate queen was collected in a chamise/Ceanothus chaparral near Claremont, Los Angeles Co. in 2010.

Material examined: USA, California, Los Angeles Co., des Lauriers, Mt. Baldy Rd., 34.18833, 117.67833, $840 \mathrm{~m}, 17$ Oct 2010, pitfall trap sample no. 10378, chamise/Ceanothus chaparral, 1 dealate queen, (casent0843952)[UCDC]; USA, California, Los Angeles Co., Claremont, 34.096676, -117.719779 $\pm 5000 \mathrm{~m}, 400 \mathrm{~m}$ $\pm 75,1$ alate queen, C.F. Baker, (lacm0328779)[LACM]; USA, California, San Luis Obispo Co., Goodwin Center, Carrizo Plain National Monument, 35.18993, -119.86432 \pm 30 m, 600 m, 25 May 2003, ex. small midden sample ( 4ml) from Solenopsis xyloni nest, grassland, 1 worker, P. S. Ward, PSW14864, (casent0843951)[UCDC].

\section{Strumigenys chiricahua (Ward, 1988)}

\section{Distribution. USA; Arizona}

Comments. This species is known from two collections and possibly a third. The holotype worker was collected in a Berlesate sample of concentrated leaf litter from an oak woodland, and a colony of more than 20 workers was extracted from a rotten root in a juniper woodland. Both validated collections were made in August at or near the Southwestern Research Station in the Chiricahua Mountains in Arizona. A third possible specimen is an alate queen 
tentatively identified from images. This specimen was collected by Gary Alpert in a Malaise trap $16 \mathrm{~km}$ southeast of Flagstaff in Walnut Canyon National Monument, Coconino County, in the bottom of a ravine (BugGuide 2020a).

Material examined: USA, Arizona, Coconino Co., Walnut Canyon National Monument, 16 km SE Flagstaff, 35.171583, -111.513917, 1946 m, 22 Aug 2017, ex. SLAM trap \#1, in the bottom of ravine, 1 alate queen, coll. Gary Alpert, WP 243, [MNA]; USA, Arizona, Cochise Co., Chiricahua Mtns, 4.8 km W Portal, 31.88351, -109.17806, 1535 m, 11 Aug 2009, ex rotten root, Oak-pine-juniper woodland, 1 worker, coll. Brian L. Fisher, BLF22737, (casent0009929-d01)[CASC].

\section{Strumigenys collinsae sp. nov.}

Figure 37

\section{Distribution. USA; Colorado}

Holotype Queen. USA, Colorado, Pueblo County, 23 miles north of Walsenburg, berlese of sifted litter, estimated GPS 37.939013, -104.812018 $\pm 2500 \mathrm{~m}, 15$ August 1958, Collector Clayton Hoff, el 1802m, collection code \#124, unique specimen identifier (FMNH-INS 0000119 056) [FMNH].

Holotype queen measurements: $\mathrm{HL}=0.614 ; \mathrm{HW}=0.459 ; \mathrm{ML}=0.124 ; \mathrm{PW}=0.328 ; \mathrm{SL}=0.362 ; \mathrm{FL}=0.457$; $\mathrm{HT}=0.384 ; \mathrm{EL}=0.144 ; \mathrm{WL}=0.744 ; \mathrm{CI}=74.8 ; \mathrm{SI}=78.9 ; \mathrm{MI}=20.2$.

Diagnosis. Strumigenys collinsae is distinguished from all other North American species by dentition, having four principle teeth with the first two nearly equal in size followed by two smaller teeth of equal size. This species is most similar to $S$. reliquia, having similarities in shape of clypeus, dentition of mandibles, and pilosity. However, in S. reliquia the second principle tooth is much shorter than the first and has flagellate apicoscrobal and tibial setae where S. collinsae does not.

Description of queen. Mandibles with exposed basal lamellae followed by a diastemmic gap longer than the longest tooth. Diastema followed by a set of small teeth that do not overlap when mandibles are closed, four principal teeth, and several smaller interlocking denticular teeth.

Labrum with laterally flattened setae extending from apical digitate lobes. Clypeus with narrow peripheral groove; with free margins of dorsal lamella of groove projecting further than ventral lamella in full frontal view. Anterior border of clypeus broadly rounded between mandible insertions, lateral free margin weakly concave between lateral posterior corners to mandible insertion. Clypeus 1.02 times broader than long. In profile posterior border of clypeus is abruptly raised above adjoining frontal area. Scrobal margins lamellate extending posterior level of eye. Pronotum slightly smaller in width (0.328) than mesosoma (0.376). Propodeal spines triangular and lamellate; about equal in length to maximum width of broadly convex free margin of declivitous lamella below narrowed section just below spines.

Pilosity. Setae on anterior margin of scape shallowly curved, simple, and acutely tipped; all curved and declinate towards apex. Differentiated elongate flagellate to subflagellate setae limited to those at lateral-posterior border of mesoscutum just anterior of wing scars; on dorsal surface of petiolar node, post-petiolar disc, and a row present on anterior portion of first abdominal tergite. Flagellate setae in these positions seem to be unbroken and so setae not present at apicoscrobal position or on tibia or femur are suspected to be truly absent. Ground pilosity of head, mesosoma, and gaster are numerous fine, apically acute, and shallowly curved short to slightly elongated setae. Ground pilosity on dorsum and borders of clypeus directed unevenly towards mandibles; on dorsum of head these setae are directed mostly medially. Ground pilosity of first gastral tergite elongate irregularly curved to simple setae closely following the surface of gaster.

Sculpture. Dorsum of clypeus heavily punctate. Frontal area with a small smooth patch free of sculpture just posterior of clypeal border. Dorsum of head heavily reticulopunctate. Dorsum and side of pronotum rugulo-reticulate with heavy punctations between rugae. Meso- and meta-pleurae smooth with some peripheral punctate sculpture. Dorsal surfaces of petiolar node lightly punctate, the postpetiolar node smooth and shining. Gaster smooth and shining with basigastral costulae 0.35 times length of tergite.

Spongiform appendages. Dorsal and lateral spongiform appendages of petiole and postpetiole prominent. Ventral lamella of petiole at least as deep as shortest height of peduncle. Sub-postpetiolar process well developed and longer than the height of exposed node in lateral view. 


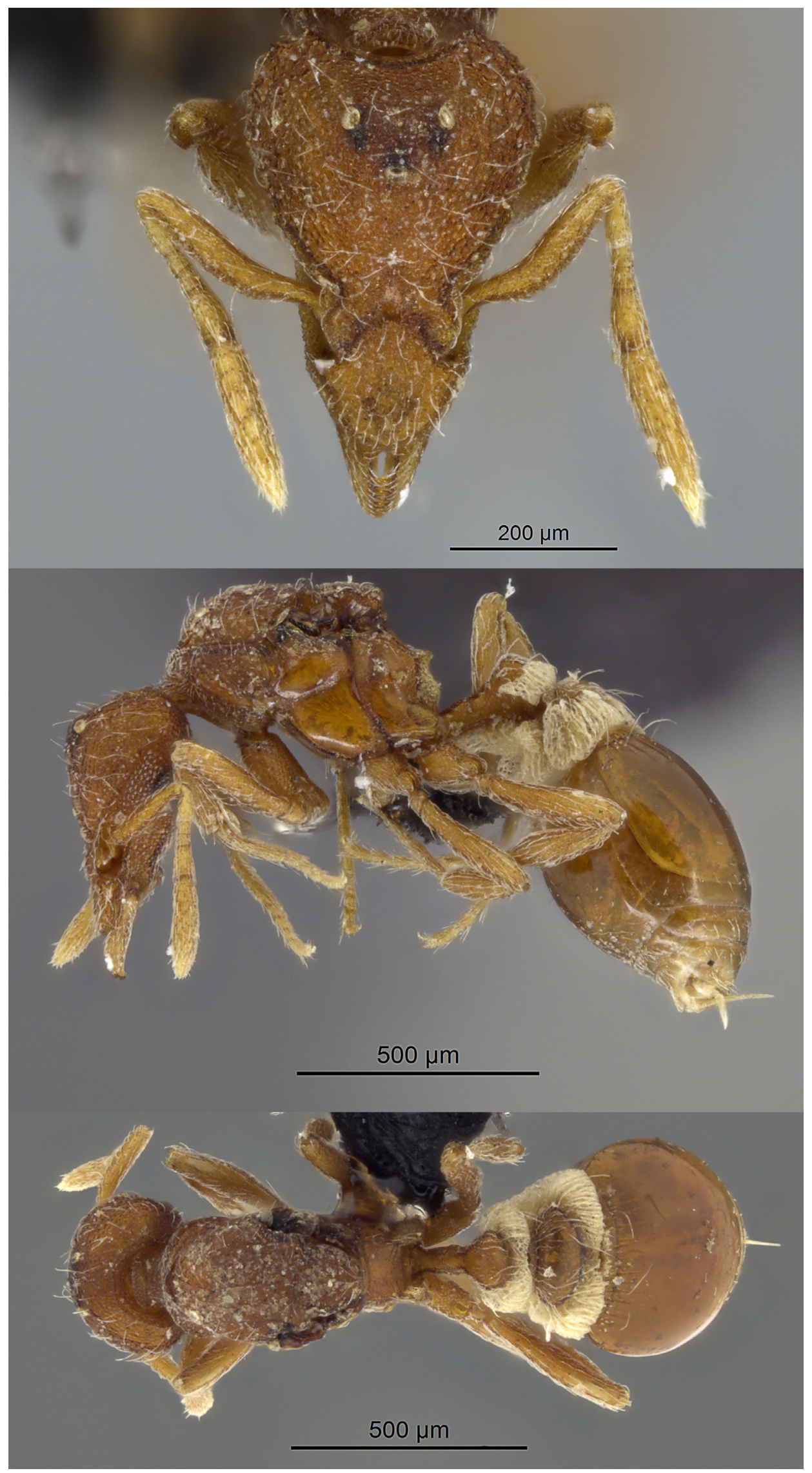

FIGURE 37. Holotype queen of Strumigenys collinsae [FMNH: FMNH-INS 0000119 056]. Photographed by Maureen Turcatel (Field Museum). 
Etymology. This species is named in honor of the brilliant entomologist and civil rights advocate Dr. Margaret S. Collins who through her science and activism helped change impediments she faced, improving conditions for future Black female scientists. It is important to celebrate those who have created a lasting impact despite cultural and systemic barriers, making it easier for others to follow in their path. The name was created by adding the singular Latin genitive case suffix -ae to the last name of a female person. The orthography of an eponym is unchangeable and not dependent on the generic name in which the epithet is used.

Comments. This species is known from a single dealate queen collected in August without associated workers. Although the label gives the habitat as oak woodland, the collector only reports sampling yellow pine and juniper litter for the given locality in his publication focusing on Pseudoscorpiones (Hoff 1961). This specimen was discovered in the FMNH collection misidentified by R. G. Gregg as Strumigenys ohioensis (Junior synonym of Strumigenys pilinasis).

\section{Strumigenys clypeata Roger, 1863}

Distribution. USA; widespread in eastern USA from Florida to New York and west to Iowa; in western USA occurs in Oklahoma, Texas, and possibly Kansas.

Comments. This species is a relatively common eastern species with a large range. Although reported to occur in northern Mexico (Guzmán-Díaz 2014), the specimen imaged is incorrectly identified. Pilosity, sculpture, and lack of spongiform appendages separate this species from any smithistrumiform species, and I suspect it is $S$. margaritae from the visible characters in the image provided. Kansas specimens held at the SEMC were not examined but are left here as possible to that state. This species has been collected in a variety of forest habitats but most often in wet, heavily canopied bottomland forests nesting in moist litter and woody debris (AntWeb 2021).

Material examined: USA, Oklahoma, Latimer Co., 34.835035, -95.31025, 224 m, 15-May-83, 6w 1dq, K. Stephan, [ABS]; USA, Texas, Lamar Co., Camp Maxey, Osmuda bog, 33.848745, -95.538077, 165 m, 25-Sep-03, malaise, Formicidae, 1aq, Godwin SF, (casent0799610)[DBBC]; USA, Texas, Nacogdoches Co., 12 miles southwest of Nacogdoches, 31.496515, -94.798552, 74 m, 13-Apr-84, 8w 2dq, Walter Suter, [ABS]; USA, Texas, Sabine Co., Hemphill, 14 Kilometers east of Hemphill, 31.339698, -93.707155, 96 m, 11-May-88, litter, 1w, R. Anderson, 12764, [TAMUIC]; USA, Texas, San Jacinto Co., Big Creek Scenic Area, 30.511358, -95.09486, 74 m, 13Nov-96, berlese, litter, 15w, J.L. Cook \& J.B. Martin, [DBBC]; USA, Texas, Titus Co., Bob Sandlin State Park, 33.06135, -95.098737, 110 m, 18-Jun-09, nest in log, mixed hardwood forest, 5w, W.\&E. Mackay, Mackay\#23254, (casent0875751)[DBBC ]; USA, Texas, Walker Co., Huntsville State Park, 30.620904, -95.522363, 135 m, 30Sep-03, 1w, J.L. Cook \& S. Clarke, [SHSU]; USA, Texas, Wood Co., 3.5 miles SW of Hainesville, 32.663324, -95.360107, 30-Apr-00, Berlese, Forest, 6w 1dq, E.G. Riley, (casent0799608)[DBBC].

\section{Strumigenys dietrichi Smith, 1931}

Distribution. USA to Mexico; widespread in eastern USA from Florida to Maryland and west to Missouri; in western USA occurs in Kansas, Oklahoma, and Texas.

Comments. This is another wide-ranging eastern species with a continuous USA distribution from the Florida Keys to Maryland and west to Kansas, Oklahoma, and Texas (Deyrup 2006). Outside the USA, this species is known from the Mexican state of Puebla. The Puebla collection included a few specimens collected in a patch of mesic forest litter along a roadside. It is likely this species is native in Puebla as there are other ants (Ponera exotica Smith, 1962, Cryptopone sp.) and trees (Liquidambar, Acer) that are native in both the southeastern USA and southern Mexico (J. Longino, pers. comm.). From personal collections, I have found S. dietrichi is most often associated with extremely wet environments across a wide range of habitats: sloped mid-elevation deeply shaded ravines, marsh-like sunny ditches along roadsides, and in deep moist pockets of litter in upland woodlands. However, collection notes from several Ohio colonies were associated with rotted logs found in 'dryish' woods (Wesson \& Wesson 1939). In Kansas, a colony was collected in rotted wood in a moist deciduous forest (DuBois 1985). These Kansas specimens had slightly apically expanded bulbous setae extending from the anterior portion of the clypeus; typically, these setae are filiform along their entire length. 
Material examined: USA, Kansas, 1 worker, [MCZC]; USA, Oklahoma, Cleveland Co., Norman, 35.243579, -97.443519, 364 m, 5 Apr 1969, 1 queen \& 1 worker, coll. Walter Suter, [ABS]; USA, Oklahoma, Latimer Co., 34.835035, -95.31025, 224 m, 15 May 1983, 1 queen, K. Stephan, [ABS]; USA, Texas, Nacogdoches Co., 12 miles south southwest of Nacogdoches, 31.470424, -94.715606, 60 m, 1 Feb 1984, Hardwood Forest, 1 queen \& 4 workers, D.M. Field, [ABS].

\section{Strumigenys laevinasis Smith, 1931}

Distribution. USA; widespread in eastern USA from Florida to Maryland and west to Missouri; in western USA occurs in Kansas, Oklahoma, and Texas.

Comments. Strumigenys laevinasis most often inhabits heavily canopied forest with deep litter accumulation in eastern forests and forest remnants in the western portion of their range. This species is often nests in rotting logs and in pockets of leaf litter.

Strumigenys laevinasis is morphologically most similar to $S$. brevisetosa but can be easily separated by the shape of the extremely fine setae on the surface of the clypeus. These setae are inclined anteriorly at their base and curve evenly along their midlength so that their apices point upward or posteriorly. Strumigenys laevinasis is less frequently collected than $S$. brevisetosa but also has a mostly eastern range overlapping almost completely with its close relative. It is suspected that $S$. laevinasis and $S$. brevisetosa hybridize infrequently over their range which has led to some taxonomic confusion (Booher 2019). There are two confirmed collections from Texas, one from Houston County in Big Slough State Park, and one from Walker County, Huntsville State Park (MacKay \& Anderson 1993; Bolton 2000).

Material examined: USA, Kansas, Atchinson Co., 39.570114, -95.352088, 500 m, 22 May 1978, casent0875742, 1 worker, coll. M.B. DuBois, 78\#3E, [DBBC]; USA, Kansas, Atchison Co., 39.563052, -95.121636, 252 m, 22 May 1978, 2 workers, coll. M.B. Dubois, SBSK\#365, [MCZ]; USA, Oklahoma, Latimer Co., 34.835035, -95.31025, 15 May 1993, 1 worker \& 1 queen, coll. K. Stephan, [ABS].

\section{Strumigenys louisianae Roger, 1863}

Distribution. USA to Argentina; widespread in eastern USA from Florida to New York and west to Missouri; in western USA occurs in Oklahoma and Texas.

Comments. Strumigenys louisianae has one of the largest continuous native ranges of any Strumigenys species, from South America through Mexico and into the USA. In the USA, it is the most commonly encountered long mandible trap-jaw species north of Florida (Deyrup \& Cover 2009; Booher unpublished data). It was first recorded in Oklahoma with a collection near the city of McCurtain in the southwestern Ozark Mountains (Wheeler \& Wheeler 1989). All specimens I have examined from Arizona were mistakenly identified and corrected to be S. mixta.

Material examined: USA, Texas, Trinity Co., Davy Crockett National Forest, 31.298061, -95.102841, 109 m, 10 Jun 2004, 1 worker, coll. S. Clarke, DC2-Trap 1, (casent0799638)[DBBC].

\section{Strumigenys lucky sp. nov.}

Figure 38

Distribution. USA; Illinois, Iowa, Minnesota, and Wisconsin.

Holotype worker. USA, Minnesota, Houston Co.: Winnebago Creek, 31 May 1941, Collectors Jerry L. Cook \& J. B. Martin (colony 275), bottom specimen mounted on pin with pinned identifier code (MCZCENT00683064)[MCZC].

Paratypes. Three workers and two queens from the same colony (colony 275) all with same collections data as type; one worker, top specimen mounted on same pin as type (MCZC-ENT00683064)[MCZC]; two workers mounted on the same pin (MCZC-ENT00683065) [MCZC]; two dealate gynes (MCZC-ENT00683066, MCZCENT00683067) [MCZC]. 

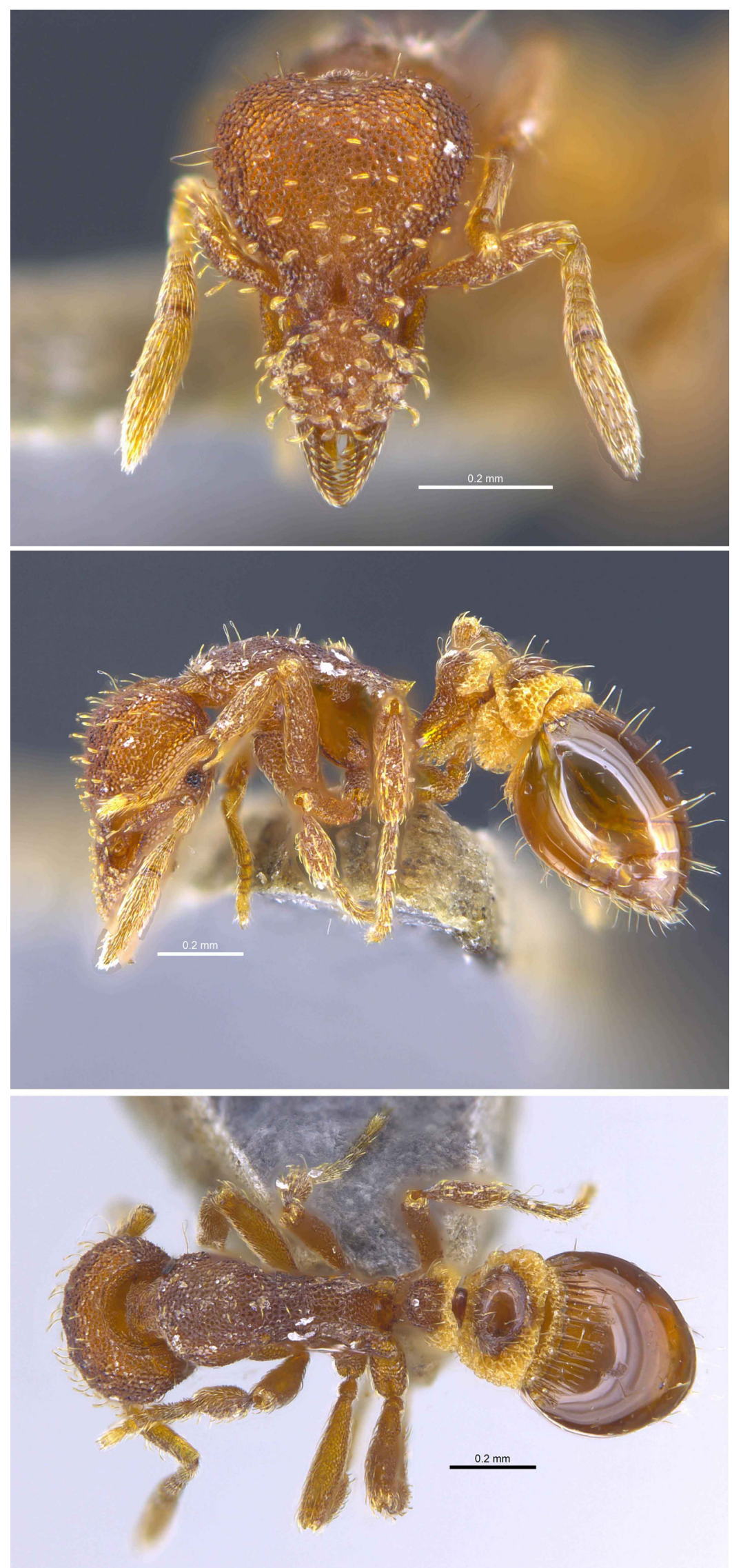

FIGURE 38. Holotype worker of Strumigenys lucky [MCZC: MCZC-ENT000683064 (bottom specimen)]. Photographed by Michele Esposito (AntWeb.org 2021). 
Holotype and paratype measurements $(\mathbf{n}=4): \mathrm{HL}=0.531-0.562(0.546) ; \mathrm{HW}=0.394-0.41(0.402) ; \mathrm{ML}=$ $0.097-0.1$ (0.099); $\mathrm{PW}=0.264-0.273$ (0.269); $\mathrm{SL}=0.261-0.299$ (0.281); $\mathrm{FL}=0.355-0.399$ (0.369); HT = 0.2940.318 (0.31); $\mathrm{EL}=0.033-0.051$ (0.044); $\mathrm{WL}=0.557-0.584$ (0.568); $\mathrm{CI}=72.4-75.1$ (73.7); $\mathrm{MI}=17.3-18.6$ (18); $\mathrm{SI}=66.1-74.4$ (69.9).

Paratype queen measurements $(\mathbf{n}=\mathbf{2})$ : $\mathrm{HL}=0.594-0.598(0.596)$; $\mathrm{HW}=0.432-0.433(0.433)$; $\mathrm{ML}=0.092-$ 0.109 (0.101); $\mathrm{PW}=0.325-0.339$ (0.332); $\mathrm{SL}=0.299-0.308$ (0.304); $\mathrm{FL}=0.351-0.41(0.381) ; \mathrm{HT}=0.344-0.352$ (0.348); $\mathrm{EL}=0.117-0.121(0.119) ; \mathrm{WL}=0.674-0.693(0.684) ; \mathrm{CI}=72.2-72.9$ (72.6); $\mathrm{MI}=15.4-18.4(16.9) ; \mathrm{SI}=$ $69.2-71.1(70.2)$.

Diagnosis. Of species occurring in the western USA, only four have spatulate to spoon-shaped setae on the free margins of the clypeus curving away from the midline, S. reflexa, S. missouriensis Smith, 1931, S. pulchella Emery, 1895, and S. lucky. Strumigenys lucky is most morphologically similar to S. missouriensis (I believe to be a complex of species requiring taxonomic treatment) but can be separated from the $S$. missouriensis complex by head pilosity. Strumigenys lucky has long flagellate hairs at apicoscrobal position and at the vertex margin of head. In S. missouriensis these hairs, if present, are shorter stiff and straight; varying in shape from simple to apically expanded; and may not be much longer than the background pilosity. Strumigenys reflexa have setae that curve away from the midline of the head at the nearest point where the outer mandibles and clypeus meet, in S. lucky and S. pulchella, these setae curve towards the midline or are directed ventrally. Strumigenys lucky can be separated from S. pulchella by teeth dentition, in S. pulchella the first two teeth are nearly equal in size with the third tooth smaller than the first two. In S. lucky, the first (excluding first denticle if present) and third tooth are nearly equal in size with the second tooth smaller.

Description of worker. Mandibles with a triangular flattened lamella that is slightly smaller in length than the first basal tooth. Basal lamella followed by a diastemmic gap that is longer than the first basal tooth. Masticatory margin with seven principle teeth followed by four evenly sized denticles and terminating with an enlarged apical tooth. Counting from base of mandible, principle teeth alternate in size with teeth two, four and six being similarly sized and smaller than teeth one, three, five, and seven. Elongate teeth one, three, five, and seven decreasing in size from tooth one to tooth seven, with tooth seven being only slightly larger than tooth six. Similar to ananeotes, some specimens have a minute denticle present before the first principle tooth. Clypeus about 1.1-1.3 times wider than long; with an extremely narrow peripheral groove with the lower anterior margin extending beyond dorsal anterior margin and visible as a narrow translucent cuticular projection in full frontal view; in full frontal view continuously convex over lateral and anterior free margins. Ventral postbuccal groove broad and shallow. Upper scrobal margin weakly marginate; terminating just past level of eye. Preocular carinae well developed with straight lateral margins; posterior portion obscured by scrobal margin in full frontal view.

Head in profile flat from vertex to clypeus. Clypeus slightly raised above area of frontal lobes with a shallowly convex area between them. Eye with 2-4 pigmented ommatidia. Scape slightly expanded past subbasal bend and narrowly marginate along anterior border. In profile, dorsal outline of pronotum and mesonotum flat, angulate at their junction; propodeum weakly convex and separated from mesonotum by a shallow and slightly impressed metanotal suture. Propodeal teeth lamellate, pointed, and broadly triangular; subtended by an uneven lamella, narrowing strongly to about midlength then expanding to a length about the same size as the propodeal tooth just above bulla of metapleural gland.

Pilosity. Elongate subflagellate, flagellate, or looped setae present at apicoscrobal position, as pair straddling the midline near the posterior margin of head, at humeral angles, straddling the central portion of pronotal dorsum, and at anterior dorsolateral corners of mesonotum. Outer surfaces of meso- and meta- tibia and basitarsi with a single flagellate seta. Two pairs of shorter subflagellate or apically looped setae present on dorsum of petiolar node, three pair present on exposed disc of postpetiole, and three to four rows of 1-3 pairs of setae on first gastral tergite.

Clypeus with lateral border fringed with three to four pairs of spatulate setae that curve ventrally; anterior border between mandible insertions with a pair of similar setae that curve away from the midline. Setae on dorsum of clypeus are shorter than those on anterior margin, slightly less expanded, and with most directed laterally away from the midline of head; setae closer to lateral margins curve away from the midline and those located more centrally tend to curve posteriorly towards the back of head. Setae on dorsum of head spatulate at apices; longer and more shallowly curved than those on the dorsum of clypeus; directed towards the midline; those anterior to vertex are more expanded at apices than those posterior to vertex. Setae along upper anterior scrobal margin narrowly spatulate at apices; seta at subbasal bend longest and directed anteriorly away from anterior margin of scape the one or two 
setae following this seta curve towards base; all other setae curve towards apex of scape. Mesosoma ground pilosity limited to a few short reclinate simple setae on the pronotum. Shorter evenly curved simple setae cover surface of petiolar node and legs, ground pilosity absent from exposed disc of postpetiole and first gastral tergite.

Sculpture. Clypeus and head reticulopunctate with a small smooth patch in frontal area between frontal lobes; scrobal area reticulopunctate. Dorsum of mesosoma punctate without a distinct medial carina. Sculpture on declivitous face of propodeum limited to weakly reticulopunctate sculpture on upper half. Anterior edge of metanotal suture with a thin transverse cuticular ridge. Surface of petiolar node reticulopunctate. Petiolar node punctate. Exposed disc of postpetiole without sculpture and shining. First gastral tergite with basigastral costulae extending between $1 / 4$ to $1 / 3$ the length of the first gastral tergite and without any other sculpture.

Spongiform appendages. Spongiform cuticular processes well developed; as a lateral process on petiolar node; as a ventral curtain of peduncle of petiole that is shallowly to deeply impressed medially; as a lateral lobe on postpetiole connecting with posterior and anterior fringe that completely encircles exposed disc in dorsal view; and a ventral lobe of postpetiole that is usually at least twice as deep as the maximum length of exposed disc in profile view.

Queen description. Other than morphological differences associated with queen caste e.g., larger size, larger eyes, size, and presence of ocelli, the queen matches worker description, can be diagnosed by dentition and clypeal pilosity, and can be keyed out.

Etymology. Named after midwestern-born myrmecologist Andrea Lucky to recognize the contributions she has made to myrmecology, for her integration of citizen science into fundamental research, for being a strong advocate for women in myrmecology, and as an award-winning teacher and student mentor. The name 'lucky' is given as a proper noun in the nominative case used in apposition. The orthography of an eponym is unchangeable and does not depend on the generic name in which the epithet is used.

Comments. This species has the most northern range of any Nearctic species and is known from a few collections taken in four neighboring states (Wisconsin, Minnesota, Illinois, and Iowa). However, in at least one locality (in Waukesha, Wisconsin), this species has been collected multiple times by young myrmecologist Anthony Prothero who provided the only natural history account of $S$. lucky in personal communications. Prothero found them in a 'forest' which used to be a prairie. The forest is almost completely dominated by invasive Buckthorn trees, but random clearings hold many prairie plants. He has located several partial colonies of a few workers and an occasional queen, always under rocks and most commonly during or recently after rain. He expects they are nesting in soil cavities beneath rocks or other debris. The soil in these areas is mostly silt/clay mix.

This species has been misidentified as $S$. missouriensis, likely due to similarities of clypeal pilosity and shape, for this reason and because they overlap in the eastern portion of $S$. lucky's range I have included S. missouriensis in the key but not the synopsis of species in the western region.

Nontype material examined: two workers mounted on same pin, USA, Illinois, Cook Co.: Sag Canal Area, spring 1954, Collectors H. S. Dybas \& C. H. Seevers, specimen identifier (MCZC-ENT00683071) [MCZC]; one worker, USA, Iowa, Story Co.: Ames, 16 Apr 1941, Collector W. F. Buren, unique specimen identifier (MCZCENT00683068) [MCZC]; one worker, USA, Iowa, Story Co.: Ames, 20 Apr 1940, Collector W. F. Buren, unique specimen identifier (MCZC-ENT00683070) [MCZC].

Nontype worker measurements $(\mathbf{n}=\mathbf{4}): \mathrm{HL}=0.521-0.553(0.538) ; \mathrm{HW}=0.395-0.403(0.400) ; \mathrm{ML}=0.094-$ $0.11(0.100) ; \mathrm{PW}=0.253-0.275$ (0.264); $\mathrm{SL}=0.258-0.293(0.280) ; \mathrm{FL}=0.335-0.357(0.348) ; \mathrm{HT}=0.296-0.307$ (0.303); $\mathrm{EL}=0.035-0.045$ (0.042); $\mathrm{WL}=0.526-0.565$ (0.541); $\mathrm{CI}=72.3-75.8$ (74.3); $\mathrm{MI}=17.2-19.9$ (18.6); $\mathrm{SI}$ $=64-73.3(70.1)$.

\section{Strumigenys macgowni sp. nov.}

Figure 39

Distribution. USA; in eastern USA occurs in Louisiana; in western USA occurs in Texas.

Holotype worker: USA, Texas, San Jacinto County, Big Creek Scenic Area, 30.51966 -95.08816 \pm 1000 m, 16 October 1997, $80 \pm 5 \mathrm{~m}$, Collectors Jerry L. Cook \& J. B. Martin (unique specimen identifier casent0747540) [UGCA].

Paratype queen: Same as worker (unique specimen identifier casent0747059)[CAS] 


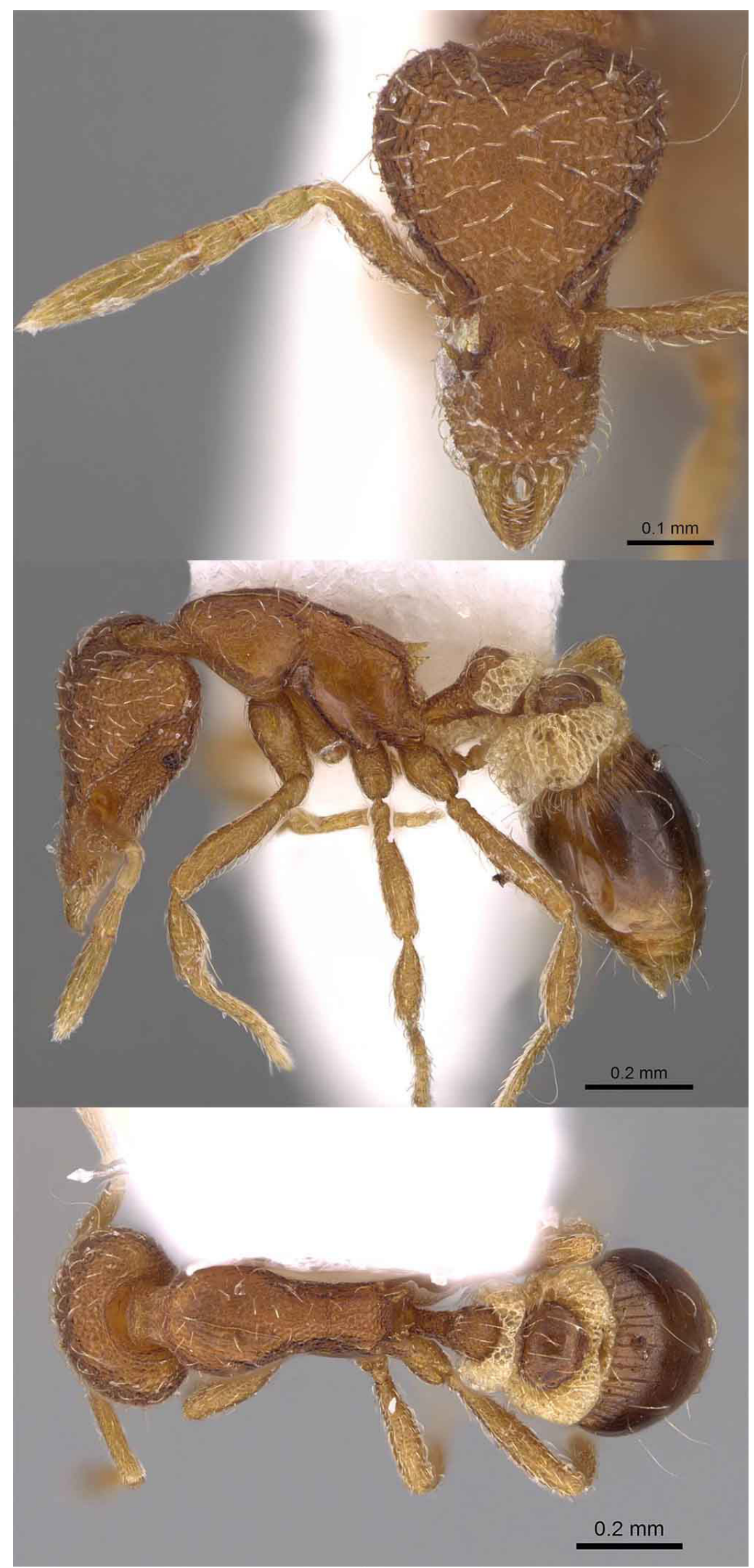

FIGURE 39. Holotype worker of Strumigenys macgowni [UGCA: casent0747540]. Photographed by Michele Esposito (AntWeb 2021). 
Holotype worker measurements: $\mathrm{HL}=0.495 ; \mathrm{HW}=0.345 ; \mathrm{ML}=0.105 ; \mathrm{PW}=; \mathrm{SL}=0.259 ; \mathrm{FL}=0.321 ; \mathrm{HT}$ $=0.253 ; \mathrm{EL}=0.038 ; \mathrm{WL}=0.515 ; \mathrm{CI}=69.8 ; \mathrm{MI}=21.2 ; \mathrm{SI}=74.9$.

Paratype queen measurements: $\mathrm{HL}=0.585 ; \mathrm{HW}=0.409 ; \mathrm{ML}=0.113 ; \mathrm{PW}=0.295 ; \mathrm{SL}=0.295 ; \mathrm{FL}=0.403$; $\mathrm{HT}=0.321 ; \mathrm{EL}=0.093 ; \mathrm{WL}=0.635 ; \mathrm{CI}=70.0 ; \mathrm{MI}=19.3 ; \mathrm{SI}=72.0$.

Diagnosis. Strumigenys macgowni is morphologically most similar to $S$. talpa group members (Bolton 2000) but is differentiated from all other members by the shape and orientation of setae on the lateral margins and dorsum of clypeus. In S. macgowni, all the setae fringing the lateral and anterior clypeal margins are narrowly spatulate and are directed anteriorly or towards the midline, those on the clypeal dorsum are short simple setae that curve abruptly above their base and are directed apically towards the head. Strumigenys not belonging to the talpa group with similar dentition and also having posteriorly directed setae on the clypeal dorsum are differentiated by having setae fringing the clypeal border directed away from the midline or mandibles (S. wrayi (Brown, 1950), S. reflexa Wesson \& Wesson, 1939, S. cloydi (Pfitzer, 1951), S. ornata Mayr, 1887, S. dietrichi Smith, 1931, S. boltoni (Deyrup, 2006), and S. apalachicolensis (Deyrup \& Lubertazzi, 2001)).

Description of worker. Mandibles with basal lamella fully exposed in full frontal view followed by a short diastemmic gap longer than the first tooth; with four principle teeth, tooth one, two, and four being similar in size and tooth three slightly smaller. Principle teeth followed by two teeth that are slightly smaller than third principle tooth, four minute denticles, and terminating with an enlarged apical tooth. Clypeus 1.25 times wider than long and without a peripheral groove; in full frontal view the lateral and anterior margins are evenly convex; lateral margins weakly serrated due to weakly expanded cuticular areas projecting out from base of extending setae. Dorsal surface of clypeus narrowly domed when viewed from apex of mandible to back of head. Ventral postbuccal groove broad and shallow. Upper scrobal margin terminates past level of eye. Preocular carina well-developed, lateral margin straight and visible in full frontal view along entire length. Head in profile shallowly convex from vertex to clypeus; shallowly depressed at frontal lobes; clypeus slightly raised above area of frontal lobes and shallowly convex between posterior and anterior portions. Eye with four pigmented ommatidia. Scape slightly expanded past subbasal bend with a narrowly marginate anterior border; subcylindrical in shape.

In profile, pronotum shallowly convex meeting mesonotum at a broadly convex angle; mesonotum and propodeum evenly flat in profile without a distinctly impressed metanotal suture. Bulla of propodeal spiracle small and directed posteriorly. Propodeal teeth lamellate, pointed, and broadly triangular; subtended by a narrowed even-margined lamella (no indentations or lobes) that is about half as wide (0.028), as length of tooth (0.048).

Pilosity. Elongate flagellate setae limited to those present at apicoscrobal position, a pair at humeral angles, a pair on mesonotum just anterior of metanotal suture, a pair on anterior node of petiole, a pair on the anterior exposed disc of postpetiole, and several pairs on gastral tergites. A single pair of elongate flagellate setae on meso- and metabasitarsi.

Clypeus with lateral border evenly fringed with short narrowly spatulate setae that curve anteriorly towards mandible; anterior border between mandible insertions fringed with similar but slightly smaller setae that curve ventrally. Setae on dorsum of clypeus shorter than those on anterior margin, simple to slightly expanded, and bend to curve posteriorly towards the head. Setae on dorsum of head are nearly as long as eye $(\sim 0.035)$ and are simple to shallowly expanded; setae arise at base and are evenly curved with apices contacting head; those anterior to vertex curve medially and those posterior vertex curve towards vertex. Setae along upper scrobal margin curve sharply at base and are directed anteriorly following scrobal margin. Other than the single pair of elongate flagellate setae at apicoscrobal position, there are no differentiated standing setae anywhere else on head. Setae on scape simple and curved towards apex of scape. Note - the first seta on the leading edge of the left scape is slightly more elongate than flanking setae and is slightly more expanded, directed anteriorly.

Mesonotum ground pilosity similar to head, but more elongate. Dorsum of propodeum without any pilosity. Nodes of petiole and postpetiole with elongate posteriorly curved setae. First gastral tergite with three or four rows of flagellate setae and with scarce pilosity similar to those on the head present but limited to the lateral borders of tergite.

Sculpture. Clypeus heavily punctate; head reticulopunctate with a small smooth patch in frontal area between frontal lobes; scrobal area reticulopunctate. Dorsum of mesonotum punctate with a medial carina that more distinct than additional striae that flank it. Dorsum of propodeum lightly punctate medially with striate sculpture running laterally from base of propodeal tooth to metanotal suture; declivitous face with similar punctate sculpture. Side of pronotum and mesonotum without sculpture. Medial portion of side of propodeum free of sculpture, some reticulopunctate sculpture along posterior margin that borders the declivitous face. Anterior edge of metanotal suture with 
a shallowly raised transverse ridge. Surface of petiolar node reticulopunctate. Exposed disc of postpetiole without sculpture and shining. First gastral tergite with basigastral costulae extending $1 / 3$ of first gastral tergite and without any other sculpture.

Spongiform appendages. Spongiform cuticular processes well developed; as a lateral process on petiolar node (0.088 long and 0.062 deep); as a ventral curtain of peduncle of petiole narrowing medially (maximum depth 0.055 ); as a lateral lobe on postpetiole connecting with posterior and anterior fringe that completely encircles exposed disc in dorsal view; and a ventral lobe of postpetiole (0.168 deep) that is much longer than the maximum length of exposed disc in lateral view (0.028).

Queen description. Other than morphological differences associated with queen caste e.g., larger size, larger eyes, size, and presence of ocelli, the queen matches worker description and can be diagnosed by dentition and clypeal pilosity.

Etymology. Named after prominent southeastern naturalist, self-taught myrmecologist, and artist, Joseph A. MacGown. MacGown has been instrumental in helping southeastern myrmecologists identify ants, obtain natural history information, and jumpstart their scientific careers (mine included). The name was created by adding the singular Latin genitive case suffix -i to the last name of a male person. The orthography of an eponym is unchangeable and not depend on the generic name in which the epithet is used.

Comments. At present, this species is known only from a queen and worker from the type locality in San Jacinto Co., Texas and a single worker collected in Sam Houston Jones State Park, Louisiana. However, as this species is easily confused with S. talpa, there are likely more specimens of this species lurking in collections and misidentified as such. The directionality, density, and shape of dorsal clypeal pilosity has not been a focal character in previous treatments of Nearctic Strumigenys but has provided clear morphological separations among many species in this study and can easily separate $S$. macgowni from S. talpa. Not much is known about this ant other than basic collection information on collection labels. The type specimens from Texas were Winkler extracted from litter in October at Big Creek Scenic Area, a densely forested hardwood and pine nature preserve in east Texas. The single Louisiana worker was collected in a pitfall trap in a forested area of Sam Jones State Park.

Nontype material examined: USA, Louisiana, Calcasieu Parrish, Sam Houston Jones State Park, 1 worker, 30.51966 -95.08816 \pm 1000 m, 17 August 1987, el $80 \pm 5$ m, Collector W. MacKay \#8971 (unique specimen identifier casent0799752) [DBBC].

\section{Strumigenys margaritae Forel, 1893}

Distribution. USA to Suriname and most Caribbean Islands; in eastern USA from Florida to Virginia, west to Missouri; in western USA occurs in Oklahoma and Texas.

Comments. Strumigenys margaritae is an infrequently collected non-native (Neotropical) ant that has established along a wide southern USA swath (Ivanov et al. 2019; Bolton 2000). This species is collected over a wide range of habitats but is often found in more arid sites such as prairie remnants, scrub, and grassy areas -predicting further spread throughout other more western states with similar habitats (Mississippi Entomological Museum 2020). Strumigenys margaritae has often been collected using sweep nets off low vegetation (Mississippi Entomological Museum 2020). Although observed to forage above ground, it appears S. margaritae nests in the ground from limited observations. According to the few USA collections from flight traps $(\mathrm{n}=4$ from Louisiana and Mississippi) mating flights occur between July and August. I found a nest in an open pasture-edged woodland near Athens, Georgia, in mid-September, and males and alate queens were still present. In addition, S. subnuda (MacGown \& Hill, 2010) is a rarely collected social parasite thought to be associated with $S$. margaritae. Although not collected in Texas, it occurs in Louisiana and there is no reason to think it might not also co-occur with S. margaritae elsewhere.

\section{Strumigenys membranifera Emery, 1869}

Distribution. Globally introduced to all continents except Antarctica; in eastern USA from Florida to Virginia, west to Arkansas; in western USA occurs in Arizona, California, and Texas.

Comments. An unmistakable introduced species, S. membranifera is a global tramp with unclear origin (Wet- 
terer 2011). Brown \& Wilson (1959) suggested this species was native to Africa, however this native origin was questioned by Bolton (1983) and its phylogenetic position places it as Indomalayan in origin (Booher et al. 2021). This species is often found in grass clippings, mulch piles, and litter debris in more open and disturbed areas. It is more commonly collected in eastern states. It has been collected infrequently in the western states of California (Los Angeles and Yolo counties), Arizona (Maricopa County) and Texas (Brazos and Robertson counties).

Strumigenys membranifera, like several other Strumigenys tramp species, reproduces asexually through thelytokous parthenogenesis (Ito et al. 2010) and produces alate queens over a much longer period when compared with natives. In southeastern USA states, alate queens have been collected in all months between June and November, whereas in California alates have been collected in February and late July. A confirmed male identification for this species suggests it may also be capable of reproducing sexually. This male specimen was identified genetically (Booher et al. 2021).

\section{Strumigenys mendezi sp. nov.}

Figure 40

\section{Distribution. USA; Arizona}

Holotype worker USA, Arizona, Cochise County, Chiricahua Mountains at the Jct. of Basin Trail \#247 \& Forest Service Road 42, 31 ${ }^{\circ} 53.94^{\prime} \mathrm{N} 109^{\circ} 14.27^{\circ} \mathrm{W}, 13$ August 2009, $1890 \mathrm{~m}$, Collector S. P. Cover, collection number 81600 (unique specimen identifier MCZ-ENT00584721) [MCZC].

Paratype workers 2 workers, same collection as type (unique specimen identifier MCZ-ENT00584719, MCZENT00584720) [MCZC].

Holotype and paratype worker measurements $(\mathbf{n}=\mathbf{3}) \mathrm{HL}=0.64-0.719(0.682) ; \mathrm{HW}=0.418-0.451(0.433)$; $\mathrm{ML}=0.111-0.131(0.125) ; \mathrm{PW}=0.279-0.315(0.300) ; \mathrm{SL}=0.369-0.381(0.372) ; \mathrm{FL}=0.492-0.513(0.500) ; \mathrm{HT}=$ 0.352-0.375 (0.367); $\mathrm{EL}=0.049-0.067(0.056) ; \mathrm{WL}=0.648-0.741$ (0.709); $\mathrm{CI}=59.9-66.7$ (63.6); $\mathrm{MI}=16.1-20.5$ (18.3); SI = 81.8-88.2 (86.0).

Diagnosis. Strumigenys mendezi is morphologically most similar to S. arizonica (Ward, 1988) (sharing similar dentition, sculpturing, and most characters of pilosity) but can be most easily distinguished from $S$. arizonica by lack of flagellate pronotal humeral setae.

Description of worker. Mandible with a triangular basal lamella about as long as the base. Lamella followed by a short diastema that is about as long as length of first principle tooth. Mandible with five principle teeth. From base of mandible, first three and fifth tooth about equal in length with the fourth tooth obviously shorter. Principle teeth are followed by three sets of denticles decreasing in size with two large denticles, two intermediate sized denticles, and four minute denticles. Mandible terminating with small spiniform apical tooth for a total tooth count of 14. The first four principle teeth do not fully overlap when mandibles are fully closed and leave a zipperlike gap of open space between them. Labral lobes digitate and long, extending to third tooth in closed position, posterior half to apex of lobes with a series of projecting transparent spoon-shaped setae. Lateral to anterior free margins of clypeus broadly rounded and about 1.25 times as wide as long. In profile view head and clypeus nearly evenly flat with clypeus slightly raised above adjoining frontal area. Scape elongate SI 85. with a narrowly marginate anterior border. Propodeal teeth triangular and well formed with lamella of propodeal declivity narrowing below tooth followed by a broadly lamellate expansion above bulla of metapleural gland that is wider than propodeal tooth.

Pilosity. Setae on anterior margin of scape are spatulate with two or more setae curving towards base of scape at and posterior sub-basal bend. All setae extending from lateral and anterior margin of clypeus consist of spatulate curved setae that are directed anteriorly towards mandibles or to the midline. Clypeal dorsum covered with similar but shorter evenly distributed setae that curve anteriorly. Pilosity on dorsum of head, pronotum, and mesonotum consisting of more sparse but similar setae as on clypeal dorsum and are directed anteriorly or medially. Setae on dorsal nodes of petiole and post-petiole short simple arched setae directed posteriorly. Ground pilosity of gaster consisting of numerous short arched simple setae about as long as EL and mostly directed posteriorly. Differentiated subflagellate to flagellate setae limited to the basal quarter of the first gastral tergite, not present on head or body. Ground pilosity of legs short reclined to suberect simple setae. Outer surfaces of metatibia and basitarsi with a row of finer elongate setae that tend to recurve at midlength with apices resting against leg so that they appear looplike. However, on at least one metatibia in some specimens, one to two of these setae do not recurve and appear as elongate flagellate setae. 


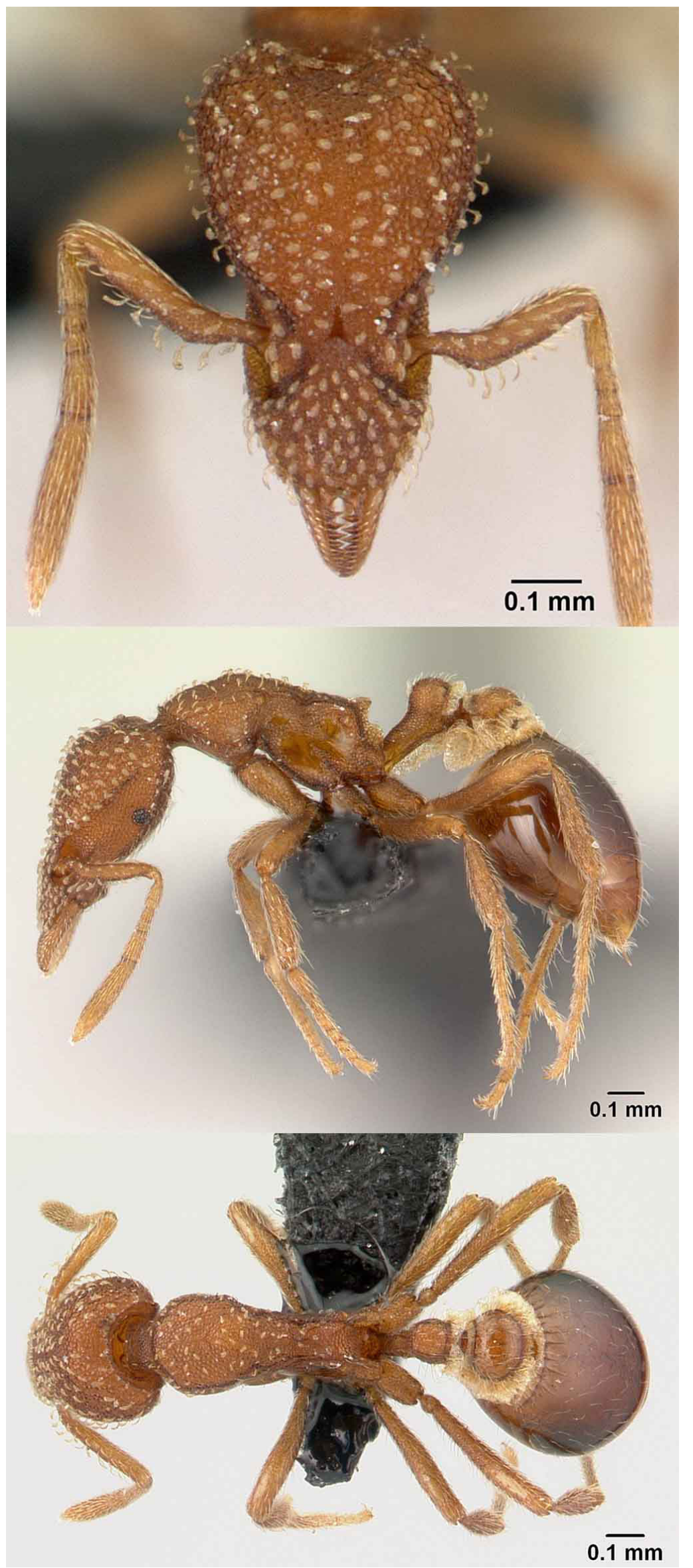

FIGURE 40. Worker of Strumigenys mendezi [CAS: casent0179538]. Photographed by Erin Prado (AntWeb.org 2020). 
Sculpture. Dorsum of clypeus, head, mesosoma, and node of petiole densely covered with reticulopunctate sculpture as is the side of pronotum. Median carinal ridge on dorsum of pronotum lightly pronounced to absent. Meso- and metapleurae smooth and shining with peripherally reticulopunctate sculpture. Exposed disc of postpetiole smooth and shining. Basigastral costulae well developed but short, limited to the basal quarter of first gastral tergite mostly smooth and shining, but with some superficial punctuations present.

Spongiform appendages. Spongiform tissue well-developed and present as a ventral flange of the petiole, a lateral flange on node of petiole, as a flange surrounding the exposed disc of postpetiole, and as a ventral process of the postpetiole. Sub postpetiolar flange near the length of exposed portion of postpetiolar disc in profile.

Etymology. This species was discovered by Stefan Cover at The Ant Course (organized by Brian Fisher). Both Fisher and Cover expressed their wishes for this species to be named after Ray Mendez. Ray Mendez, an artist and myrmecological associate that has in many ways - over many years - provided his talents to help The Ant Course, a course instrumental to nearly all early career myrmecologists for the last 20 years. The name was created by adding the singular Latin genitive case suffix $-\mathrm{i}$ to the last name of a male person. The orthography of an eponym is unchangeable and does not depend on the generic name in which the epithet is used.

Comments. The morphologies of $S$. mendezi and $S$. arizonica are strikingly similar at first glance and both occur in Arizona, however they are ecologically dissimilar. Strumigenys arizonica is an obligate nest inhabitant of Trachymyrmex arizonensis where it benefits from the climate-controlled refuse chambers of their host and preys on Collembola associated with their host's refuse (Gray al. 2018). Strumigenys mendezi appears to be a freely living ant species, not obligately associated with $T$. arizonensis or any other ants according to the collector Stefan Cover who discovered this species. He collected $S$. mendezi in a dense gray oak, juniper, emory oak woodland with vegetation height approximately $7.5 \mathrm{~m}$, on a gentle southeastern facing slope. Individuals were collected by sifting litter under an oak stump in shade. I tentatively identify an alate queen as $S$. mendezi, based on images (BugGuide 2020b) (collection data: September 26, 2019, by Gary Alpert and Mark Szydlo 16 km southeast of Flagstaff in Walnut Canyon National Monument, Coconino County, Arizona, USA, 26 September 2019, Gary Alpert and Mark Szydlo).

Nontype material examined 3 workers, same collection as type (unique specimen identifier casent 0747777 , casent0747778, casent074779) [MCZC].

Nontype worker measurements. $\mathrm{HL}=0.64-0.697(0.659) ; \mathrm{HW}=0.418-0.451(0.431) ; \mathrm{ML}=0.123-0.131$ (0.127); $\mathrm{PW}=0.279-0.308(0.291) ; \mathrm{SL}=0.369-0.369(0.369) ; \mathrm{EL}=0.049-0.057(0.053) ; \mathrm{WL}=0.648-0.722$ (0.693); $\mathrm{CI}=64.7-66.7$ (65.6); $\mathrm{MI}=18.2-20.5$ (19.3); $\mathrm{SI}=81.8-88.2(85.5)$.

\section{Strumigenys missouriensis Smith, 1931}

Distribution. USA; in eastern USA from Florida to Virginia, west to Arkansas.

Comments. Strumigenys missouriensis probably represents a complex of species is an extremely wide-ranging and morphologically variable species. Because it is most morphologically similar to $S$. lucky and occurs in sympatry, I have included it here and in the key but not in the synoptic list of western USA species. A more thorough taxonomic treatment of $S$. missouriensis across its range is needed.

\section{Strumigenys mixta Brown, 1953}

Distribution. USA to Venezuela; in USA occurs in Arizona.

Comments. Strumigenys mixta has a spotty a native range from Venezuela to southern Guatemala and was most likely introduced in the USA. It has been collected several times among ornamental, irrigated landscapes at the University of Arizona, Pima, Arizona, and in residential areas of Yuma and Phoenix.

Material examined: USA, Arizona, Maricopa Co., Phoenix, $\mathrm{nr}$ 12th street and E. Northern Ave, 33.553333, -112.056667, 383 m, 3 Sep 2002, Residential Area, 1 dealate queen, coll. R.A. Johnson, Phx-LTERV14\#9, (casent0873026)[RAJC]; USA, Arizona, Maricopa Co., Phoenix, nr 12th street and E. Northern Ave, 33.553333, -112.056667, 383 m, 3-Sep-02, Residential Area, 1 worker, coll. R.A. Johnson, Phx-LTER-V14\#8, (casent0873027)[RAJC]; USA, Arizona, Pima Co., University of Arizona Campus, 32.2315, -110.9545, 750 m, 28 Sep 2006, 2 workers, coll. M. Lanan, (casent0799765 \& casent0799764)[DBBC]; USA, Arizona, Yuma Co., 1340 
3rd st. space 111, Yuma trailer park, 32.72244, -114.6349, 40 m, 9 Aug 1996, urban area, at orange tree, 1 alate queen, coll. K.R. Helms \& J. Corpuz, YD-96-4273, [MCZC].

\section{Strumigenys moreauviae sp. nov.}

Figure 41

Distribution. USA; New Mexico

Holotype worker: USA, New Mexico, Sandoval County, Coronado Island in Rio Grande, 35.331059 106.55382 \pm 1000 m, 24 May 1999, 1544 m, pitfall trap, Collector E.R. Millard, Site10PB4. unique specimen identifier (casent0799753) [transferred from CWEM to CUIC].

Holotype worker measurements: $\mathrm{HL}=0.585 ; \mathrm{HW}=0.408 ; \mathrm{ML}=0.099 ; \mathrm{PW}=0.256 ; \mathrm{SL}=0.323 ; \mathrm{FL}=0.339$; $\mathrm{HT}=0.286 ; \mathrm{EL}=0.045 ; \mathrm{WL}=0.562 ; \mathrm{CI}=69.7 ; \mathrm{MI}=17.1 ; \mathrm{SI}=79.2$.

Diagnosis. Of western species, $S$. moreauviae shares a similar dentition pattern with $S$. chiricahua and $S$. reliquia (Ward, 1988) (tooth one and four of similar size and much shorter than similarly long teeth two, three, and five) but can be distinguished from these two species by head pilosity. Strumigenys moreauviae has no flagellate setae on head whereas $S$. chiricahua and S. reliquia have a pair at apicoscrobal position and a pair straddling the midline just anterior of the posterior margin of head. Strumigenys reliquia also has another pair about midlength of the upper scrobal margin and is the only western species with a fringe of simple fine and elongate setae on the anterior margin of clypeus. Otherwise, general head and clypeal pilosity is similar to western species $S$. arizonica, S. californica (Brown, 1950), and S. mendezi, but dentition differs. The diastema is absent or shorter than the length of the first basal tooth in S. arizonica, S. californica, and S. mendezi; in S. moreauviae it is longer.

Description of worker. Mandible with five main teeth followed by two smaller teeth nearly as large as first tooth. These teeth are followed by two smaller denticles (these teeth are very difficult to see in closed mandible holotype) and ending with a slightly longer apical tooth. The first principle tooth is about half as long as second tooth. These first two teeth do not overlap in closed position; diastema is about equal or subequal to first tooth and longer than length of second tooth; teeth two through five alternating in length with teeth one through three progressively increasing in size. Of the first four teeth, only the third touches or overlaps, teeth one and four each with an obvious space between teeth when closed, denticles at apices are the only teeth to fully overlap. Eye with six pigmented ommatidia. Head in dorsolateral view flat without a noticeably higher vertex and only raised slightly at antennal insertion and posterior border of clypeus. Clypeus is 1.14 times wider than long and pentagonal in shape, having angular junctions on free margins where anterior and anterolateral margins meet. Anterior margin generally flat but having a slight concave impression between inner margins of mandibles (excluding basal mandibular process). Upper scrobal margin weakly marginate and ending at level of eye. Anterior of scape marginate, enlarged and flattened at sub-basal bend but not strongly angulate, subcylindrical in cross section, and with ventral glandular bulla of scape apparent as an elongate narrow oval patch located in apical third scape. In profile, dorsal surfaces of pronotum and mesonotum are flat and join at a broadly rounded angle. Propodeal tooth lamellate, triangular, and not well differentiated from subtended lamella of declivitous face.

Pilosity. No flagellate setae present on any surface of the body. Head with short spatulate setae that bend and point towards the midline of head and with 2-3 pairs of elongate simple and shallowly curved setae near the posterior vertex border beyond the vertex of head. Dorsum of clypeus with similar and slightly larger spatulate to spoonshaped setae directed toward the mandibles or toward the midline. Lateral and anterior border of the clypeus also fringed with short spatulate to spoon-shaped that are slightly larger than those on the clypeal dorsum; lateral fringe of setae are spoon-shaped and are directed anteriorly; anterior fringe of setae limited to two pair of spatulate setae that are smaller than lateral setae and are directed ventrally and slightly towards the midline of mandibles. Scape sparsely covered with short simple to shallowly expanded appressed setae; anterior margin with a row of differentiated spatulate setae with 2-3 spatulate setae curving toward the base of scape. Dorsum of mesosoma with four pair of suberect to shallowly curved elongate simple to slightly expanded setae; one pair at humeral angle; two pair on pronotal dorsum; and a smaller pair of curved simple setae at anterior edge of metanotal suture. Node of petiole and postpetiole with long simple setae that closely follow their surfaces. First gastral tergite with a row of four elongate simple setae arising near the margin of the limbus; first gastral sternite without standing pilosity; short appressed pubescence sparsely scattered on tergite and present only on lateral surfaces of tergite. No standing setae on legs. 


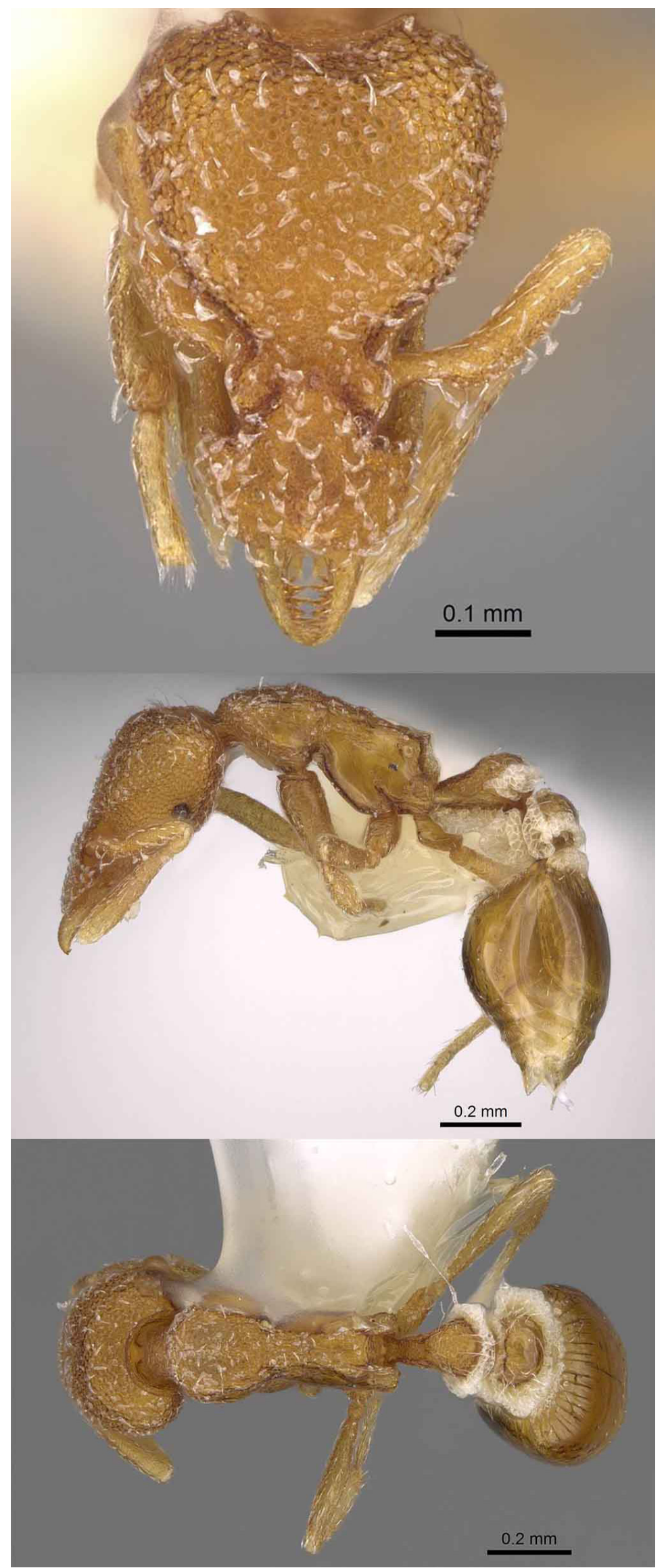

FIGURE 41. Holotype worker of Strumigenys moreauviae [CAS: casent0799753]. Photographed by Michele Esposito (AntWeb 2021). 
Sculpture. Head and clypeus strongly punctate to reticulopunctate with lateral scrobal margins punctate. Dorsum of mesosoma without or with a weakly developed medial carina that is covered by reticulopunctate sculpture; flanked by weak irregular striae that are more strongly developed on dorsum of propodeum. Side of pronotum is reticulopunctate and having a large smooth and shining medial band without sculpture. Side of mesonotum and propodeum smooth and shining except for a small punctate sculpture present at the base of the mesopleurae; covering the bulla of the mesopleural gland and the small area between the propodeal spiracle and the lamella of the propodeum. Node of petiole heavily reticulopunctate. Exposed disc of postpetiole free of sculpture. Gaster smooth and shining without sculpture between and posterior basigastral costulae that extend about 1/3 of the first gastral tergite.

Spongiform appendages. Lateral lobe of petiole as long as length of petiolar node; ventral curtain as on postpetiole and present as a ventral curtain on the peduncle of petiole that is as deep as the base of the peduncle; disc of postpetiole encircled by a fringe of spongiform cuticle; ventral lobe of postpetiole deeper than exposed height of disc in lateral view; margin of lamella following the declivitous face of propodeum is irregular and projecting further than length of propodeal tooth in basal half above bulla of metapleural gland.

Taxonomic notes: The holotype is missing some body parts (the last funicular segment of the right antenna, the left foreleg beyond the trochanter, the right hind leg, and the left tarsal segments, and likely some pilosity). However, complementary body parts or setae are present to appear to represent a full description.

Etymology. Named after distinguished scientist and myrmecologist Dr. Corrie S. Moreau for her significant contributions as an evolutionary biologist. I met Dr. Moreau as a student at the first Ant Course in 2001 and was infected, as many other myrmecologists have been, by her viral enthusiasm of the ant world and unapologetic inclusiveness. The name was created by adding the singular Latin genitive case suffix -ae to the last name of a female person, this ending preceded by the infix -vi- inserted for ease of pronunciation. The orthography of an eponym is an unchangeable genitive noun and does not depend on the generic name in which the epithet is used.

Comments. Known only from the holotype worker collected by a student, E. R. Millard on a riparian island of the Rio Grande in late Spring.

\section{Strumigenys ornata Mayr, 1887}

Distribution. USA to Mexico; in eastern USA from Florida to Maryland and west to Iowa including Michigan; in eastern USA occurs in Oklahoma and Texas.

Comments. Strumigenys ornata is a wide-ranging and common eastern species with a western distribution extending into Texas and Oklahoma. Although not previously collected outside the USA, a specimen examined and housed at the MCZ was collected at high-altitude in Cerro Potosi, Nuevo Leon, Mexico, expanding the known range. This species has often been found in forested habitats nesting in litter, crevices, and log debris, but is rarely found in hollowed twigs or nuts on the ground where many other Strumigenys often nest (Brown 1953; Duffield \& Alpert 2011; Booher et al. 2017).

Material examined: MEXICO, Cerro Potosi, Galeana N.L., 24.861823, -100.229436, $3400 \mathrm{~m} \pm 500,14$ Apr 1988, 1 worker, coll. R. Anderson, \#12762, [TAMUIC]; USA, Oklahoma, Latimer Co., 34.835035, -95.31025, 224 m, 15 May 1983, 1 worker, coll. K. Stephan, [ABS]; USA, Texas, Angelina Co., 2 miles south of Lufkin, 31.298494, -94.737509, 79 m, 24 Mar 1984, Riparian Mosses on Stream Bank Litter, 1 queen \& 1 worker, coll. Walter Suter, [ABS]; USA, Texas, Brazos Co., College Station, Big Creek Park, 30.32832, -96.574313, 82 m, 19 Sep 1996, berlese, 1 worker, coll. J.L. Cook, [SHSU]; USA, Texas, Houston Co., Big Slough Wilderness, 31.487537, -95.117138, 68 m, 9 May 1988, 2 workers, coll. R. Anderson, 12760, [TAMUIC]; USA, Texas, Lamar Co., Camp Maxey, Osmuda bog, 33.848745, -95.538077, 165 m, 25 Sep 2003, malaise, 1 alate queen, coll. S.F. Godwin, [DBBC]; USA, Texas, Nacadoches Co., 12 miles southwest of Nacogdoches, 31.496515, -94.798552, 74 m, 11 Feb 1984, 1queen \& 3 workers, coll. Byers and Jenks, [ABS]; USA, Texas, Polk Co., Big Thicket Nature Preserve, 30.473533, 94.346036, 25 m, 12 May 1988, litter, 1 worker, coll. R. Anderson, [TAMUIC]; USA, Texas, Sabine Co., Hemphill, 31.327373, -93.84642, 90 m, 25 Aug 1989, Berlese, Magnolia trunk in Beech Bottom, 1 worker, coll. R. Anderson \& E. Riley, [TAMUIC]; USA, Texas, San Jacinto Co., Cold Spring 6 mi E; at Big Creek, 30.598469, -95.030912, 26 m, 1 Apr 1995, 1 worker, coll. J.L. Cook \& J.B. Martin, [SHSU]; USA, Texas, Tyler Co., Camp Cove, dam B, 32.431824, -95.362425, 155 m, 16 Aug 1975, Berlese of Sycamore Litter, Hardwood, 3 workers, coll. S.J. Merritt, [DBBC]; USA, Texas, Walker Co., Huntsville State Park, 30.621113, -95.521798, 106 m, 1 specimen, [MCZC]. 
Distribution. Canada to USA; in eastern USA from Georgia to NY and west to Iowa; in western USA occurs in Kansas.

Comments. Morphologically similar to S. angulata, S. pergandei has elongate non-trap jaw mandibles. Strumigenys pergandei is a wide-ranging species that is more commonly collected in northern states and does not extend into Florida. It is often found nesting and foraging within nests of other ants e.g., Camponotus, Formica, and Aphaenogaster. Strumigenys pergandei may form unusually large colony sizes ( $>700$ workers) compared to other Nearctic natives that typically have around 30 workers (Wesson \& Wesson 1939; Brown 1964). In Canada it has been collected several times in the province of Ontario (Guénard et al. 2017). Brown (1964) took the first collection in Kansas (Lawrence).

\section{Strumigenys pilinasis Forel, 1901 (Note: senior synonym of ohioensis)}

Distribution. USA; in eastern USA from Florida to New York and west to Missouri; in western USA occurs in Kansas, Oklahoma, and Texas.

Comments. One of the most widespread and commonly collected Nearctic Strumigenys, S. pilinasis often nests in cavities such as hollowed nuts on forest floors (Duffield \& Alpert 2011). DuBois (1985) reports two colonies collected on the Ozark Plateau in two counties (Cherokee and Jefferson) were found nesting in rotten wood in a deciduous forest. This species has been collected multiple times in Texas, but only a single series is known from Oklahoma (Latimer County). The single specimen identified as S. pilinasis in the Field Museum database from Colorado is not S. pilinasis but is here described as S. collinsae (FMNHINS 0000119056 ).

Material examined: USA, Oklahoma, Latimer Co., 34.835035, -95.31025, 224 m, 15 May 1983, 9 workers \& 1 queen, coll. K. Stephan, [ABS]; USA, Texas, Houston Co., Big Slough Wilderness, 31.487537, -95.117138, 68 m, 9 May 1988, litter, 4 workers, coll. R. Anderson, 12760, [TAMUIC]; USA, Texas, Angelina Co., 2 miles south of Lufkin, 31.298494, -94.737509, 79 m, 24 Mar 1984, Riparian Mosses on Stream Bank Litter, 12 workers, coll. Walter Suter, \#84-247, [ABS]; USA, Texas, Lamar Co., Camp Maxey, Osmuda bog, 33.848745, -95.538077, 165 m, 15 Sep 2003, malaise, 1 alate queen, coll. Godwin SF, [SHSU]; USA, Texas, Nacogdoches Co., 12 miles southwest of Nacogdoches, 31.496515, -94.798552, 74 m, 13 May 1983, 15 workers, coll. Byers and Jenks, [ABS]; USA, Texas, Nacogdoches Co., 12 miles southwest of Nacogdoches, 31.496515, -94.798552, 74 m, 11 Feb 1984, 2 queens \& 2 workers, coll. Walter Suter, [ABS]; USA, Texas, Sabine Co., 14 Kilometers east of Hemphill, 31.339698, 93.707155, 97 m, 11 May 1988, litter, 2 workers, coll. R. Anderson, \#12764, [TAMUIC]; USA, Texas, San Jacinto Co., Big Creek Scenic Area, 30.518456, -95.085363, 91 m, 9 Sep 1999, 1 worker, coll. J.L. Cook \& J.B. Martin, [SHSU]; USA, Texas, San Jacinto Co., Big Creek Scenic Area, 30.518467, -95.079755, 86 m, 18 Dec 1999, 1 worker, coll. J.L. Cook \& J.B. Martin, [SHSU].

\section{Strumigenys pulchella Emery, 1895}

Distribution. Canada to USA; in eastern USA from Florida to New York and west to Iowa; in western USA occurs in Kansas, and Texas.

Comments. Strumigenys pulchella is a wide-ranging eastern to midwestern species often found nesting in hardwood stumps and rotting fallen branches. In Kansas, Dubois (1985) reports a colony collected in rotten wood in a deciduous forest. The Field Museum houses a specimen from North Dakota (FMHD 0000050 802), but this specimen's collection data were digitized erroneously. This specimen was collected by H. Dybas in 1950 near Station Lake, Porter County, Indiana. There are no validated records of Strumigenys in North Dakota.

Material examined: USA, Texas, Lamar Co., Camp Maxey, Osmuda bog, 33.848745, -95.538077, 165 m, 25 Sep 2003, malaise, 1 alate queen, coll. S.F. Godwin, SFASU 84, (casent0799701) [DBBC]. 
Distribution. USA; in eastern USA from Florida to Maryland and west to Missouri; in western USA occurs in Kansas and Texas.

Comments. This ant is a relatively uncommon and wide-ranging eastern species. Like S. pulchella, S. reflexa colonies have most often been collected in rotting wood and stumps (Wesson \& Wesson 1939). DuBois (1985) reports the single colony collected in Kansas was nesting in rotted wood near a permanent waterway in a deciduous forest. Of the Texas specimens examined, one provided habitat details. The worker collected near Hemphill, Texas was extracted from a magnolia trunk in a beech bottom forest.

Material examined: USA, Texas, Sabine Co., 9 miles east of Hemphill, 31.341042, -93.692656, 76 m, 25 Jul 1989, ex. Berlese, Beech Bottom Magnolia trunk, 1 worker, coll. R. Anderson \& E. Riley, (casent0799717)[DBBC]; USA, Texas, San Jacinto Co., Big Creek Scenic Area, 30.513102, -95.090501, 83 m, 16 Jul 1998, 1 worker, coll. J.L. Cook \& J.B. Martin, (casent0799716)[DBBC]; USA, Texas, San Jacinto Co., Big Creek Scenic Area, 30.510552, -95.083337, 81 m, 18 Apr 1999, 1 worker, coll. J.L. Cook \& J.B. Martin, (casent0799715)[DBBC].

\section{Strumigenys reliquia (Ward, 1988)}

Distribution. USA; California.

Comments. This species is a western endemic known from six workers taken in two collections in the spring of 1986. Both collections were taken in the same remnant patch of riparian oak woodland in the Sacramento Valley of California (Ward 1988).

Other than pilosity, Strumigenys reliquia is morphologically quite like $S$. collinsae and shares several mandible characters. In S. reliquia the first tooth arises after a long diastemmic gap and this tooth shorter than the following teeth. These first teeth also do not overlap when mandibles are closed, both characters shared with $S$. collinsae, but unlike $S$. collinsae these first teeth are more than half the length of the following teeth where the first teeth in $S$. collinsae are only about $1 / 4$ the length of the following tooth. Of the four teeth following this first short tooth, the third is shorter than the first two or last. In S. collinsae the third and fourth are nearly equal in size. The clypeal groove is also not visible along the anterior border unlike $S$. collinsae. Other major differences are discussed under $S$. collinsae.

Material examined: USA, California, Yolo Co., 4 km E of Yolo, 38.73333, -121.76667, 15 m, 8 May 1986, 1 worker, coll. S. Shattuck, ANTC33912, (lacm0328720)[LACM].

\section{Strumigenys rostrata Emery, 1895}

Distribution. USA; in eastern USA from Florida to New York and west to Missouri; in western USA occurs in Texas.

Comments. Strumigenys rostrata is a common eastern species associated with mesic temperate forests and often found in cavities under bark of fallen branches, tree stumps, and empty nuts (Duffield and Alpert 2012; Booher et al. 2017). Strumigenys rostrata ranges from Florida to New York and becomes less commonly encountered in states at the western edge of its range, Missouri, Arkansas, and Texas. It has only been collected a handful of times in these states and collected most frequently in those states in dense thickets and forested stands. Strumigenys rostrata is often found with other ants (Wesson and Wesson 1939). However, this is probably not due to any biotic symbiosis, but due to the fact many species opportunistically nest in woody and litter debris on the ground. Likely a polydomous species, $S$. rostrata is a polygynous species forming compound nests (unpublished data).

Material examined: USA, Texas, Polk Co., Big Thicket Nature Preserve, 30.473533, -94.346036, 25 m, 12 May 1988, litter, 1 worker, coll. R. Anderson, [TAMUIC]; USA, Texas, Sabine Co., 9 miles east of Hemphill, 31.341042, -93.692656, 76 m, 24 Apr 1989, Berlese, Neotoma nest inside Magnolia trunk in Beech Bottom, 2 workers, coll. R. Anderson \& E. Riley, [DBBC]; USA, Texas, Sabine Co., Hemphill, 31.327373, -93.84642, 90 m, 25 Jul 1989, Berlese, Beech Bottom, Magnolia trunk, 1dealate queen \& 1 worker, coll. R. Anderson \& E. Riley, [TAMUIC]; USA, Texas, Sabine Co., 14.5 Kilometers east of Hemphill, 31.356189, -93.684559, 56 m, 11 May 
1988, litter, 1dealate queen \& 1 worker, coll. R. Anderson, 12763, [TAMUIC]; USA, Texas, Tyler Co., Spurger, 30.691203, -94.17743, 51 m, 24 Apr 1988, ex. litter, 1 worker, coll. R. Anderson, \#12761, [TAMUIC]; USA, Texas, Tyler Co., Big Thicket Nature Preserve, 30.473533, -94.346036, 25 m, 8 Mar 1989, litter, 1 worker, coll. R. Anderson, \#12757, [TAMUIC].

\section{Strumigenys silvestrii Emery, 1906}

Distribution. Argentina to Guyana; introduced in USA, Mexico, most Caribbean Islands and Portugal; in eastern USA from Florida to North Carolina and west to Louisiana; in western USA occurs in California and Texas.

Comments. Strumigenys silvestrii is a native to tropical and subtropical South America and has been introduced to the USA, Mexico, and Portugal (MacGown et al. 2012; Guénard et al. 2017). Although ranging across all southeastern Atlantic Gulf states, it is not commonly collected across its USA range. This species inhabits drier more open habitats than most Nearctic species and is often picked up in pitfall traps or flight traps in areas with little leaf litter accumulation. Fewer collectors have recorded this species occurring in heavily forested habitats. Both males and queens have been collected for this species, with mating flights in Texas between late May and mid-July (estimated from alate collections). The earliest record from Texas is 1969 and from California is 1996 (MacGown et al. 2012).

Material examined: USA, Texas, Brazos Co., TAMU Range Sci. Area, 30.589389, -96.375818, 90 m, 18 Jun 1978, Malaise, 1 queen, coll. S.J. Merritt, (casent0875756)[TAMUIC]; USA, Texas, Robertson Co., Mumford, 8 miles from TX-21, 30.761658, -96.581392, 79 m, 29 May 2000, Pitfall, Pecan Orchard, 5 alate queens, 1 worker, coll. A. Calixto, [TAMUIC]; USA, Texas, Brazos Co., Riverside Campus, 30.636667, -96.463333, 82 m, 21 Jun 1999, pitfall, coll. K. Helms, [SHSU]; USA, Texas, Brazos Co., College Station, Lick Creek Park, 30.566667, 96.211667, 75 m, 21 Jun 1999, pitfall, coll. K. Helms, [SHSU]; USA, Texas, Brazos Co., Leachman Ranch, 30.29, -96.538333, 90 m, 21 Jun 1999, pitfall, coll. K. Helms, [SHSU]; USA, Texas, Brazos Co., Kopper Bridge rd \& Brazos rd, 30.520192, -96.316328, 99 m, 19 Oct 1995, coll. J.L. Cook, [SHSU]; USA, Texas, Brazos Co., Hicks Ranch, 30.633563, -96.45009, 85 m, 21 Jun 1999, pitfall, coll. K. Helms, [SHSU]; USA, Texas, Brazos Co., Ellington Farm S of College Station, 30.633604, -96.449816, 87 m, 21 Jun 1999, pitfall, coll. K. Helms, [SHSU]; USA, Texas, Brazos Co., Arnold Site, 30.575, -96.29, 91 m, 21 Jun 1999, pitfall, coll. K. Helms, [SHSU]; USA, Texas, Brazos Co., Coulter Airfield, 30.71, -96.328333, 110 m, 21 Jun 1999, pitfall, coll. K. Helms, [SHSU]; USA, Texas, Brazos Co., 4.5 miles S of College Station, at Vinson property, 30.566856, -96.338314, $101 \mathrm{~m}, 11$ Nov 1998, coll. K. Helms, [SHSU]; USA, Texas, Harris Co., Baytown, 5800 Baker rd, 29.771306, -95.0166667, 8 m, 12 Jul 2013, Malaise Trap, 1 dealate queen, coll. Danny L. McDonald, ANTC31206, (casent0747056)[DBBC]; USA, Texas, Polk Co., Livingston, 18.7 miles east of Livingston on US 190, 30.74708, -94.61835, 91 m, 16 Aug 1975, Berlese Pine litter, Pine, 1 worker, coll. S.J. Merritt, [TAMUIC]; USA, Texas, Robertson Co., Mumford, 30.761658, -96.581392, 79 m, 25 Jul 2000, Pitfall, Pecan Orchard, 1 queen, coll. A. Calixto, [TAMUIC]; USA, Texas, San Jacinto Co., Big Creek Scenic Area, 30.513102, -95.090501, 83 m, 16 Jul 1998, coll. J.L. Cook, [DBBC]; USA, Texas, Walker Co., Ellis Prison Unit, 30.875748, -95.460792, 61 m, 15 Jun 1980, SuctionTrap, 2 males, 1 alate queen, coll. D.A. Dean, [TAMUIC]; USA, Texas, Walker Co., Ellis Prison Unit, 30.875748, -95.460792, 61 m, 15 Jun 1980, SuctionTrap, 1 alate queen, coll. D.A. Dean, (casent0751469)[UGCA]; USA, Texas, Washington Co., Yegua, 8 miles from TX 21, 30.29595, -96.540439, 84 m, 21 Jun 1999, pitfall, coll. K. Helms, [SHSU].

\section{Strumigenys subtilis sp. nov.}

Figure 42

Distribution. USA; California.

Type material examined. Holotype Queen. USA, California, San Bernardino County, 1 mile west of Pichalka Spring, Clark Mountains, blackbush scrub, pitfall trap, 35.5185 -115.64213, 4 January 2006, $4600 \mathrm{ft}$, Collector J. des Lauriers, unique specimen identifier (casent0104307) [PSWC].

Holotype queen measurements: $\mathrm{HL}=0.685 ; \mathrm{HW}=0.422 ; \mathrm{ML}=0.105 ; \mathrm{PW}=0.304 ; \mathrm{SL}=0.390 ; \mathrm{FL}=0.513$; $\mathrm{HT}=0.359 ; \mathrm{EL}=0.122 ; \mathrm{WL}=0.716 ; \mathrm{CI}=61.6 ; \mathrm{SI}=92.4 ; \mathrm{MI}=15.3$. 


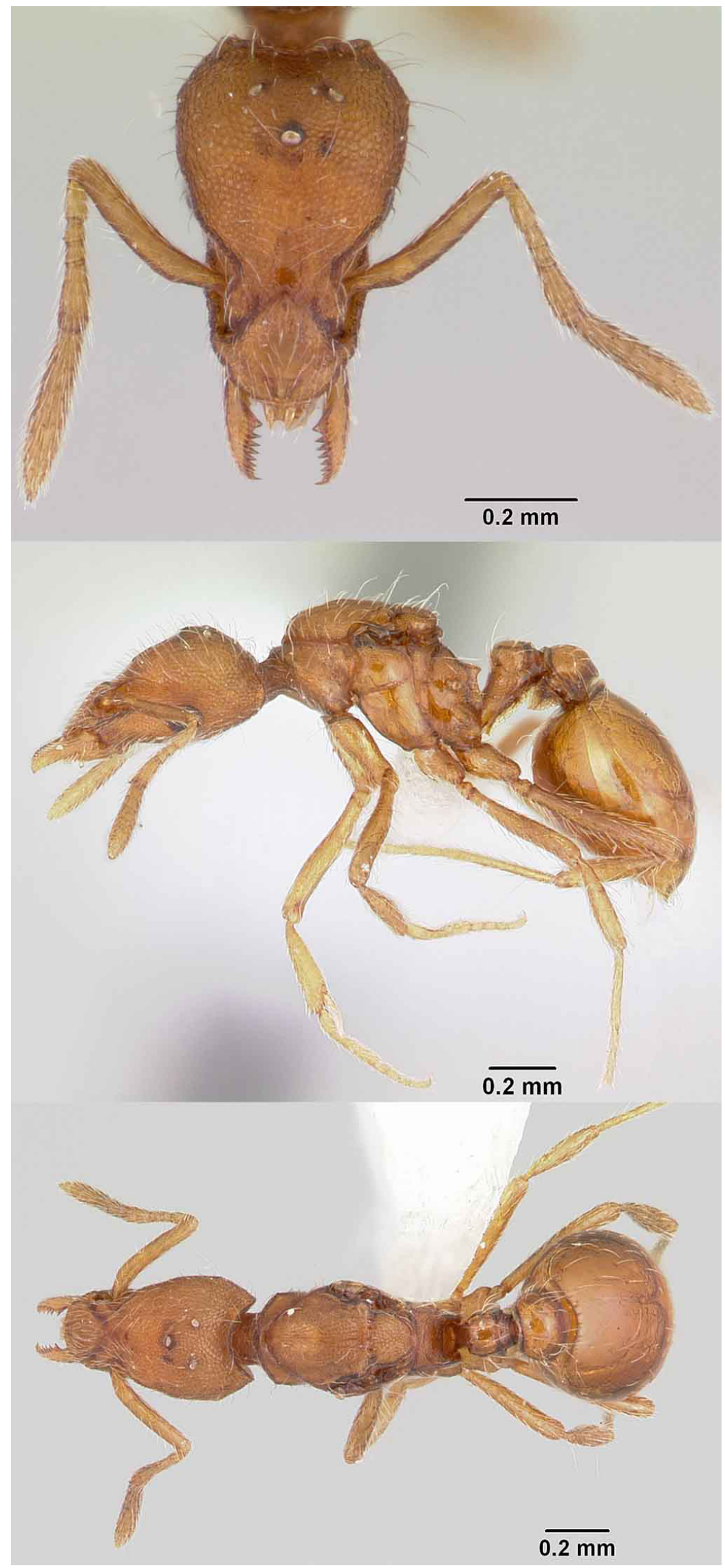

FIGURE 42. Holotype queen of Strumigenys subtilis [PSWC: casent0104307].

Photographed by Michele Esposito (AntWeb 2021). 
Diagnosis. Strumigenys subtilis is the only western species possessing a narrow peripheral groove along the free margin of the clypeus and highly reduced spongiform appendages. All eastern USA species with a peripheral groove also have well developed lateral petiolar and post-petiolar spongiform appendages; these spongiform appendages are reduced to narrow cuticular lamellae in S. subtilis. Strumigenys subtilis superficially resembles $S$. inopina (Deyrup \& Cover, 1998), a southeastern USA species only known from a few queens and suspected to be a social parasite, but is easily distinguished by the presence of short basigastral costulae in S. subtilis (in S. inopina costulae are absent) (Bolton 2000).

Description of worker. Mandibles with a triangular basal lamella with basal free side at least three times longer than anterior facing free side. Mandibles with six principle teeth, first three basal teeth are largest and about equal in length followed by three smaller teeth with tooth five being the longest and tooth six being the shortest. Principle teeth followed by five similarly sized blunt denticles and terminating with an elongated and acute apical tooth for a total tooth count of 12. Labrum with apical digitate lobes that curve ventrally. Clypeus with narrow peripheral groove; anterior border of ventral lamella of groove projecting further than dorsal lamella in full frontal view. Anterior border of clypeus broadly rounded between mandible insertions; lateral free margin weakly concave between lateral posterior corners to mandible insertion; 1.22 times broader than long. In profile posterior border of clypeus is abruptly raised above adjoining frontal area. Free margin of ocular carina is irregular in full frontal view. Head having expanded posterior-lateral corners located below midpoint of head in lateral view. Anterior and lateral dorsum of pronotum marginate. Pronotum slightly smaller in width (0.304) than mesosoma (0.390). Propodeal spines triangular and lamellate; about equal in length to maximum width of broadly convex free margin of declivitous lamella.

Pilosity. Setae on anterior margin of scape shallowly curved simple and acutely tipped with one or two setae curving towards the base of scape. Differentiated elongate flagellate to subflagellate setae present at apicoscrobal position; two pairs present between occipital posterior corners and midline of head just anterior of posterior margin; ventral surface of head with three pairs positioned at posterior ventral occipital margin, below position of eyes, and at rear of postbuccal groove; four pairs present on dorsum mesonotum; two pairs present on lateral dorsal surfaces of petiole and postpetiole; one pair of standing setae on anterior third of first gastral tergite that straddle the midline; two pairs of elongate simple setae present on mesa- and metatibia and one or two present on mesa- and meta-basitarsi. Ground pilosity of head, mesosoma, and gaster numerous fine, apically acute, and shallowly curved elongate setae. Ground pilosity on dorsum and borders of clypeus directed towards mandibles; on dorsum of head these setae are directed anteriorly or medially; on dorsum of mesosoma these setae directed medially to posteriorly. Ground pilosity of first gastral tergite elongate irregularly curved to flagellate setae closely following the surface of gaster.

Sculpture. Dorsum of clypeus smooth with light punctations along lateral and posterior borders. Frontal area with large smooth oval patch free of sculpture. Dorsum of head reticulopunctate and heaviest in posterior portion near the posterior margin of head. Dorsum of pronotum smooth and shining. Dorsum of mesosoma punctate. Side of pronotum mostly smooth and shining with finely punctate sculpture heaviest peripherally. Pleurae and side of propodeum smooth with some peripheral punctate sculpture. Dorsal surfaces of petiolar and postpetiolar node smooth and shining. Gaster smooth and shining with extremely short basigastral costulae (maximum length 0.016).

Spongiform appendages. Dorsal and lateral spongiform appendages of petiole and postpetiole are reduce to weakly sculptured cuticular ridges or lamellae. Ventral lamella of petiole at most $1 / 4$ of the depth of the peduncle of petiole; translucent and weakly reticulopunctate along lowest portion; ending anteriorly as a well-defined short sharp tooth. Sub-postpetiolar process lamellate; weakly reticulopunctate and shorter (0.92) than exposed height of postpetiolar node.

Etymology. Named for the subtle sculpturing and fine pilosity of this species. The specific epithet subtilis (meaning "fine") is a Latin singular feminine adjective in the nominative case and refers to the subtle sculpturing and fine pilosity of this species.

Comments. Strumigenys subtilis is known from a single specimen collected during a survey of the ant fauna of the Mohave National Preserve. Strumigenys subtilis is likely an inquiline or social parasite as it shares several common characters with other presumed or known Strumigenys inquilines: S. inopina (Deyrup \& Cover, 1998), $S$. inquilina (Bolton, 1983), and S. subnuda (MacGown \& Hill, 2010). Shared characters include reduced sculpture, small or absent spongiform appendages, and simple non-expanded setae (MacGown \& Hill 2010; Deyrup \& Cover 1998). However, it is not likely these expected inquiline species are closely related. The unusual and uncommon character of the peripheral groove and similar dentition as species in the clypeata group suggest S. subtilis is potentially a member of this group. However, no other members of the clypeata group have ranges that extend much 
further west than eastern Texas, and several other morphological differences, e.g. short basal gastral costulae, are not consistent with the clypeata group (Bolton 2000).

\section{Strumigenys superstes Booher \& Uhey 2020}

\section{Distribution. USA; Arizona.}

Comments. This species is a most unusual Strumigenys and is known from a single dealate queen collected in a pitfall trap between Flagstaff and the Grand Canyon between late June and mid-July. Strumigenys superstes belongs to the excisa species-group, a morphologically distinct clade of shiny short-mandible species that once belonged in the genus Glamyromyrmex (Booher et al. 2021; Booher \& Uhey 2020). Strumigenys superstes was collected in an undisturbed arid pinyon-juniper woodland on the Colorado Plateau. All other excisa species-group members have ranges in the Neotropics.

\section{Strumigenys talpa Weber, 1934}

Distribution. USA; in eastern USA from Florida to New Jersey and west to Missouri; in western USA occurs in Oklahoma and Texas.

Comments. This species is among the most commonly collected Nearctic species. It occurs from Florida to Washington, D.C., and extends west to Oklahoma and Texas (Brown 1950). Strumigenys talpa tolerates a wide variety of mesic to dry habitats and is less common in wet habitats (Deyrup 2016). Unlike the wide-ranging species $S$. missouriensis, S. talpa exhibits little morphological variation across its range. However, there appears to be a smooth morphological transition over geographic space between $S$. talpa and S. deyrupi. Setae on the anterior margin of the scape are typically directed towards the apex of the scape in $S$. talpa but some setae are directed towards the base of the scape in specimens collected in Florida from where S. deyrupi was described. Mark Deyrup (for whom $S$. deyrupi was named), has also come to this realization and we believe $S$. deyrupi to either be the same species or to hybridize heavily where their ranges overlap (southern half of Georgia into Florida). I have not observed scape setae variation anywhere else across the range of $S$. talpa except in specimens from Texas and there is no evidence of discrete forms in sympatry. All other setae characters of the Texas specimens are congruent with $S$. talpa. Texas specimens all have flagellate setae on their mesosoma, pronotal shoulders, abdominal tergites, and femur/tibia. Also unusual are the Oklahoma workers that lack elongate apicoscrobal setae. This character is uniformly present in all other collections across $S$. talpa's range that I have examined including those from Texas. Although these setae could have been abraded, this is unlikely as the specimens examined were in excellent shape and had no missing or broken flagellate setae on other portions of the body. I expect the Oklahoma specimens represent a new species but am grouping them with $S$. talpa until more specimens are found and $S$. talpa is examined across its range.

Material examined: USA, Oklahoma, Payne Co., 1 Jun 1963, 2 workers, coll. W.G. Carter, (MCZENT00683080)[MCZC]; USA, Texas, Hunt Co., Clymer Meadow, 33.301169, -96.243838, 199 m, 19 Apr 1992, 1 worker \& 1 queen, coll. J.R. Morris, [TAMUIC]; USA, Texas, Hunt Co., Clymer Meadow, 33.301169, 96.243838, 199 m, 19 Apr 1992, 1 worker, coll. J.R. Morris, [DBBC].

\section{Acknowledgments}

I am grateful for many collectors, curators, and museum infrastructure committed to keeping specimens safe and available for future research. I first would like to thank $\mathbf{C}$. Dandridge for providing illustrations for the key. She is a talented high school myrmecologist and artist and I expect to see her around the ant world for many years to come. Maisha Lucas (Yale University), is a friend and fellow myrmecologist who has helped me with many curatorial projects and wrote the etymology for S. collinsae. I am thankful for sharing her experience and honoring Dr. Collins through her writing. I would like to specifically thank Jack Longino (University of Utah) for providing invaluable and insightful feedback on this manuscript. The Ant Course for giving me the foundation to begin my taxonomic work, Brian Fisher, and Barry Bolton for creating and managing AntCat.org and AntWeb.org and Michele Esposito 
for imaging specimens. I would like to thank Joe MacGown (Mississippi State University) for reviewing this manuscript and James Trager (Missouri Botanical Gardens) for feedback on manuscript drafts. I also would like to thank supporting myrmecologist Corrie Moreau (Cornell), Andrew Suarez (University of Illinois), William and Emma Mackay (University of Texas), Benoit Guénard (University of Hong Kong), Evan P. Economo (Okinawa Institute of Science and Technology), Kyle Gray (Arizona State University), Eli Sarnat (Ant Consulting, LLC) and Phil Ward (UC Davis). I thank Walter Jetz (Yale) for supporting my continuous taxonomic work. I would like to additionally thank the young myrmecologist Anthony D. Prothero in Wisconsin that collected specimens and shared information, and Crystal Maier, E. O. Wilson, Stefan Cover, and Kathy Horton for their support (Museum of Comparative Zoology). This research was possible through funding support from The Ernst Mayr Grant of the Museum of Comparative Zoology for travel support to examine museum specimens, funding support from NSF grant \#2013162846 and NSF Biological Collections postdoc 000733206.

\section{References}

AntWeb (2021) AntWeb.org. Available from: https://www.antweb.org (accessed 13 February 2021)

Blackith, R.E. \& Blackith, R.M. (1975) Zoogeographical and ecological determinants of collembolan distribution. Proceedings of the Royal Irish Academy Section B-Biological Geological and Chemical Science, 75, 345-368.

Bolton, B. (1983) The Afrotropical dacetine ants (Formicidae). Bulletin of the British Museum (Natural History) Entomology, 46 (4), 267-416.

Bolton, B. (2000) The ant tribe Dacetini. Memoirs of the American Entomological Institute, 65, 1-1028.

Bolton, B. (2020) An online catalog of the ants of the world. Available from https://antcat.org (accessed 8 August 2019)

Booher, D.B., MacGown, J.A., Hubbell, S.P. \& Duffield, R.M. (2017) Density and dispersion of cavity dwelling ant species in nuts of eastern US forest floors. Transactions of the American Entomological Society, 143, 79-93.

Booher, D.B., (2019) Taxonomic clarification of two Nearctic Strumigenys (Hymenoptera: Formicidae). Zootaxa, 4664 (3), 401-411.

https://doi.org/10.11646/zootaxa.4664.3.7

Booher, D.B. \& Uhey, D., (2020) New native trap-jaw ant, Strumigenys Smith, from the Neotropical excisa species group discovered in a disjunct region and climate on the Colorado Plateau. Southwestern Naturalist, 45 (3), 663-672.

Booher, D.B., Gibson, J., Cong, L., Longino, J.T., Fisher, B.L., Janda, M., Narula, N., Toulkeridou, E., Mikheyev, A.S., Suarez, A.V. \& Economo, E.P. (2021) Functional innovation promotes diversification of form in the evolution of an ultrafast trapjaw mechanism in ants. PLoS Biology, 19 (3), e3001031. https://doi.org/10.1371/journal.pbio.3001031

Brown, W.L. Jr. (1949) Revision of the ant tribe Dacetini. I. Fauna of Japan, China and Taiwan. Mushi Fukuoka, 20, 1-25.

Brown, W.L. Jr. (1950) Preliminary descriptions of seven new species of the dacetine ant genus Smithistruma Brown. Transactions of the American Entomological Society, 76, 37-45.

Brown, W.L. Jr. (1953) Revisionary studies in the ant tribe Dacetini. American Midland Naturalist, 50, 1-137.

Brown, W.L. Jr. (1959) The neotropical species of the ant genus Strumigenys Fr. Smith: group of emeryi Mann. Entomological News, 70, 97-104.

Brown, W.L. Jr. \& Wilson, E.O. (1959) The Evolution Of The Dacetine Ants. Quarterly Review of Biology, 34, 278-294.

Brown, W.L. Jr. (1964) The ant genus Smithistruma: a first supplement to the world revision (Hymenoptera: Formicidae). Transactions of the American Entomological Society, 89, 183-200.

Buckley, S.B. (1866) Descriptions of new species of North American Formicidae. Proceedings of the Entomological Society of Philadelphia, 6, 152-172.

BugGuide (2020a) Available from: https://bugguide.net/node/view/1435479 (accessed 1 November 2020)

BugGuide (2020b) Available from: https://bugguide.net/node/view/1734394 (accessed 1 November 2020)

Deyrup, M. \& Cover, S. (1998) Two new species of Smithistruma Brown (Hymenoptera: Formicidae) from Florida. Proceedings of the Entomological Society of Washington, 100, 214-221.

Deyrup, M. (1998) Smithistruma memorialis (Hymenoptera: Formicidae), a new species of ant from the Kentucky Cumberland Plateau. Entomological News, 109, 81-87.

Deyrup, M. \& Cover, S. (2009) Dacetine Ants in Southeastern North America (Hymenoptera: Formicidae). Southeastern Naturalist, 8 (2), 191-212.

Deyrup, M. \& Lubertazzi, D. (2001) A new species of ant (Hymenoptera: Formicidae) from north Florida. Entomological News, $112,15-21$.

Deyrup, M. (2006) Pyramica boltoni, a new species of leaf-litter inhabiting ant from Florida (Hymenoptera: Formicidae: Dacetini). Florida Entomologist, 89, 1-5.

Deyrup, M. (2016) Ants of Florida: identification and natural history. 1 ${ }^{\text {st }}$ Edition. CRC Press, Taylor \& Francis Group, Boca Raton, Florida, $437 \mathrm{pp}$.

DuBois, M.B. (1985) Distribution of ants in Kansas: subfamilies Ponerinae, Ecitoninae, and Myrmicinae (Hymenoptera: For- 
micidae). Sociobiology, 11, 153-1252

Duffield, R.M. \& Alpert, G.D. (2011) Colony structure and nest location of two species of dacetine ants: Pyramica ohioensis (Kennedy \& Schramm) and Pyramica rostrata (Emery) in Maryland (Hymenoptera: Formicidae). Psyche, Cambridge, 2011,1-9.

Emery, C. (1893) Beiträge zur Kenntniss der nordamerikanischen Ameisenfauna. Zoologische Jahrbücher. Abteilung für Systematik, Geographie und Biologie der Tiere, 7, 633-682.

Emery, C. (1895) Beiträge zur Kenntniss der nordamerikanischen Ameisenfauna (Schluss). Zoologische Jahrbücher Abteilung für Systematik, Geographie und Biologie der Tiere, 8, 257-360.

Emery, C. (1906) Studi sulle formiche della fauna neotropica. XXVI Bullettino della Società Entomologica Italiana, 37, 107194.

Emery, C. (1869) Enumerazione dei formicidi che rinvengonsi nei contorni di Napoli con descrizioni di specie nuove o meno conosciute. Annali dell'Accademia degli Aspiranti Naturalisti. Secunda Era, 2, 1-26.

Evenhuis, N.L. (2019) The insect and spider collections of the world website. Available from: http://hbs.bishopmuseum.org/ codens (accessed 8 August 2020)

Forel, A. (1893) Formicides de l'Antille St. Vincent, récoltées par Mons. H. H. Smith. Transactions of the Entomological Society of London, 1893, 333-418.

Forster, J.A. (2003) The Ants (Hymenoptera: Formicidae) of Alabama. Master of Science Thesis, Auburn University, Auburn, Alabama, $224 \mathrm{pp}$.

Gray, K.W., Cover, S.P., Johnson, R.A. \& Rabeling, C. (2018) The dacetine ant Strumigenys arizonica, an apparent obligate commensal of the fungus-growing ant Trachymyrmex arizonensis in southwestern North America. Insectes Sociaux, 65 (3), 401-410.

Guénard, B., Weiser, M., Gomez, K., Narula, N. \& Economo, E.P. (2017) The Global Ant Biodiversity Informatics (GABI) database: a synthesis of ant species geographic distributions. Myrmecological News, 24, 83-89.

Guzmán-Díaz, L. (2014) Diversidad de formícidos (Hymenoptera: Formicidae) en el bosque mesófilo de montaña de la Reserva de la Biosfera El Cielo, Tamaulipas, México. Tesis de maestría, Colegio de Postgraduados, Montecillo, Texcoco, Estado de México, 88 pp.

Hoff, C.C. (1961) Pseudoscorpions from Colorado. Bulletin of the American Museum of Natural History, 122 (5), 409-464

Ito, F., Touyama, Y., Gotoh, A., Kitahiro, S. \& Billen, J. (2010) Thelytokous parthenogenesis by queens in the dacetine ant Pyramica membranifera (Hymenoptera: Formicidae). Naturwissenschaften, 97 (8), $725-8$. https://doi.org/10.1007/s00114-010-0688-5.

Ivanov, K., Hightower, L., Dash, S.T. \& Keiper, J.B. (2019) 150 years in the making: first comprehensive list of the ants (Hymenoptera: Formicidae) of Virginia, USA. Zootaxa, 4554 (2), 532-560.

Janicki, J., Narula, N., Ziegler, M., Guénard, B. \& Economo, E.P. (2016) Visualizing and interacting with large-volume biodiversity data using client-server web-mapping applications: The design and implementation of antmaps.org. Ecological Informatics, 32, 185-193. Available from: http://antmaps.org/?mode=diversity\&genus=Strumigenys (accessed 10 February 2020)

Longino, J.T. \& Booher, D.B. (2019) Expect the unexpected: a new ant from a Backyard in Utah. Western North American Naturalist, 79 (4), 496-499.

MacGown, J.A. \& Hill, J.G. (2010) A new species of Pyramica from Mississippi, USA. Florida Entomologist, 93 (4), $571-$ 576.

MacGown, J.A., Wetterer, J.K. \& Hill, J.G. (2012) Geographic spread of Strumigenys silvestrii (Hymenoptera: Formicidae: Dacetini). Terrestrial Arthropods Reviews, 5, 213-222.

MacGown, J.A., Hill, J.G., Schiefer, T.L. \& Brown, R.L. (2012) Ant diversity and habitat associations at the Noxubee National Wildlife Refuge in Mississippi. Mississippi Agricultural and Forestry Experiment Station Technical Bulletin, 1197, 1-30.

MacKay, W.P. \& Anderson, R.S. (1993) New distributional records for the ant genus Smithistruma (Hymenoptera: Formicidae) in southern United States. The Southwestern Naturalist, 38, 388-389.

Mayr, G. (1887) Südamerikanische Formiciden. Verhandlungen der Kaiserlich-Königlichen Zoologisch-Botanischen Gesellschaft in Wien, 37, 511-632.

McCook, H.C. (1880) Formicariae, In: Comstock, J.H., Report upon cotton insects. Government Printing Office, Washington, D.C., pp. $182-189$.

Mississippi Entomological Museum (2020) Available from: https://mississippientomologicalmuseum.org.msstate.edu/Researchtaxapages/Formicidae (accessed 1 November 2020)

Pfitzer, D.W. (1951) A new species of Smithistruma from Tennessee (Hymenoptera: Formicidae). Journal of the Tennessee Academy of Science, 26, 198-200.

Roger, J. (1863) Die neu aufgeführten Gattungen und Arten meines Formiciden-Verzeichnisses nebst Ergänzung einiger früher gegebenen Beschreibungen. Berliner Entomologische Zeitschrift, 7, 131-214.

Santschi, F. (1927) A propos du Tetramorium caespitum L. Folia. Myrmecologica et Termitologica, 1, 52-58.

Say, T. (1836) Descriptions of new species of North American Hymenoptera, and observations on some already described. Boston Journal of Natural History, 1, 209-305.

Smith, M.R. (1931) A revision of the genus Strumigenys of America, north of Mexico, based on a study of the workers (Hymnoptera: Formicidae). Annals of the Entomological Society of America, 24, 686-710. 
Smith, M.R. (1935) Two new species of North American Strumigenys (Formicidae: Hymenoptera). Annals of the Entomological Society of America, 28, 214-216.

Smith, M.R. (1962) A new species of exotic Ponera from North Carolina (Hymenoptera, Formicidae). Acta Hymenopterologica, 1, 377-382.

Lewis, V.R. (2016) Child Prodigy, Pioneer Scientist, and Women and Civil Rights Advocate: Dr. Margaret James Strickland Collins (1922-1996). Florida Entomologist, 99 (2), 334-336.

Ward, P.S. (1988) Mesic elements in the western Nearctic ant fauna: taxonomic and biological notes on Amblyopone, Proceratium, and Smithistruma (Hymenoptera: Formicidae). Journal of the Kansas Entomological Society, 61, 102-124.

Weber, N.A. (1934) A new Strumigenys from Illinois (Hymenoptera: Formicidae). Psyche (Cambridge), 41, 63-65.

Wesson, L.G. (1935) Contributions toward the biology of Strumigenys pergandei: a new food relationship among ants. Entomological News, 47,171-174.

Wesson, L.G. \& Wesson, R.G. (1939) Notes on Strumigenys from southern Ohio, with descriptions of six new species. Psyche, Cambridge, 46, 91-112.

Wesson, L.G. \& Wesson, R.G. (1940) A collection of ants from southcentral Ohio. American Midland Naturalist, 24, 89-103.

Wetterer, J.K. (2011) Worldwide spread of the membraniferous dacetine ant, Strumigenys membranifera (Hymenoptera: Formicidae). Myrmecological News, 14, 129-135.

Wheeler, W.M. (1907) The fungus-growing ants of North America. Bulletin of the American Museum of Natural History, 23, 669-807.

Wheeler, G.C. \& Wheeler, J. (1989) A checklist of the ants of Oklahoma. Prairie Naturalist, 21, 203-210. 